\title{
Interfacial Engineering Strategy for High-Performance Zn Metal Anodes
}

Cite as

Nano-Micro Lett.

(2022) 14:6

Received: 20 August 2021

Accepted: 12 October 2021

Published online: 2 December 2021

(C) The Author(s) 2021

\author{
Bin $\mathrm{Li}^{1}$, Xiaotan Zhang ${ }^{2}$, Tingting Wang ${ }^{1}$, Zhangxing $\mathrm{He}^{1}{ }^{凶}$, Bingan $\mathrm{Lu}^{3}$, \\ Shuquan Liang ${ }^{2}$, Jiang Zhou ${ }^{2} \bowtie$
}

\section{HIGHLIGHTS}

- The interfacial engineering strategies of surface and electrolyte modifications for high-performance $\mathrm{Zn}$ metal anodes are reviewed.

- The reaction mechanisms for inhibiting dendrite growth and side reactions in interface engineering are systematically summarized.

- An outlook on future reference directions for new interface strategies to advance this field is provided.

ABSTRACT Due to their high safety and low cost, rechargeable aqueous $\mathrm{Zn}$-ion batteries (RAZIBs) have been receiving increased attention and are expected to be the next generation of energy storage systems. However, metal $\mathrm{Zn}$ anodes exhibit a limited-service life and inferior reversibility owing to the issues of $\mathrm{Zn}$ dendrites and side reactions, which severely hinder the further development of RAZIBs. Researchers have attempted to design high-performance $\mathrm{Zn}$ anodes by interfacial engineering, including surface modification and the addition of electrolyte additives, to stabilize $\mathrm{Zn}$ anodes. The purpose is to achieve uniform $\mathrm{Zn}$ nucleation and flat $\mathrm{Zn}$ deposition by regulating the deposition behavior of $\mathrm{Zn}$ ions, which effectively improves the cycling stability of the $\mathrm{Zn}$ anode. This review comprehensively summarizes the reaction mechanisms of interfacial modification for inhibiting the growth of $\mathrm{Zn}$ dendrites and the occurrence of side reactions. In addition, the research progress of interfacial engineering strategies for RAZIBs is summarized and classified. Finally, prospects and

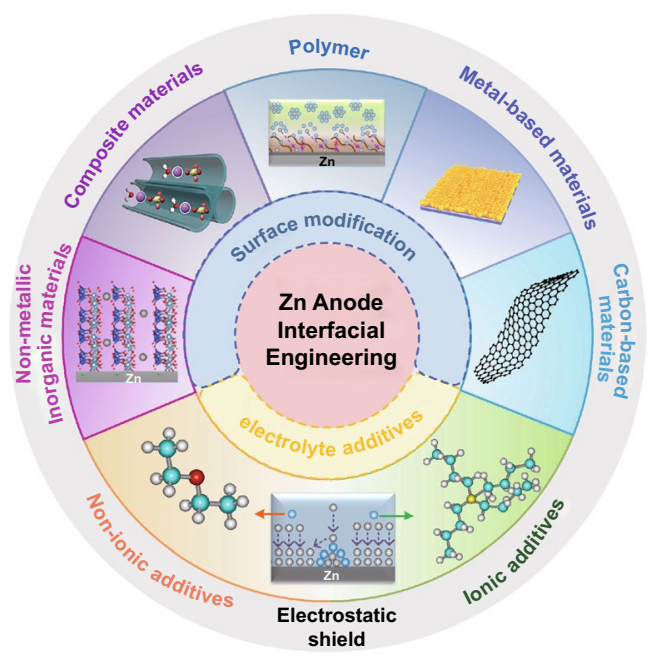
suggestions are provided for the design of highly reversible $\mathrm{Zn}$ anodes.

KEYWORDS Interfacial engineering; Zn anode; Dendrites; Side reactions; Aqueous zinc-ion batteries

Bin Li and Xiaotan Zhang have contributed equally to this work.

$\triangle$ Zhangxing He, zxhe@ncst.edu.cn; Jiang Zhou, zhou_jiang@csu.edu.cn

1 School of Chemical Engineering, North China University of Science and Technology, Tangshan 063009, People's Republic of China

2 School of Materials Science and Engineering, Key Laboratory of Electronic Packaging and Advanced Functional Materials of Hunan Province, Central South University, Changsha 410083, People's Republic of China

3 School of Physics and Electronics, Hunan University, Changsha 410082, People's Republic of China 


\section{Introduction}

The two major issues of energy and environment are closely related to social development and human survival. With the depletion of fossil resources, such as petroleum and coal, and the threat of an increasingly deteriorating environment, the development of renewable energy sources, such as hydropower, solar energy, and wind energy, has become a global trend [1-4]. As an efficient electrochemical energy storage-conversion device, batteries can integrate the unstable energy obtained and output it into the smart grid for use $[5,6]$. Secondary batteries are a good choice, and their commercialization has provided great convenience to society [7, 8]. Lithium-ion batteries currently dominate the commercial market, but their high-cost and safety issues, arising from the use of organic electrolytes, hinder their further development [9-14]. For example, the battery pack of a Boeing 787 aircraft ignited in 2013, a Samsung Note 7 mobile phone exploded in 2016, and a Tesla Model S electric car battery spontaneously ignited in 2019, all of which were caused by the flammability of organic electrolytes. Therefore, the security issue is a non-negligible problem that must be resolved. Coupled with the urgent need for resources and environmental protection, researchers are urged to vigorously explore new battery systems with high safety, high-cost performance, green environmental protection, and high specific capacity $[15,16]$. Rechargeable aqueous $\mathrm{Zn}$-ion batteries (RAZIBs) have become one of the best choices for largescale energy storage systems because of their high safety, high capacity, low cost, and low redox potential [17-23].

The $\mathrm{Zn}-\mathrm{MnO}_{2}$ battery using an alkaline electrolyte, which can be charged and discharged repeatedly, was successfully developed in the 1960s. The energy storage mechanism of alkaline $\mathrm{Zn}$ batteries is mainly that of a conversion reaction. Moreover, in alkaline $\mathrm{Zn}$ batteries, positive and negative electrodes are prone to irreversible side reactions, resulting in low Coulombic efficiency (CE) and poor cycle performance [24]. In 1988, Shoji et al. [25] took the lead in using a weakly acidic electrolyte $\left(\mathrm{ZnSO}_{4}\right)$ instead of an alkaline electrolyte to design a new aqueous rechargeable $\mathrm{Zn}-\mathrm{MnO}_{2}$ battery. Unlike alkaline $\mathrm{Zn}-\mathrm{Mn}$ batteries, some by-products, such as $\mathrm{ZnO}$ and $\mathrm{Zn}(\mathrm{OH})_{2}$, are generated on metallic Zn. New aqueous Zn-based secondary batteries that use $\mathrm{Zn}^{2+}$ as charge carriers in aqueous electrolytes have recently received increasing attention for large-scale energy storage applications [26-28]. Redox reactions involving multiple electron transfers provide higher energy densities [29]. The ionic conductivity of aqueous electrolytes is two orders of magnitude higher than that of organic electrolytes [30].

During the charging process, $\mathrm{Zn}$ ions are extracted from the cathode and are plated on the $\mathrm{Zn}$ anode. During the discharging process, $\mathrm{Zn}$ ions are stripped from the anode and inserted into the cathode material, as shown in Fig. 1. Typical cathode electrode materials for RAZIBs, including Mn- and V-based compounds, Prussian blue analogs, organic compounds, and polysulfide, usually have a tunnel or layered structure which allow the insertion and extraction of $\mathrm{Zn}$ ions and provide storage sites for $\mathrm{Zn}$ ions [31-35]. There are usually two types of negative electrodes according to the different reaction mechanisms, namely the insertion/extraction type $\left(\mathrm{Na}_{0.14} \mathrm{TiS}_{2}\right.$ [36], $\mathrm{Mo}_{6} \mathrm{~S}_{8}$ [37], and $\mathrm{ZnMo}_{6} \mathrm{~S}_{8}$ [38]) and the plating/stripping type (metallic $\mathrm{Zn}$ [39]). The theoretical capacity of metallic $\mathrm{Zn}$ is 820 $\mathrm{mAh} \mathrm{g}^{-1}$, which is higher than that of intercalated-type anode materials [40, 41]. In aqueous electrolyte, $\mathrm{Zn}$ features the unique characteristics of a low redox potential $(-0.76 \mathrm{~V}$ vs. standard hydrogen electrode (SHE)) and a high hydrogen evolution overpotential ( $1.2 \mathrm{~V}$ vs. SHE) $[42,43]$. In addition, $\mathrm{Zn}$ exists as a trace element in the human body, and $\mathrm{Zn}$ compounds are also environmentally friendly. Metal $\mathrm{Zn}$ is abundant in the earth's crust, which helps to reduce production costs [44]. Based on the above characteristics, metallic $\mathrm{Zn}$ foil (ZF) is a promising and common anode material for aqueous $\mathrm{Zn}$-ion secondary batteries $[45,46]$.

When pure metal $\mathrm{ZF}$ is directly used as the anode in RAZIBs, the $\mathrm{Zn}^{2+}$ plating/stripping process occurs continuously on the surface of the $\mathrm{Zn}$ electrode during charge-discharge cycling, which dominates the reversibility of the RAZIBs [47]. The current problems with $\mathrm{Zn}$ anodes are primarily $\mathrm{Zn}$ dendrites and side reactions [48, 49]. Owing to their lower surface energy and higher migration energy, $\mathrm{Zn}$ ions exhibit a propensity to deposit on a lumped site to form dendrites rather than toward nearby areas. The depositions continue to accumulate and form dendrites, which can pierce the battery separator and even cause short circuits [50, 51]. This will adversely affect the battery performance, including capacity, CE, and cycle life. Moreover, Zn metal anodes inevitably encounter side reactions related to water 
molecules, such as corrosion and hydrogen evolution reactions. Inert by-products $\left(\mathrm{ZnO}, \mathrm{Zn}(\mathrm{OH})_{2}\right.$, etc.) caused by side reactions will increase the surface roughness of the $\mathrm{Zn}$ anode and decrease the number of active sites for $\mathrm{Zn}$-ion deposition, resulting in an uneven distribution of electrolyte flux, electrode polarization, and capacity degradation [52, 53]. The side reaction of hydrogen evolution and the plating/stripping reaction of $\mathrm{Zn}$ are competing reactions, which will reduce the utilization rate of the $\mathrm{Zn}$ anode. However, the problems in $\mathrm{Zn}$ metal anodes are not isolated but interactional. Zinc dendrites can not only penetrate the separator to induce battery failure but can also provide increased surface area to exacerbate side reactions on the $\mathrm{Zn}$ anode surface. The side reactions increase the surface roughness of the $\mathrm{Zn}$ anode and provide more nucleation sites for $\mathrm{Zn}$ ions, which aggravates the growth of $\mathrm{Zn}$ dendrites. Therefore, to comprehensively solve these $\mathrm{Zn}$ metal anode problems, it is necessary to consider the influence of multiple problems at the same time.

Both $\mathrm{Zn}$ dendrites and side reactions are closely related to the $\mathrm{Zn}$ anode interface toward the electrolyte. Interfacial engineering, including surface coating and the addition of electrolyte additives, is an effective strategy to regulate the deposition behavior of $\mathrm{Zn}$ ions and the effect of water molecules, which effectively alleviate $\mathrm{Zn}$ dendrite growth and the $\mathrm{Zn}$ anode side reactions [54-57]. Surface coatings can reduce direct contact between the $\mathrm{Zn}$ anode and water molecules in the electrolyte, inhibiting side reactions on the $\mathrm{Zn}$

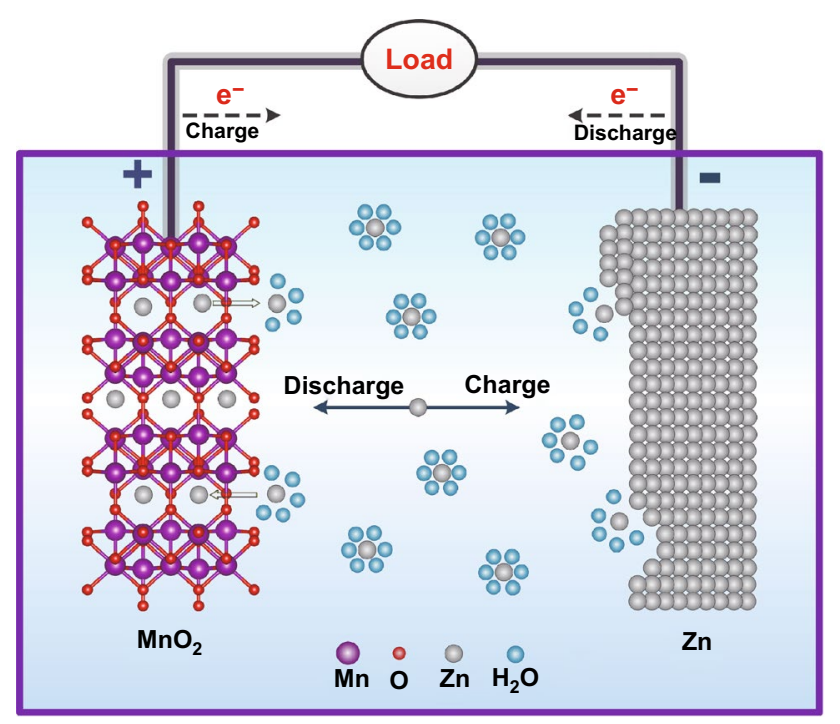

Fig. 1 Schematic diagram of the working mechanism of RAZIBs anode surface. Furthermore, the addition of ions or organic additives to the electrolyte can induce uniform deposition of $\mathrm{Zn}$ ions. The anode interfacial engineering strategy of RAZIBs has the advantages of simplicity and high efficiency and is expected to be applied to large-scale energy storage systems. This review mainly focuses on the intrinsic mechanism of interfacial engineering and the modified material types of metal $\mathrm{Zn}$ anodes, with the aim of providing guidance for the development of high-performance $\mathrm{Zn}$-ion batteries. Finally, the future development prospects and directions of the interfacial modification of $\mathrm{Zn}$ anodes are presented. It is hoped that researchers will explore high-performance and long-life RAZIBs to meet the needs of large-scale energy storage systems.

\section{Protection Mechanism of Interfacial Engineering}

The elimination of $\mathrm{Zn}$ dendrites and suppression of side reactions have attracted widespread attention. Regulating the deposition behavior of $\mathrm{Zn}$ ions by surface coating protection and electrolyte modification is an effective strategy to obtain a high reversibility and utilization rate of $\mathrm{Zn}$ anodes. However, there are different protection mechanisms. The following is a detailed summary of the two protection mechanisms of interfacial engineering for inhibiting dendrite growth and side reactions.

\subsection{Inhibiting Dendrite Growth}

In the charging and discharging process, $\mathrm{Zn}$ ions in electrolyte deposit and dissolve repeatedly on the anode surface. The uneven distribution of the electric field on the anode surface and the unrestricted two-dimensional (2D) diffusion of $\mathrm{Zn}^{2+}$ absorbed on the anode surface lead to the formation of $\mathrm{Zn}$ dendrites [58, 59] (Fig. 2a). Specifically, Zn ions tend to deposit at charge transfer sites on the anode with favorable energy, forming initial tiny bumps. To reduce the surface energy, subsequent $\mathrm{Zn}$ ions tend to deposit at these bumps, which makes them grow gradually and become primary dendrites. Under normal conditions, brittle dendrites are needle shaped; their tips act as charge centers in subsequent reactions and trigger tip effects, which further intensifies the uneven distribution of the electric field on the anode surface and causes dendrite evolution [60]. When the $\mathrm{Zn}$ dendrite grows to a certain extent, it 
punctures the separator and causes the battery to short circuit, which severely affects the battery capacity and cycle life [61]. Brittle dendrites that break off from the anode surface result in the production of "dead zinc," accelerating the depletion of $\mathrm{Zn}$, which is harmful to electrochemical behavior [62].

Coating a protective layer on the anode surface can create a physical protection layer between the metal $\mathrm{Zn}$ anode and electrolyte, which is an effective method for improving the $\mathrm{Zn}$ electrode interface stability and cycle endurance. The main purpose of constructing an artificial interface layer is to regulate the deposition behavior of $\mathrm{Zn}$ ions and suppress $\mathrm{Zn}$ dendrites. Moreover, the protective layer can prevent direct contact of the $\mathrm{Zn}$ anode with the electrolyte, avoiding side reactions [62]. The electrolyte additive that modifies the $\mathrm{Zn}$ anode interface is adsorbed on the surface of the $\mathrm{Zn}$ anode, forming an electrostatic shielding layer. Thus, $\mathrm{Zn}$ ions are deposited downward instead of at the tip [63]. Based on investigations of the employed coating materials, four reaction mechanisms for inhibiting dendrite growth on the anode interface, including efficient confinement effect, uniform interfacial electric field, increased nucleation sites, and electrostatic shielding, are summarized.

\subsubsection{Efficient Confinement Effect}

Some inorganic oxides with high dielectric constant and low conductivity have efficient confinement effects on the electrodeposition behavior of $\mathrm{Zn}$ ions. Inorganic oxide coatings with porous channels could restrict the migration path of $\mathrm{Zn}$ ions and drive $\mathrm{Zn}$ ions to orderly deposit from bottom to top along the channels rather than randomly (Fig. 2b). Similarly, some inorganic salt coatings induce the uniform deposition of $\mathrm{Zn}$ ions, which contributes to the redistribution of $\mathrm{Zn}$ ions and reduces the ion concentration gradient generated by preferential ion flux near the $\mathrm{Zn}$ nucleation clusters [64]. In addition, this type of inorganic coating shapes the uniform flux of the electrolyte through confinement effects and further guides the $\mathrm{Zn}$ plating rate on the $\mathrm{Zn}$ electrode surface. The limiting effect of the nonporous structure and the large potential change between the electrically insulated coating-medium prevents the formation of dendrites.

\subsubsection{Uniform Interfacial Electric Field}

The electrochemical reaction on the $\mathrm{Zn}$ anode surface is closely related to the plating and stripping of $\mathrm{Zn}$ ions. In general, $\mathrm{Zn}$-ion deposition is driven by the electric field, and the intensity and uniformity of the electric field directly affect the nucleation and deposition of $\mathrm{Zn}$ ions. Therefore, a uniform interfacial electric field is of great significance for compact and plain nucleation of $\mathrm{Zn}$ ions and improvement of cyclic stability. It should be noted that during nucleation, the disordered deposition of $\mathrm{Zn}$ ions on the anode surface considerably affects the relatively uniform electric field distribution [65]. Specifically, Zn-ion concentration is low in areas with low electric field intensity and high in areas with high electric field intensity. With the rapid deposition of $\mathrm{Zn}$ ions, the nucleation size increases and the concentration of $\mathrm{Zn}$ ions increases consecutively. Coating materials with high conductivity, such as carbon-based and metal materials, provide a strong electric field strength and accelerate the transfer rate on the anode surface. In this case, a highly conductive layer with a stable electric field effectively restrains the accumulation of electric charge and provides a uniform surface electric field, inducing a uniform $\mathrm{Zn}$ deposition behavior and avoiding dendrite proliferation (Fig. 2c).

\subsubsection{Increased Nucleation Sites}

Zinc ion deposition initially tends to occur at favorable nucleation locations with a relatively low nucleation overpotential [66]. Subsequently, the uneven deposition of $\mathrm{Zn}$ ions leads to dendrite growth. Balanced deposition of $\mathrm{Zn}$ ions, guided by artificially ample and uniform nucleation sites, can inhibit dendrite growth and obtain smooth $\mathrm{Zn}$ deposits (Fig. 2d). The increased number of active sites helps to reduce the overpotential of nucleation and thus refines the nucleation size, which is conducive to the uniform growth and dissolution of $\mathrm{Zn}$ on the surface. Some high-molecular polymer coatings exhibit zincophilicity because of their large number of polar functional groups and strong cooperation with $\mathrm{Zn}$ ions [64]. This provides numerous nucleation sites and helps to form a uniform deposition morphology. The strategy of introducing 
(a) Bare $\mathrm{Zn}$ foil
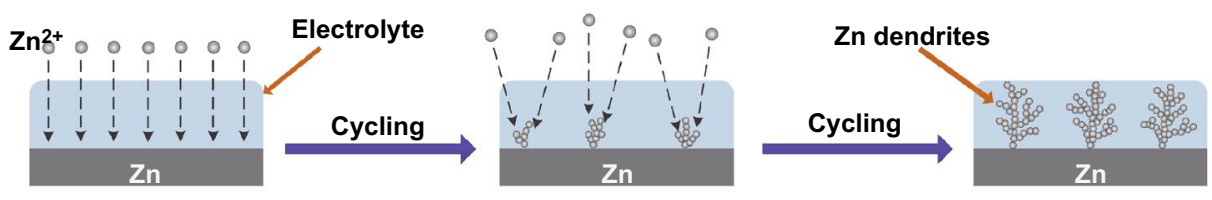

(b) Efficient confinement effect

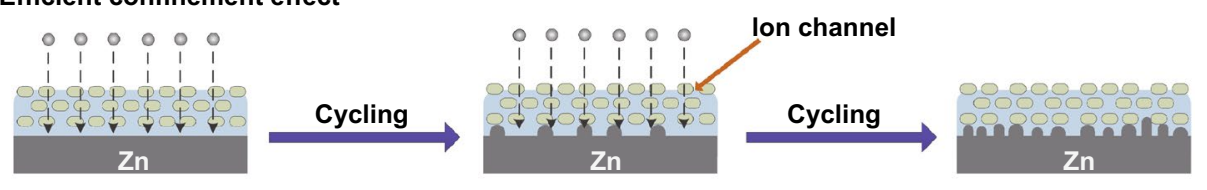

(c) Uniform interfacial electric field
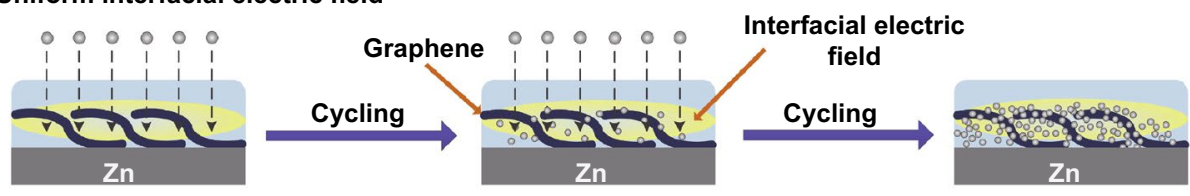

(d) Increased uncleation sites

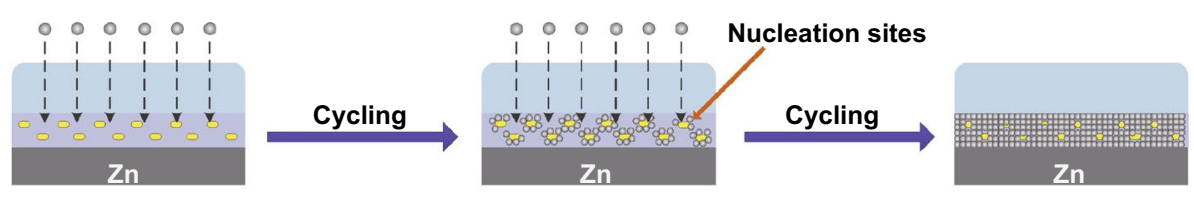

(e) Electrostatic shield mechanism

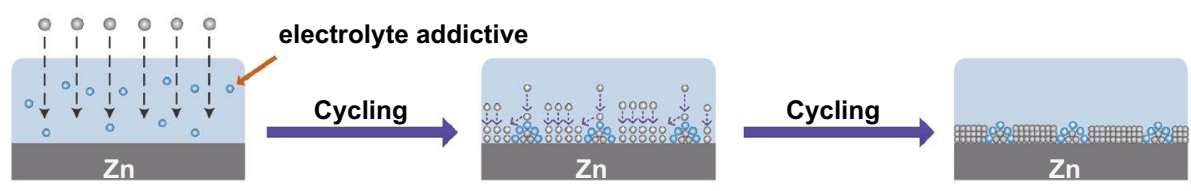

(f) Crystallographic orientation induction

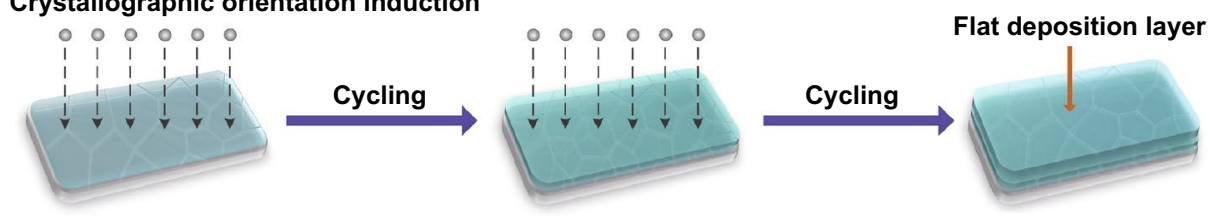

Fig. 2 a Schematic diagram of $\mathrm{Zn}$ dendrite formation on bare $\mathrm{Zn}$. Schematic diagram for various dendrite suppression mechanisms on the coating layer. b Efficient confinement effect. c Uniform interfacial electric field. d Increased nucleation sites. e Electrostatic shield. f Crystallographic orientation induction

zincophilic sites is expected to inhibit dendrite growth. A carbon host is used as a model system, and the nitrogen site is the zincophilic site. The host with zincophilic sites exhibits uniform $\mathrm{Zn}$ deposition and improved electrochemical performance [67]. The construction of a three-dimensional (3D) coating interface also has a significant impact on the uniform deposition of $\mathrm{Zn}$. For example, Zhou et al. [68] constructed a 3D nanoporous $\mathrm{ZnO}$ structure in situ on a $\mathrm{Zn}$ plate. The novel 3D structure provided more nucleation sites for $\mathrm{Zn}$ deposition and guided the ordered deposition of $\mathrm{Zn}$ ions through the electrostatic attraction of $\mathrm{Zn}^{2+}$. In addition, reduced graphene oxide (rGO) with a $3 \mathrm{D}$ structure provides a large electroactive area for $\mathrm{Zn}$ electrodeposition, and the corresponding nucleation sites increase accordingly [69]. 


\subsubsection{Electrostatic Shield}

Functional additives effectively suppress $\mathrm{Zn}$ dendrites, induce the uniform deposition of $\mathrm{Zn}$ ions, and form a flat surface. The main method is to form an electrostatic shielding layer so that $\mathrm{Zn}$ ions deposit uniformly downward. Ionic additives with a lower reduction potential can be preferentially adsorbed on the surface of the $\mathrm{Zn}$ tips to form an electrostatic shielding layer, inhibiting the growth of $\mathrm{Zn}$ dendrites [70]. Additionally, a positive charge repulsion exists between the cations of the electrostatic shielding layer and the $\mathrm{Zn}$ ions. This prevents the $\mathrm{Zn}$ ions from depositing on the $\mathrm{Zn}$ tips to form larger $\mathrm{Zn}$ dendrites and induces the deposition of $\mathrm{Zn}$ ions to form a uniform and smooth deposition layer, which is consistent with the non-ionic additive [71] (Fig. 2e). In addition, additives increase the overpotential of $\mathrm{Zn}$ anode deposition, which could increase the nucleation rate of $\mathrm{Zn}$ ions and suppress $\mathrm{Zn}$ dendrites. Furthermore, additives inhibit the 2D diffusion of $\mathrm{Zn}$ ions on the $\mathrm{Zn}$ anode surface to provide fewer nucleation sites, inhibiting the formation of $\mathrm{Zn}$ dendrites.

\subsubsection{Crystallographic Orientation Induction}

Crystallographic orientation induction is a promising method to adjust the electrochemical performance of $\mathrm{Zn}$ anodes by manipulating the crystallographic orientation of $\mathrm{Zn}$ deposition. Generally, the larger the angle between the growth direction of $\mathrm{Zn}$ dendrites and the surface of the $\mathrm{Zn}$ anode, the more favorable it is for the growth of dendrites. The crystal orientation affects the surface morphology and dendrite growth state by affecting the direction of crystal growth [63]. The angle between the crystal growth direction and the substrate, which can effectively alleviate the growth of $\mathrm{Zn}$ dendrites and occurrence of corrosion reactions, resulting in smooth deposition, is $0^{\circ}-30^{\circ}$ [72]. The angle between the crystal growth direction and the substrate is $70^{\circ}-90^{\circ}$, which is very conducive to the growth of dendrites. Therefore, the specific crystallographic structure exposed in parallel with the current collector can induce the deposition of metallic $\mathrm{Zn}$, which may facilitate the stable stripping/plating of $\mathrm{Zn}$ in a mild electrolyte [73]. In addition, the specific crystallographic structure can induce a flat $\mathrm{Zn}$ deposition morphology, which reduces the contact area between the electrolyte and $\mathrm{Zn}$ anode during cycling and effectively suppresses the growth of dendrites and generation of by-products [74] (Fig. 2f).

\subsection{Reducing Side Reactions}

The growth of $\mathrm{Zn}$ dendrites increases the surface area of the $\mathrm{Zn}$ anode. Surface-dependent reactions, such as corrosion reactions and the hydrogen evolution reaction, cause the continuous consumption of active $\mathrm{Zn}$ and fundamentally reduce the battery capacity [75]. When the side reaction of hydrogen evolution occurs in a local high-energy region, the gas will cause volume expansion of the batteries. Concurrently, the local $\mathrm{OH}^{-}$concentration increases and insoluble $\mathrm{Zn}(\mathrm{OH})_{2}$ is formed and adheres to the metal $\mathrm{Zn}$ surface, causing surface passivation of the fresh $\mathrm{Zn}[76,77]$. This reduces the conductivity of the anode, increases the interface impedance, and reduces the active nucleation sites of $\mathrm{Zn}$, resulting in a poor plating/stripping CE. These irreversible hydrogen evolution, corrosion, and passivation side reactions will fundamentally consume limited electrolyte and $\mathrm{Zn}$ ions and endanger the performance and lifespan of batteries. As shown in Fig. 3a, a schematic diagram for $\mathrm{Zn}$ corrosion, passivation, and hydrogen evolution is displayed.

\subsubsection{Reducing Active Water}

The main reason for side reactions is that $\mathrm{Zn}^{2+}$ combines with six water molecules in aqueous electrolytes to form hydrated $\mathrm{Zn}^{2+}\left(\left[\mathrm{Zn}\left(\mathrm{H}_{2} \mathrm{O}\right)_{6}\right]^{2+}\right)$. $\left[\mathrm{Zn}\left(\mathrm{H}_{2} \mathrm{O}\right)_{6}\right]^{2+}$ must undergo a desolvation process before being reduced on the surface of the $\mathrm{Zn}$ anode, which inevitably causes direct contact between the $\mathrm{Zn}$ anode and water molecules and triggers side reactions. While resolving the side reaction problem, it was found that introducing atomic groups or solid electrolyte interface layers on the anode surface is beneficial for increasing the hydrogen evolution potential of metal $\mathrm{Zn}$ and reducing the corrosion reaction [62]. Furthermore, the interfacial layer directly prevents direct contact between the electrolyte and $\mathrm{Zn}$ anode or reduces the number of water molecules that reach the $\mathrm{Zn}$ surface through the desolvation effect $[78,79]$. The $\mathrm{Zn}$ deposition is very uniform after the protection layer, as shown in Fig. 3b. When $\mathrm{Zn}$ ions are thermodynamically unstable in aqueous electrolytes, the severe passivation of the ZF by water aggravates the electrochemical behavior and reduces the 
CE. The artificial organic polyamide (PA) coating has rich polar groups and a cross-linked $\mathrm{H}$ bond network, which can combine with coordinated water molecules to destroy the solvation sheath of $\mathrm{Zn}^{2+}$ [80]. The novel structure coating of a $3 \mathrm{D}$ nanoporous $\mathrm{Zn}$ oxide coating accelerates the transport and deposition kinetics of $\mathrm{Zn}^{2+}$ by electrostatically attracting $\mathrm{Zn}^{2+}$ instead of $\left[\mathrm{Zn}\left(\mathrm{H}_{2} \mathrm{O}\right)_{6}\right]^{2+}[68]$.

\subsubsection{Modulating Coordination Status}

The high overpotential generated by the strong Coulomb interactions between the solvated $\mathrm{Zn}^{2+}$ and its surrounding $\mathrm{H}_{2} \mathrm{O}$ shell accelerates parasitic water reduction during $\mathrm{Zn}$ deposition $[81,82]$. This promotes the evolution of $\mathrm{H}$ and the formation of a passivation layer. To inhibit water reduction and $\mathrm{Zn}$ dendrites, the bonding strength between the $\mathrm{Zn}^{2+}$ ions and solvated $\mathrm{H}_{2} \mathrm{O}$ should be weakened. Introducing certain additives is a simple and effective strategy for optimizing the electrolyte composition (Fig. 3c). Some additives can replace $\mathrm{H}_{2} \mathrm{O}$ in the $\mathrm{Zn}^{2+}$-solvated sheath, preferentially solvate with $\mathrm{Zn}$ ions, and remove $\mathrm{H}_{2} \mathrm{O}$ from the
$\mathrm{Zn}^{2+}$-solvated sheath [83]. In addition, some additives also have a strong interaction with water, which reduces water activity and effectively inhibits parasitic water reactions and dendrite growth [84]. Furthermore, an in situ solid electrolyte interphase (SEI) layer can be constructed by adding additives to the electrolyte. The presence of additives not only adjusts the structure of the solvent sheath of $\mathrm{Zn}$ ions, allowing the rapid transmission of $\mathrm{Zn}^{2+}$, but also prevents $\mathrm{H}_{2} \mathrm{O}$ from penetrating the surface of the $\mathrm{Zn}$ anode, which greatly reduces the probability of side reactions [83, 84].

\section{Surface Modification of $\mathrm{Zn}$ Anode}

The purpose of constructing a surface coating is to achieve uniform $\mathrm{Zn}$ nucleation and a flat $\mathrm{Zn}$ deposition layer by regulating $\mathrm{Zn}^{2+}$ deposition, which effectively improves the interface stability and cycle lifetime of the $\mathrm{Zn}$ anode. According to previous reports, various materials have been used as interfacial layers to achieve high-performance $\mathrm{Zn}$ anodes, carbon-based materials, metal materials, inorganic non-metals, polymers, and composite materials. The

(a) Bare Zn foil

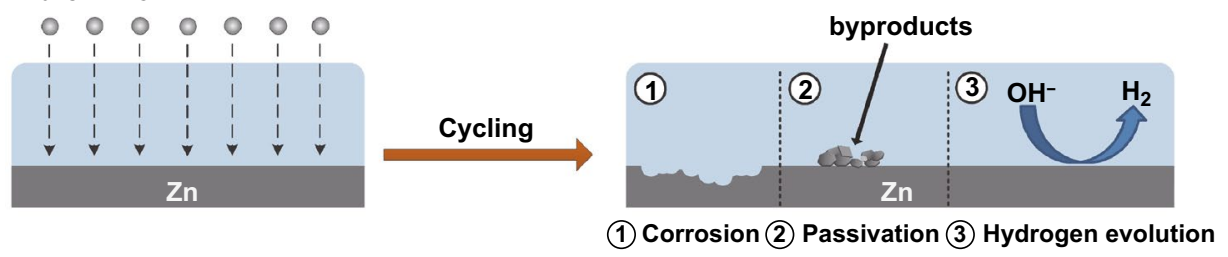

(b) Surface modification
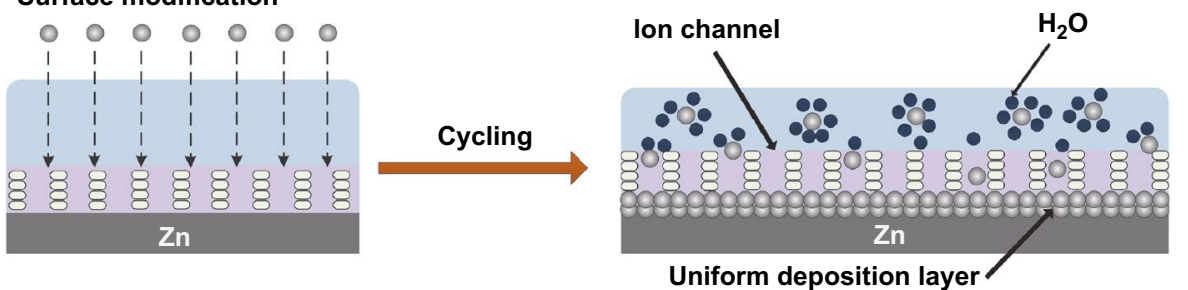

(c) Electrolyte additives
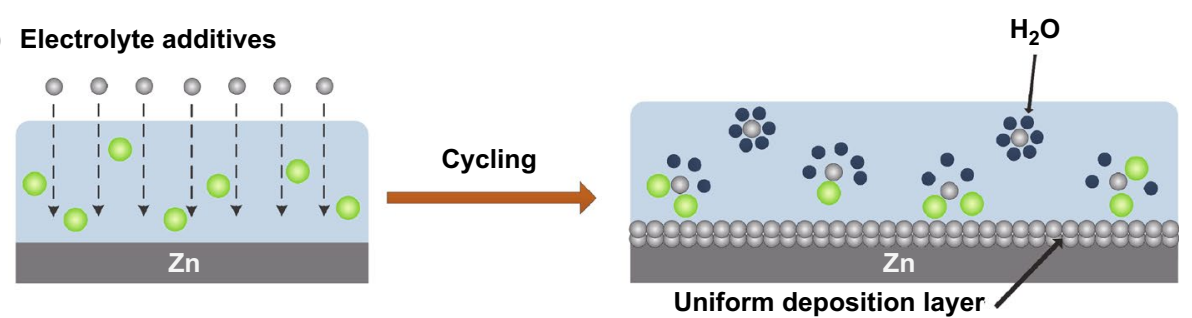

Fig. 3 a Schematic diagram of the corrosion, passivation, and hydrogen evolution reactions on bare Zn. b Schematic diagram of the morphological evolution of coated $\mathrm{Zn}$. $\mathbf{c}$ Schematic diagram of the deposition morphology of $\mathrm{Zn}$ ions by adding electrolyte additives 
research progress of these five interfacial coating materials is described in detail below.

\subsection{Carbon-Based Materials}

The key to the anode modification of RAZIBs is to reduce the growth of $\mathrm{Zn}$ dendrites and the occurrence of side reactions, such as hydrogen evolution and self-corrosion reactions [85]. Carbon materials have the natural advantages of high conductivity, wide range of sources, low price, environmental friendliness, and high stability. Therefore, many studies have focused on acquiring anodes with carbon-based materials with high specific capacitance [86]. Graphene, carbon nanotubes (CNTs), activated carbon (AC), and other carbon-based materials are suitable materials for modified $\mathrm{Zn}$ anodes. Concurrently, carbon-based materials provide abundant nucleation sites, ensure uniform $\mathrm{Zn}$ deposition, and avoid the generation of dendrites, which contribute to improving the electrochemical performance.

rGO has a layered structure, which provides a stable scaffold with good mechanical properties. Zinc ions can be released from the ZF through the natural ion channels between graphene layers to avoid ramification, which improves the cyclic stability of the battery. Liu et al. [69] studied a method for the spontaneous reduction of graphene oxide (GO) on a $\mathrm{Zn}$ metal surface and implemented selfassembly to form layer-after-layer structures. Layered rGO provides numerous nucleation sites for $\mathrm{Zn}$ nucleation, ensuring the uniform deposition of $\mathrm{Zn}$ (Fig. 4a). The $\mathrm{Zn} / \mathrm{rGO}$ electrode showed a stable voltage curve and small hysteresis, while the ZF showed a large voltage plateau (Fig. 4b). Shen et al. [87] used $\mathrm{Zn} / \mathrm{rGO}$ and $\mathrm{V}_{3} \mathrm{O}_{7} \cdot \mathrm{H}_{2} \mathrm{O} / \mathrm{rGO}$ composites as anodes and cathodes. It was found that the cell with $\mathrm{Zn} /$ rGO as the anode could be charged/discharged more than 1000 times at a rate of $5 \mathrm{C}$, while the cell based on bare $\mathrm{Zn}$ short-circuited in the 155th cycle due to dendrite growth (Fig. 4c). Compared with the ZnllZn symmetrical cell, the $\mathrm{Zn} / \mathrm{rGO} / \mathrm{Zn} / \mathrm{rGO}$ symmetrical cell maintained a smaller impedance after different cycles. Epitaxial electrodeposition, as a method to create highly reversible metal anodes, can be realized by textured conductive electrode coatings with a low lattice mismatch to the (002) texture of $\mathrm{Zn}$ metal. Zheng et al. [88] designed a fluid-based method to form an ordered graphene coating on a $\mathrm{Zn}$ surface. On the low lattice mismatch interface composed of well-arranged graphene sheets, a more uniform and compact thin plate parallel to the substrate was produced, and the newly deposited $\mathrm{Zn}$ layer adhered to the surface of the $\mathrm{Zn}$ formed in the first stage to produce a uniform metallic $\mathrm{Zn}$ coating. Xie et al. [74] used the Langmuir-Blodgett method to synthesize an artificial interfacial film of N-doped GO (NGO) in one step and obtained an ultrathin and parallel interfacial layer to modify the $\mathrm{Zn}$ anode (Fig. 4d). The parallel NGO lamellae could adjust the deposition sites of $\mathrm{Zn}^{2+}$ and effectively induce the deposition of metallic $\mathrm{Zn}$ on the (002) crystal plane. This flat deposition morphology effectively suppressed dendrite formation and side reactions. Density functional theory (DFT) was used to further study the effect of heteroatom doping of $\mathrm{N}$ and $\mathrm{O}$ on the $\mathrm{Zn}$ interaction (Fig. 4e). After deposition of $1 \mathrm{mAh} \mathrm{cm}^{-2}$, the bare $\mathrm{Zn}$ anode exhibited an anisotropic platelet-like dendritic morphology. Compared with the bare Zn electrode, even when imaged at a greater magnification, a flat and smooth surface can be obtained (Fig. 4f). The NGO@Zn electrode can achieve a flat deposition morphology and a stable interface owing to the uniform electric field and directed $\mathrm{Zn}^{2+}$ distribution/adsorption (Fig. 4g).

AC, a well-known carbonaceous material with good electrical conductivity and excellent chemical stability, has a complex pore structure, large specific surface area, high adsorption capacity, and high degree of surface reactivity. $\mathrm{Xu}$ et al. [89] prepared a $\mathrm{Zn}$ anode by mixing $\mathrm{Zn}$ powder with an AC mixture, acetylene black, polyvinylidene fluoride (PVDF), and methyl-2-pyrrolidone. The $\mathrm{ZnAB}+12 \mathrm{wt} \% \mathrm{AC}$ anode showed a relatively higher discharge plateau voltage and lower charge plateau voltage throughout the charge/ discharge process. When AC is added to the $\mathrm{Zn}$ anode, the deposition of inactive anode products preferentially occurs in the rich pores of AC rather than on the surface of $\mathrm{Zn}$ particles; thus, the neatness and activity of $\mathrm{Zn}$ particles can be maintained even after dozens of cycles. In addition, Wang et al. [90] pressed AC on ZF ( $\mathrm{Zn@C)} \mathrm{to} \mathrm{create} \mathrm{a} \mathrm{modified}$ $\mathrm{Zn}$ anode cell (Fig. 4h). After 100 cycles at $1 \mathrm{~mA} \mathrm{~cm}^{-2}$, plate-like $\mathrm{Zn}$ dendrites appeared on the surface of the $\mathrm{ZF}$, yet no apparent change was observed in Zn@C. Moreover, the Zn@C symmetrical cell exhibited the stable curve of a symmetrical cell, as compared to bare Zn (Fig. 4i). Analysis of the results after the impedance test of $\mathrm{Zn} @ \mathrm{C}$ showed that the charge transfer resistance increased slightly (Fig. 4j). The stable stripping/plating can be attributed to the equalized charge distribution and sufficient regulation of $\mathrm{Zn}$ deposition after the introduction of the $\mathrm{C}$ layer. 
(a)

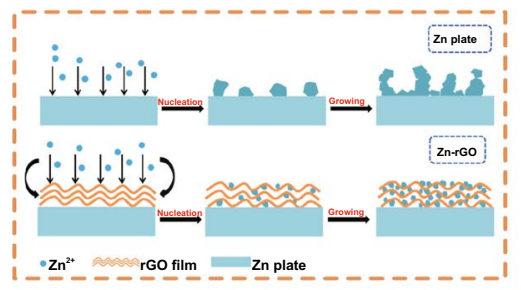

(b)

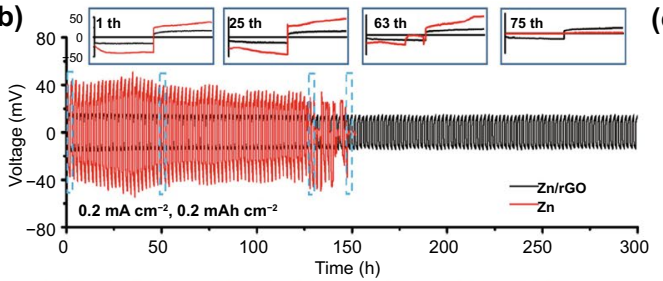

(c)

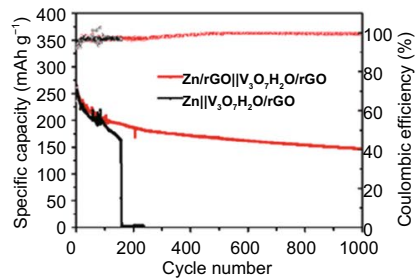

(d)

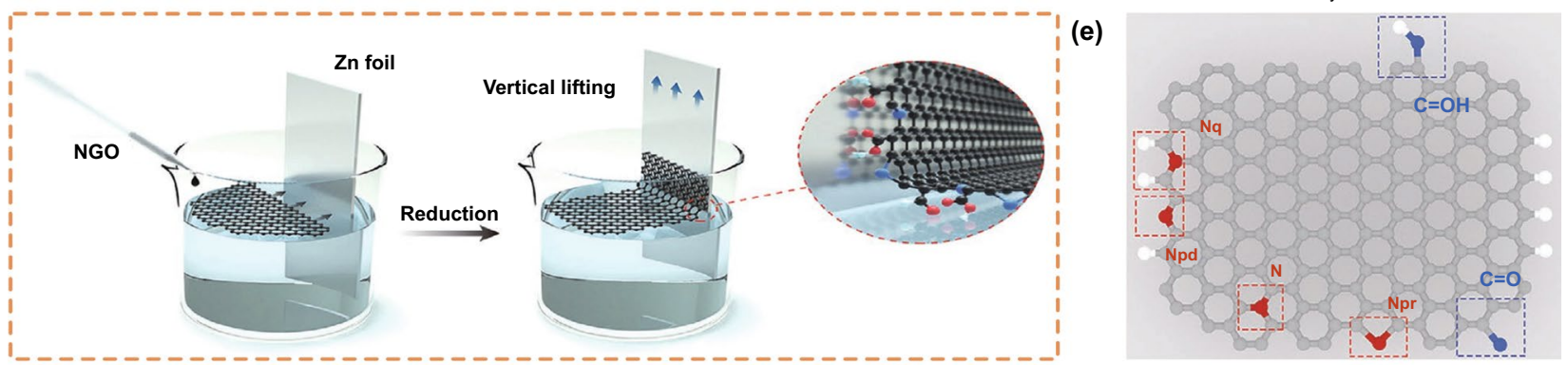

(f)

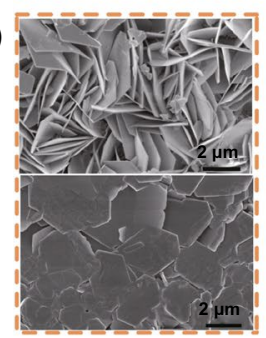

(g)

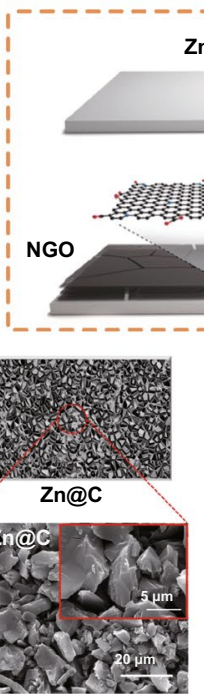

$\mathrm{Zn}$ foil
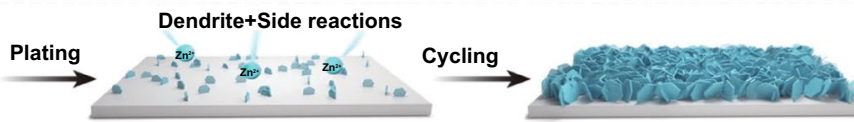

Zn absorption sites

(h)

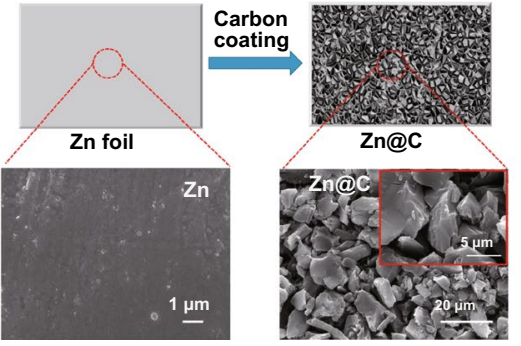

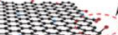
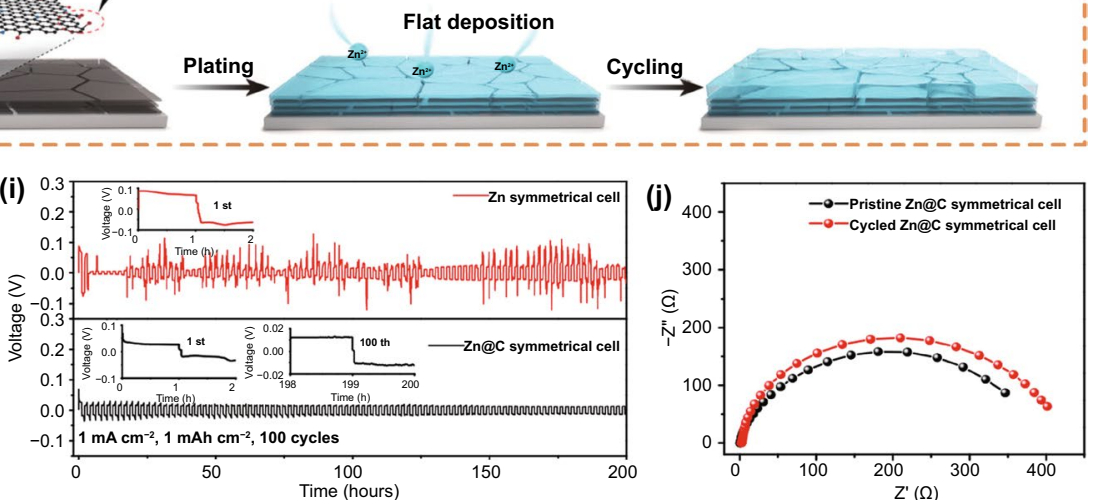

Fig. 4 a Schematic diagram illustrating the $\mathrm{Zn}$ plating behavior of the bare $\mathrm{Zn}$ and $\mathrm{Zn} / \mathrm{rGO}$ anodes. b Cycling performance of symmetrical cells using $\mathrm{Zn} / \mathrm{rGO}$ and a bare $\mathrm{Zn}$ plate at $0.2 \mathrm{~mA} \mathrm{~cm}^{-2}$ with a stripping/plating capacity of $0.2 \mathrm{mAh} \mathrm{cm}{ }^{-2}$. Copyright 2018 American Chemical Society [87]. d Schematic illustration of the fabrication of ultrathin graphene layers on ZF. e Configuration of N-and O-doped graphene. $\mathbf{f}$ Top-view SEM images of a bare ZF electrode and NGO after plating at $1 \mathrm{mAh} \mathrm{cm}{ }^{-2}$. g Schematic illustration of Zn plating on a bare ZF and NGO@Zn electrode. Copyright 2021 Wiley-VCH [74]. h Schematic illustration of a Zn@C film and SEM images of the Zn and Zn@C. i Stripping/plating performance of $\mathrm{Zn}$ and $\mathrm{Zn@C} \mathrm{cells} \mathrm{at} 1 \mathrm{~mA} \mathrm{~cm}{ }^{-2}$ with $1 \mathrm{mAh} \mathrm{cm} \mathrm{cm}^{-2}$. j Nyquist plots of the Zn@C symmetrical cell before and after 100 cycles. Copyright 2018 American Chemical Society [90]

As a widely used one-dimensional material, CNTs are lightweight and have excellent chemical properties. Because unmodified $\mathrm{Zn}$ produces dendrites that cause adverse reactions at the $\mathrm{Zn}$ anode/electrolyte interface, leading to the failure of RAZIBs (Fig. 5a), Yang et al. [91] built self-supporting, highly flexible, and conductive CNT/paper scaffolds to stabilize $\mathrm{Zn}$ metal anodes. On the surface of the $\mathrm{Zn}$ electrode, the porous skeleton of the scaffold mechanically regulated the deposition position of $\mathrm{Zn}^{2+}$, and the conductive CNT network maintained a homogenized electric field. In addition, the assembled Zn@CNT symmetrical cells exhibited a more stable charge/discharge behavior (Fig. 5b). The modified ZF showed no significant changes after cycling (Fig. 5c, d). The CNT scaffolds in symmetrical cells had the same appearance after circulation (Fig. 5e).

Carbon black is also a widely used carbon-based material. Chen et al. [92] modified $\mathrm{Zn}$ anodes with $\mathrm{C}$ black coatings and nanofibrillar cellulose adhesives. By modifying zinc foil with a $\mathrm{C}$ black coating and a nanofibrillating cellulose (NFC) binder, the dendrite growth and side reactions on the 
anode are eliminated to achieve an excellent interfacial stability between the anode and electrolyte. After 100 cycles, many dendrites grew on the surface of the ZF (Fig. 5f). The anode comprising ZF modified with a $\mathrm{C}$ black coating and NFC binder (ZF@CB-NFC) maintained a uniform surface before and after cycling (Fig. 5g). The cell composed of the modified anodes had a better cycling stability and CE (Fig. 5h, i). The symmetrical cell composed of the modified $\mathrm{Zn}$ anode exhibited a better cycling performance and lower polarization voltage (Fig. 5 j, k).
In summary, the carbon-based material coatings, such as rGO, CNTs, and AC, are conductive protective layers. They have a certain mechanical strength, which effectively inhibits the growth of dendrites and prevents dendrites from penetrating the separator. More importantly, carbon-based materials with high electrical conductivity can provide a strong electric field strength, which effectively avoids the accumulation of charges and provides a uniform interface electric field. Table 1 summarizes the currently reported coating modification strategies for carbon-based materials.

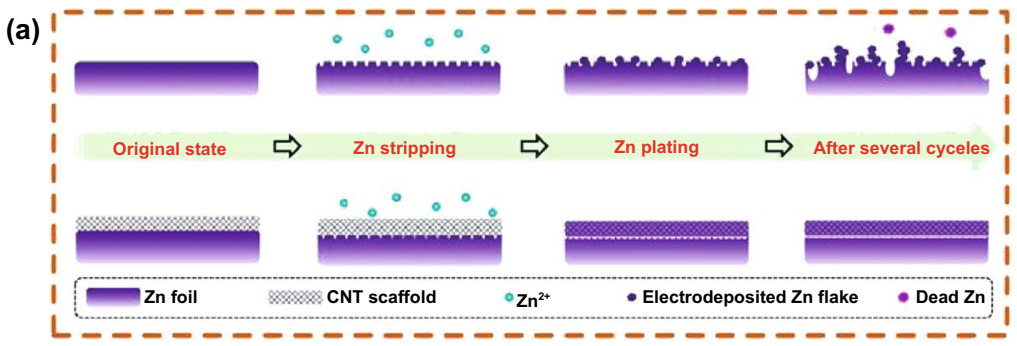

(c)

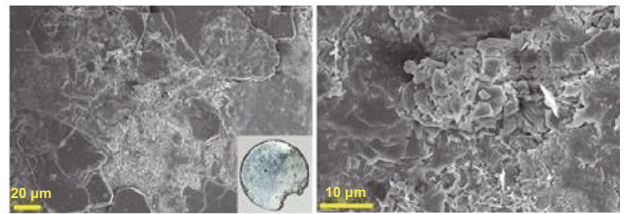

(d)

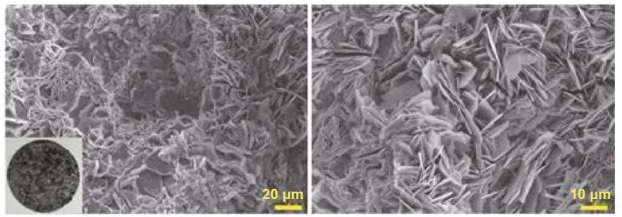

(e)

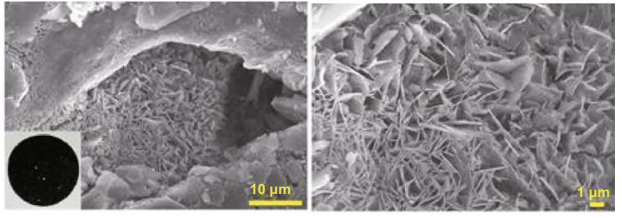

(f)

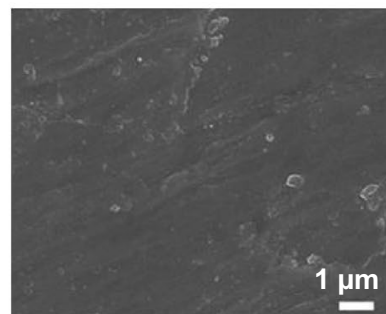

(g)

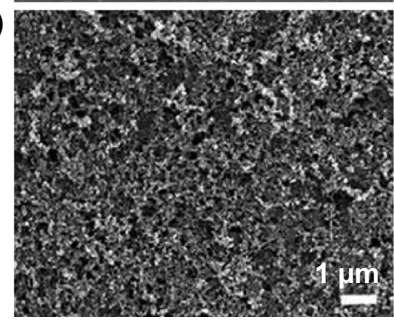

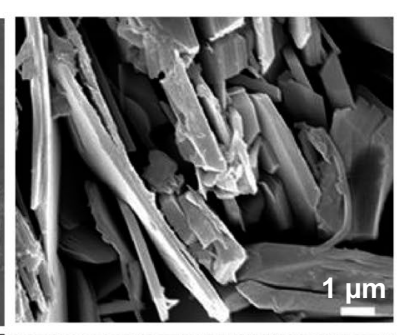

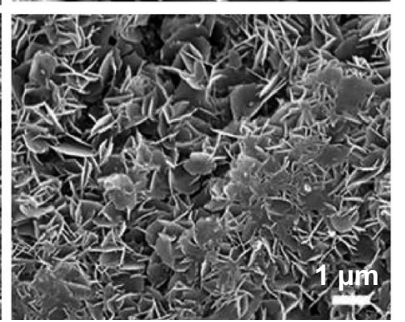

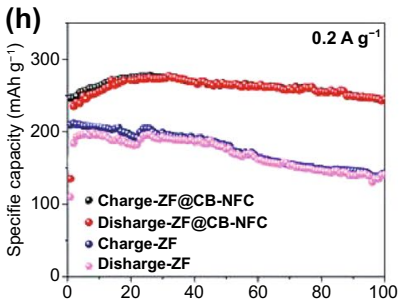

(j)

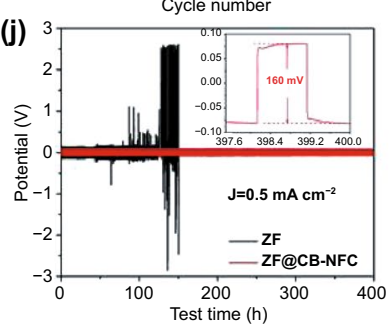

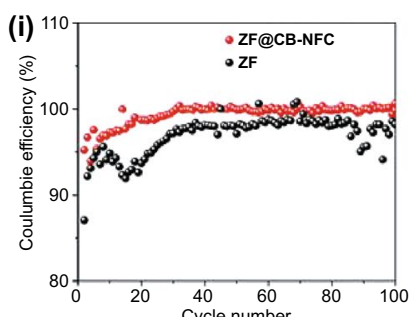

(k)

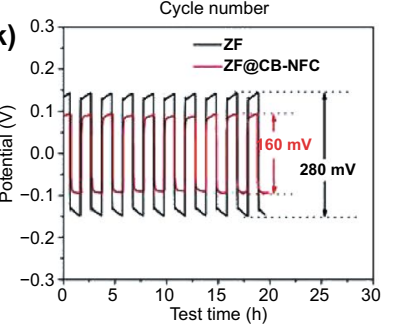

Fig. 5 a Schematics of the stripping/plating behaviors of bare ZF anodes and CNT scaffold-stabilized Zn anodes. b Rate performance at various current densities of $0.1-5 \mathrm{~mA} \mathrm{~cm}{ }^{-2}$ for $1 \mathrm{~h}$. c SEM image of Zn electrodes in ZnIIZn symmetrical cells. d SEM image of Zn electrodes in Zn@ CNTs symmetrical cells. e SEM image of CNT scaffolds in Zn@CNTs symmetrical cells (after cycling tests). Copyright 2019 Elsevier [91]. f SEM images of a ZF anode and $\mathbf{g}$ SEM images of a ZF@CB-NFC anode. $\mathbf{h}$ Cycling performances at $0.2 \mathrm{~A} \mathrm{~g}^{-1}$. i Coulombic efficiencies as a function of the cycle number. $\mathbf{j}$ Zn symmetrical cells with ZF and ZF@CB-NFC electrodes: galvanostatic charge/discharge (GCD) curves of 200 cycles at $0.5 \mathrm{~mA} \mathrm{~cm} \mathrm{~cm}^{-2} \mathbf{k} \mathrm{Zn}$ symmetrical cells with ZF and ZF@CB-NFC electrodes: voltage profiles of the $1 \mathrm{st}-10$ th cycles at $0.5 \mathrm{~mA} \mathrm{~cm}{ }^{-2}$. Copyright 2020 Elsevier [92] 
However, it should be noted that the service life of a functional conductive protective layer is not sufficiently long, and long-term operation may reduce the battery performance. Therefore, it is necessary to explore more suitable carbonbased materials as interfacial coatings for $\mathrm{Zn}$ anodes, which provide a uniform interfacial electric field and an ultra-long service life.

\subsection{Metal-Based Materials}

Some metal-based materials are considered promising coating materials for $\mathrm{Zn}$-ion batteries owing to their $\mathrm{Zn}$ affinity and excellent electrical conductivity. Zincophilicity can increase the number of nucleation sites for $\mathrm{Zn}^{2+}$, thereby promoting the uniform deposition of $\mathrm{Zn}^{2+}$. On the other hand, some metals have a uniform interfacial electric field because of their conductivity, which adsorbs $\mathrm{Zn}^{2+}$ and accelerates ion transport. Therefore, metal coating effectively suppresses the formation of large and uneven dendrites/ protrusions.

Han et al. [93] studied metallic In coatings with in situ and ex situ characterization methods. The In metal layer, with the dual function of corrosion inhibitor and nucleation agent, covered the $\mathrm{Zn}$ surface, remarkably inhibiting corrosion of the Zn electrode (Fig. 6a). The modified In layer had an inhibitory effect on dendrite growth, making the electrode present a uniform and dense $\mathrm{Zn}$ coating after cycling (Fig. 6b). Concurrently, the ZnIIn cell exhibited a lower electrochemical impedance (Fig. 6c). The initial potential of the hydrogen evolution reaction was lower, which proves that the In metal coating effectively inhibits the hydrogen evolution reaction (Fig. 6d). Compared with rough plating on the bare $\mathrm{Zn}$ surface, the dense galvanized layer on $\mathrm{ZnIIn}$ exhibited a more uniform surface (Fig. 6e). Cui et al. [94] studied a heterogeneous seed method to guide the morphology evolution of plated $\mathrm{Zn}$. Nano-Au particles were used as seed crystals to inhibit the formation of delayed interactions, thereby achieving a stable stripping/plating process (Fig. 6f). A symmetrical battery with the nano-Au-modified $\mathrm{Zn}$ anode (NA-Zn) electrode exhibited a more evident overpotential (Fig. 6g). A NA-Zn|CNT/MnO 2 cell showed excellent performance in the voltage distribution and cycle performance of constant current charge and discharge (Fig. 6h, i). After cycling, the NA-Zn-60 electrode exhibited a relatively uniform surface morphology, as compared to bare ZF (Fig. 6j).

Like carbon-based materials, metal-based materials with high conductivity provide a uniform interfacial electric field while inhibiting dendrite growth. In addition, the metal layer with an affinity for $\mathrm{Zn}$ increases the number of nucleation sites for $\mathrm{Zn}^{2+}$ and induces uniform $\mathrm{Zn}$ deposition. The recently reported coating modification strategies for metalbased materials are summarized in Table 1. However, precious metals are expensive, which significantly hinders the wide application of metal coatings on the surface of $\mathrm{Zn}$ anodes. Therefore, it is necessary to explore metal materials with large reserves and low prices as an anode protective layer. The preparation method of the metal protective layer should also be simplified; the above-mentioned chemical substitution reaction is of great significance.

\subsection{Non-metallic Inorganic Materials}

Inorganic non-metallic materials have the advantages of persistent stability, environmental protection, low cost, and easy availability. They are widely used as $\mathrm{Zn}$ anode coating materials. Some inorganic non-metals with a high dielectric constant and low conductivity induce $\mathrm{Zn}$-ion deposition with

Table 1 Summary of recently reported coatings modification strategies for carbon-based and metal-based materials

\begin{tabular}{|c|c|c|c|}
\hline Anode materials & Voltage hysteresis & Lifespan & References \\
\hline rGO-coated $\mathrm{Zn}$ foil & $\approx 20 \mathrm{mV}\left(1 \mathrm{~mA} \mathrm{~cm}{ }^{-2}\right)$ & $300 \mathrm{~h}\left(1 \mathrm{~mA} \mathrm{~cm}{ }^{-2}, 1 \mathrm{mAh} \mathrm{cm}^{-2}\right)$ & [69] \\
\hline rGO-coated $\mathrm{Zn}$ foil & $\approx 170 \mathrm{mV}\left(10 \mathrm{~mA} \mathrm{~cm}{ }^{-2}\right)$ & $80 \mathrm{~h}\left(10 \mathrm{~mA} \mathrm{~cm}{ }^{-2}, 2 \mathrm{mAh} \mathrm{cm}{ }^{-2}\right)$ & [87] \\
\hline NGO-coated $\mathrm{Zn}$ foil & $\approx 32 \mathrm{mV}\left(1 \mathrm{~mA} \mathrm{~cm}{ }^{-2}\right)$ & $1200 \mathrm{~h}\left(1 \mathrm{~mA} \mathrm{~cm}{ }^{-2}, 1 \mathrm{mAh} \mathrm{cm}^{-2}\right)$ & {$[74]$} \\
\hline AC-coated $\mathrm{Zn}$ foil & $\approx 20 \mathrm{mV}\left(1 \mathrm{~mA} \mathrm{~cm}{ }^{-2}\right)$ & $200 \mathrm{~h}\left(1 \mathrm{~mA} \mathrm{~cm}{ }^{-2}, 1 \mathrm{mAh} \mathrm{cm}^{-2}\right)$ & [90] \\
\hline CNT scaffold-stabilized $\mathrm{Zn}$ anode & $\approx 36 \mathrm{mV}\left(0.1 \mathrm{~mA} \mathrm{~cm}^{-2}\right)$ & $1800 \mathrm{~h}\left(0.1 \mathrm{~mA} \mathrm{~cm}{ }^{-2}, 0.5 \mathrm{mAh} \mathrm{cm}{ }^{-2}\right)$ & [91] \\
\hline ZF@CB-NFC anode & $160 \mathrm{mV}\left(0.5 \mathrm{~mA} \mathrm{~cm}{ }^{-2}\right)$ & $400 \mathrm{~h}\left(0.5 \mathrm{~mA} \mathrm{~cm}{ }^{-2}, 0.5 \mathrm{mAh} \mathrm{cm}^{-2}\right)$ & {$[92]$} \\
\hline ZnIIn anode & $54 \mathrm{mV}\left(0.2 \mathrm{~mA} \mathrm{~cm}^{-2}\right)$ & $1500 \mathrm{~h}\left(0.2 \mathrm{~mA} \mathrm{~cm}^{-2}, 0.2 \mathrm{mAh} \mathrm{cm}^{-2}\right)$ & [93] \\
\hline NA-Zn-60 anode & $\approx 80 \mathrm{mV}\left(0.25 \mathrm{~mA} \mathrm{~cm}{ }^{-2}\right)$ & $2000 \mathrm{~h}\left(0.25 \mathrm{~mA} \mathrm{~cm}-2,0.05 \mathrm{mAh} \mathrm{cm}^{-2}\right)$ & [94] \\
\hline
\end{tabular}


(a)

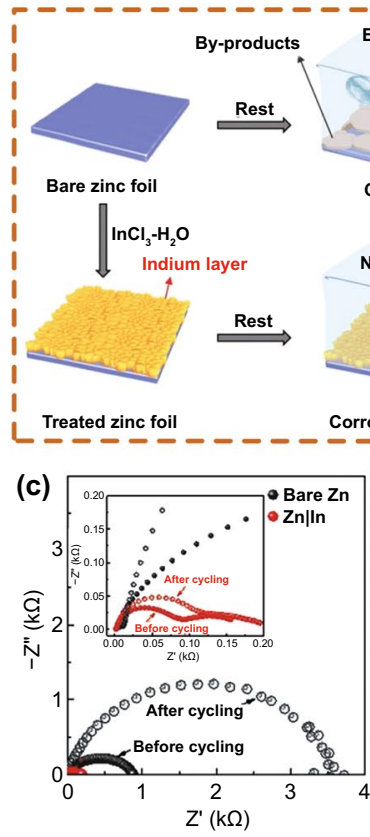

(f)

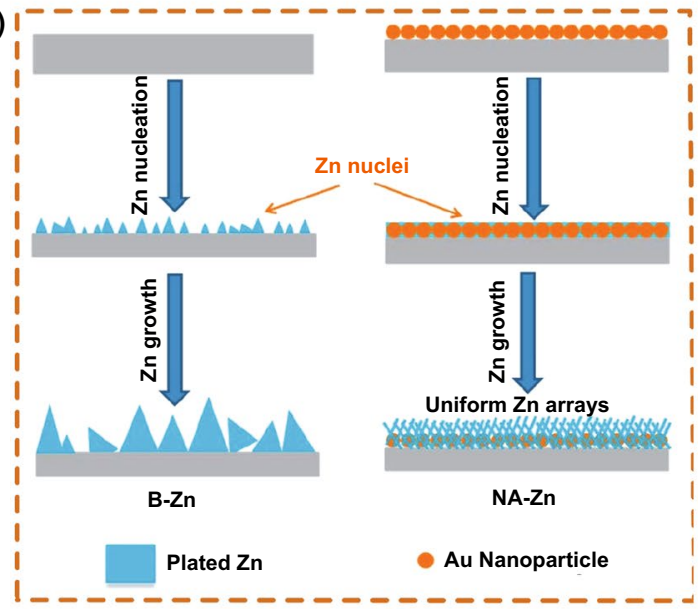

(b)
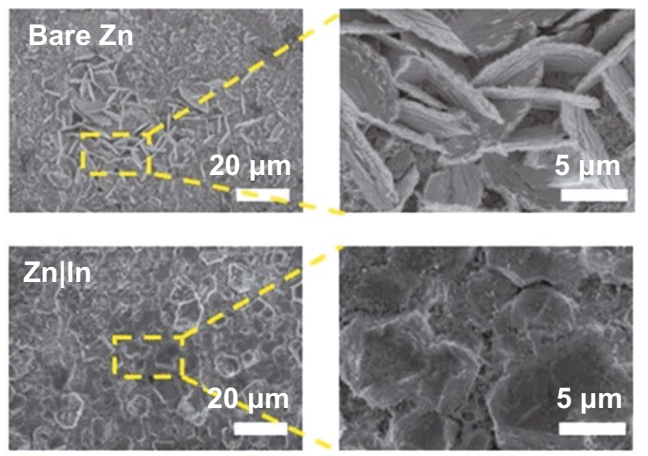

Dendrite free

(e) Bare Zn
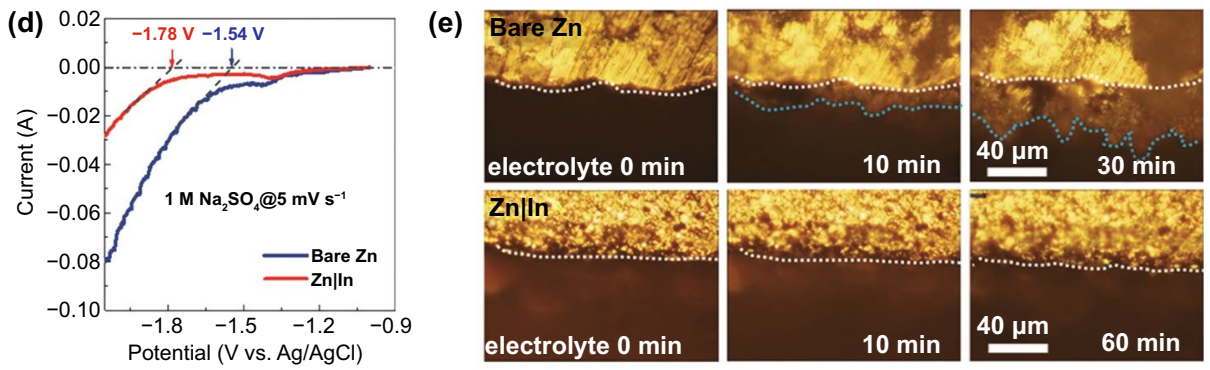

(g)
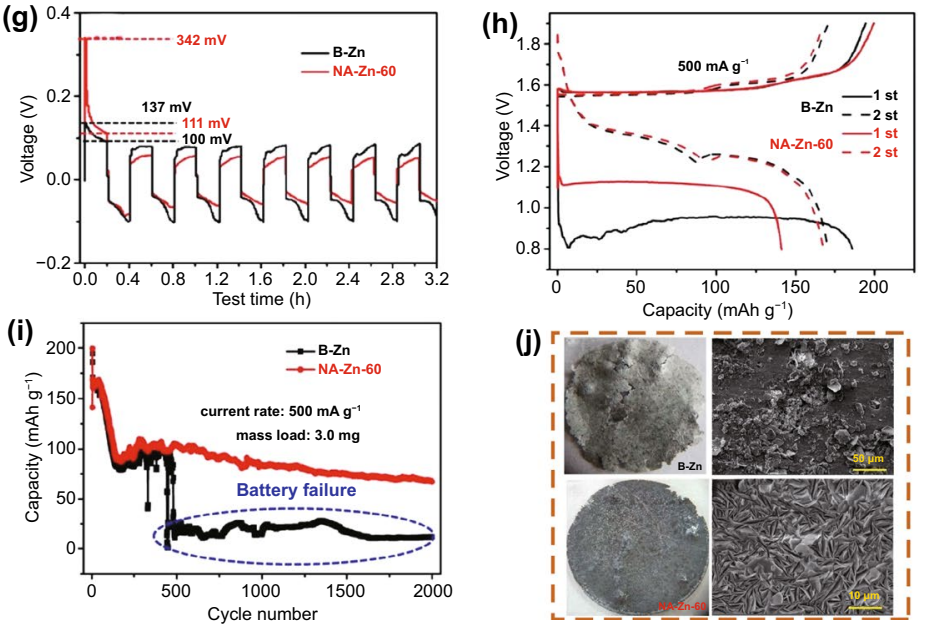

Fig. 6 a Schematics and characterization of Zn and ZnIIn foils. b SEM images of bare $\mathrm{Zn}$ and ZnlIn in symmetrical cells after the first plating process at $1 \mathrm{~mA} \mathrm{~cm}{ }^{-2}$ for $1 \mathrm{mAh} \mathrm{cm} \mathrm{cm}^{-2}$. $\mathbf{c}$ Electrochemical impedance spectroscopy of bare $\mathrm{Zn}$ and $\mathrm{ZnIIn}$ before and after cycling in symmetrical cells with an aqueous $\mathrm{ZnSO}_{4}$ electrolyte and $\mathbf{d}$ Linear sweep voltammetry curves of bare $\mathrm{Zn}$ and $\mathrm{ZnIIn}$ in a $1 \mathrm{M}$ aqueous $\mathrm{Na}_{2} \mathrm{SO}_{4}$ electrolyte at a scan rate of $5 \mathrm{mV} \mathrm{s}^{-1}$. e Operando optical microscope images of bare $\mathrm{Zn}$ and $\mathrm{ZnIIn}$ in an aqueous $\mathrm{ZnSO}_{4}$ electrolyte. Copyright $2020 \mathrm{Wiley-}$ $\mathrm{VCH}$ [93]. f Schematic illustration of the Zn stripping/plating process on a bare $\mathrm{Zn}$ and NA-Zn. $\mathbf{g}$ Initial discharge/charge profiles of ZnlZn sym-

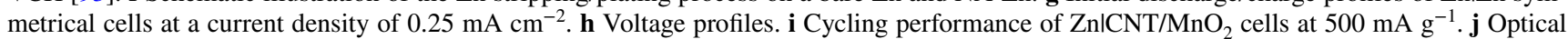
and SEM images of bare Zn anode and NA-Zn-60 anode. Copyright 2019 American Chemical Society [94]

different working mechanisms to redistribute $\mathrm{Zn}$ ions. Thus, the ion concentration gradient generated by the preferred ion flux near the $\mathrm{Zn}$ nucleation cluster is reduced to inhibit dendritic growth and side reactions, improving the electrochemical performance of the $\mathrm{Zn}$ anode. Various inorganic non-metallic materials, such as metal oxides, kaolin, and salts, have been reported for interface engineering strategies.
Metal oxides have been widely studied for inorganic nonmetallic coatings in $\mathrm{Zn}$ anodes. By employing inorganic non-metallic oxides as $\mathrm{Zn}$ anodes, Yi et al. [55] synthesized a nano- $\mathrm{ZrO}_{2}$ coating on a $\mathrm{Zn}$ anode by a simple sol-gel method, which was beneficial for controlling the nucleation position of $\mathrm{Zn}^{2+}$ and achieving the rapid transport of $\mathrm{Zn}^{2+}$. The $\mathrm{ZrO}_{2}$-coated $\mathrm{Zn}$ anode exhibited a longer cycle 
life and lower polarization (Fig. 7a). After 100 cycles, the $\mathrm{ZrO}_{2}$-coated $\mathrm{Zn}$ anode presented a flat and uniform morphology under the same conditions as the bare $\mathrm{Zn}$ anode (Fig. 7b). Mai et al. [47] used a $\mathrm{TiO}_{2}$ coating, deposited by the atomic layer deposition (ALD) technique, as the protective layer of a metal $\mathrm{Zn}$ anode. The use of ultra-thin $\mathrm{TiO}_{2}$ coating, as a stable passivation of $\mathrm{Zn}$ metal, avoided direct contact between the $\mathrm{Zn}$ anode and electrolyte. The 100 ALD cycles of $\mathrm{TiO}_{2}$ on the $\mathrm{Zn}$ plate only deposited a small number of thin slices, as compared to bare $\mathrm{Zn}$ (Fig. 7c), and symmetrical cells coated with $\mathrm{TiO}_{2}$ on the $\mathrm{Zn}$ plate showed excellent cycling stability (Fig. 7d). Wang et al. [95] studied the effects of crystal orientation on the affinity of $\mathrm{Zn}$. As a protective layer on the $\mathrm{Zn}$ anode, multi-faceted Ti dioxide has a low affinity for $\mathrm{Zn}$, which limits the formation of dendrites (Fig. 7e). When commercial $\mathrm{TiO}_{2}$ is used as the intermediate layer, $\mathrm{Zn}$ tends to grow on the surface of $\mathrm{TiO}_{2}$ and has a high affinity for $\mathrm{Zn}$. By establishing a model of $\mathrm{Zn}$ atoms adsorbed on the surface of $\mathrm{TiO}_{2}$, the affinity of the $\mathrm{TiO}_{2}$ surface to $\mathrm{Zn}$ can be determined (Fig. 7f). As shown in Fig. $7 \mathrm{~g}, \mathrm{Zn}$ is more inclined to deposit on the $\mathrm{TiO}_{2}$ surface than on the $\mathrm{Zn}$ surface. By controlling the exposure of a specific surface, an appropriate protective material can be obtained (Fig. 7h). Through the cyclic stability test, the ZF@F-TiO $/$ ZF @F-TiO 2 symmetrical cell was charged and discharged for a long time and had a relatively long life (Fig. 7i).

In addition, Liu et al. [96] prepared $\mathrm{Al}_{2} \mathrm{O}_{3}$ coatings using ALD. By coating ultra-thin $\mathrm{Al}_{2} \mathrm{O}_{3}$ on the surface of a $\mathrm{Zn}$ plate, the corrosion resistance was improved and the growth of $\mathrm{Zn}$ dendrites was effectively inhibited (Fig. 8a). $100 \mathrm{Al}_{2} \mathrm{O}_{3} @ \mathrm{Zn}$ exhibited good cyclic stability and a small voltage lag during repeated $\mathrm{Zn}$ plating and stripping, as compared to bare $\mathrm{Zn}$. Fang et al. [97] prepared a new type of $\mathrm{Zn}$ anode with a hydrophobic multi-channel $\mathrm{Sc}_{2} \mathrm{O}_{3}$ coating and realized a layered absorption effect on the anode. As shown in Fig. 8 b, the $\mathrm{Sc}_{2} \mathrm{O}_{3}$ coating not only provided a physical barrier to prevent direct contact between the $\mathrm{Zn}$ anode and electrolyte, but also formed $\mathrm{H}$ bonds with $\mathrm{H}_{2} \mathrm{O}$ molecules. The energy of water absorbed on the $\mathrm{Sc}_{2} \mathrm{O}_{3}$-coated $\mathrm{Zn}$ anode was lower than that on the bare $\mathrm{Zn}$ anode (Fig. 8c). Zhou et al. [68] developed a 3D nanoporous $\mathrm{ZnO}$ structure (Zn@ $\mathrm{ZnO}-3 \mathrm{D}$ ) by a one-step liquid deposition method to modify the surface of the $\mathrm{Zn}$ anode, which adjusted the solvation sheath structure of $\mathrm{Zn}^{2+}$ in electric double layers. By comparing the morphologies, the $\mathrm{ZnO}-3 \mathrm{D}$ structure-modified $\mathrm{Zn}$ anode inhibited dendrite growth with good cycling stability. Furthermore, a first-principles calculation confirmed that the extra surface charge concentration reduced the energy barrier of $\mathrm{Zn}^{2+}$ desolvation and accelerated the kinetics of $\mathrm{Zn}^{2+}$ deposition on $\mathrm{Zn} @ \mathrm{ZnO}-3 \mathrm{D}$ (Fig. 8d, e). In addition, Zhou et al. [98] prepared a kaolin-coated $\mathrm{Zn}$ anode (KL$\mathrm{Zn}$ ), which provided abundant active adsorption sites for $\mathrm{Zn}^{2+}$, and its porous structure greatly assisted in realizing uniform dendrite-free $\mathrm{Zn}$ deposition. During the 3D diffusion of KL-Zn, the homogeneous porous structure of kaolin constrained $\mathrm{Zn}^{2+}$ and inhibited the formation of $\mathrm{Zn}$ dendrites (Fig. 8f). After a full-cell cycle test, the KL-Zn electrode surface retained its morphological stability (Fig. 8g). The $\mathrm{KL}-\mathrm{Zn}$ anodes exhibited superior corrosion resistance and long-term cycling stability (Fig. 8h).

Coatings on the surface of the $\mathrm{Zn}$ anode can be obtained by in situ and ex situ methods. The in situ SEI layer is an important strategy for the preparation of high-performance $\mathrm{Zn}$ metal anodes. An in situ SEI layer was constructed on the surface of the $\mathrm{Zn}$ anode by adding additives to the electrolyte. Electrolyte additives can change the solvation sheath of $\mathrm{Zn}$ ions, and the formed SEI layer can effectively prevent the growth of dendrites and inhibit the decomposition of solvated $\mathrm{H}_{2} \mathrm{O}$. Wang et al. [83] inhibited water reduction and $\mathrm{Zn}$ dendrite growth in dilute aqueous electrolytes by adding dimethyl sulfoxide (DMSO) to $\mathrm{ZnCl}_{2}$. Moreover, the preferential solvation of DMSO changed the $\mathrm{Zn}^{2+}$ sheath of $\mathrm{H}_{2} \mathrm{O}$ solvation (Fig. 9a). The $\mathrm{SEI}$ compositions on the $\mathrm{Zn}$ anodes were analyzed by X-ray diffraction (XRD) (Fig. 9b) and X-ray photoelectron spectroscopy (XPS) (Fig. 9c), and it was clearly visible in the XPS images that the ZnS content increased gradually with an increase in time. Therefore, the contribution of the DMSO additive to the formation of the $\mathrm{Zn}_{12}\left(\mathrm{SO}_{4}\right)_{3} \mathrm{Cl}_{3}(\mathrm{OH})_{15} \cdot 5 \mathrm{H}_{2} \mathrm{O}-\mathrm{ZnSO}_{3}$ - $\mathrm{ZnS}$ SEI is closely related to the solvation structure of $\mathrm{Zn}^{2+}$ ions in the electrolyte. SEI allows $\mathrm{Zn}^{2+}$ transport but prevents $\mathrm{H}_{2} \mathrm{O}$ infiltration, which further inhibits water reduction and $\mathrm{Zn}$ dendrite growth.

Some inorganic salts are also suitable coating materials for the protection of $\mathrm{Zn}$ anodes. Kang et al. [99] constructed $\mathrm{Zn|ZnSO}{ }_{4}+\mathrm{MnSO}_{4} \mid \mathrm{MnO}_{2}$ aqueous batteries with nano$\mathrm{CaCO}_{3}$-coated $\mathrm{Zn}$ metal anodes. During the $\mathrm{Zn}$ stripping/ plating cycle, the electrical insulation of the $\mathrm{CaCO}_{3}$ coating led to the deposition of $\mathrm{Zn}$ under the coating, thereby forming a three-layer structure of $\mathrm{CaCO}_{3} / \mathrm{Zn}$ sheet/ZF, which 

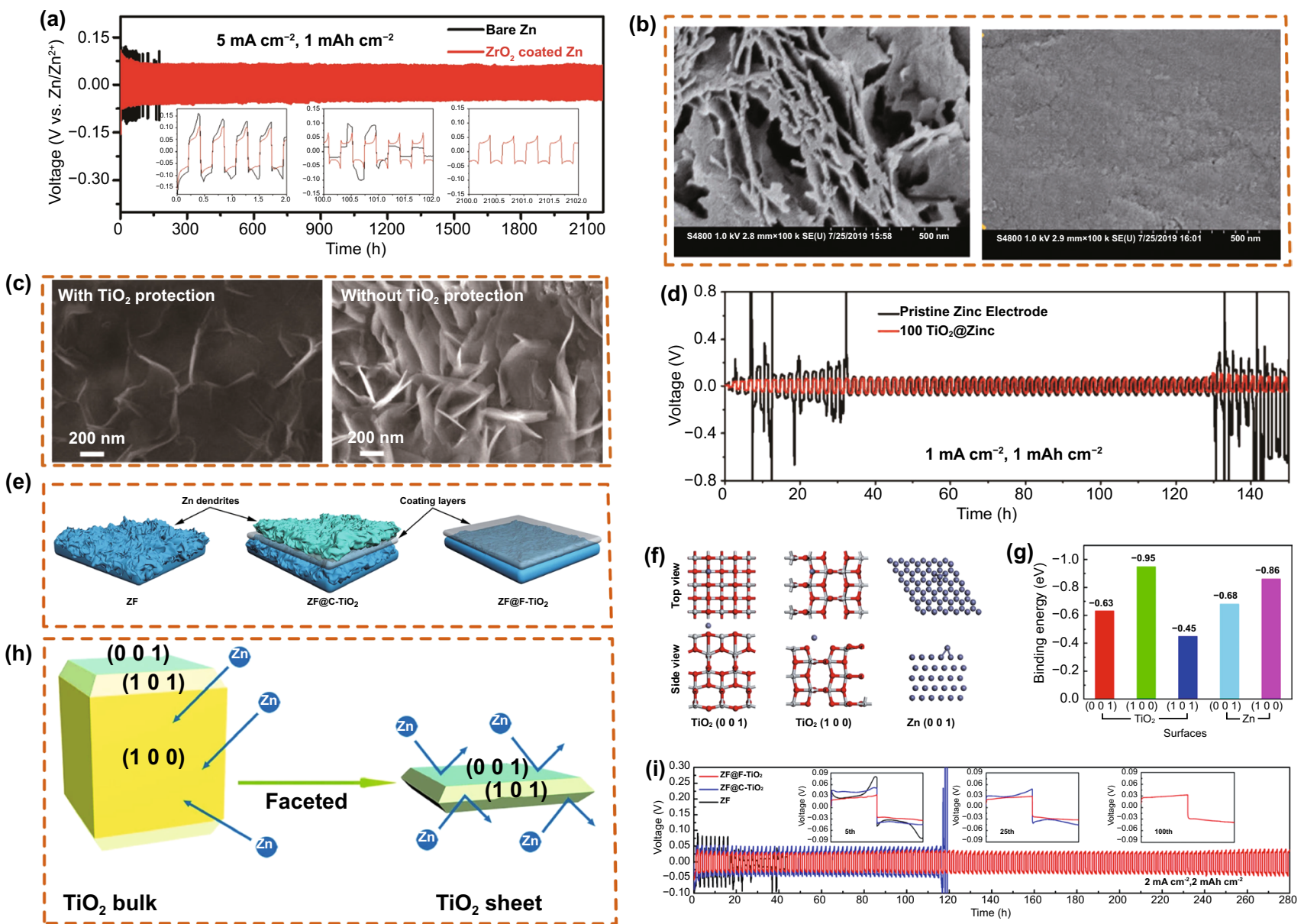

Fig. 7 a Voltage profiles of metallic $\mathrm{Zn}$ stripping/plating in a bare $\mathrm{Zn}$ and $\mathrm{ZrO}_{2}$-coated $\mathrm{Zn}$ symmetrical full-cell at $5 \mathrm{~mA} \mathrm{~cm}^{-2}$ for $1 \mathrm{mAh} \mathrm{cm}^{-2}$. b Digital images and corresponding SEM images of a bare $\mathrm{Zn}$ and $\mathrm{ZrO}_{2}$-coated $\mathrm{Zn}$ anode after 100 cycles at $5 \mathrm{~mA} \mathrm{~cm}{ }^{-2}$ with $2.5 \mathrm{mAh} \mathrm{cm}^{-2}$. Copyright 2020 Royal Society of Chemistry [55]. c Ex situ SEM images of 100TiO @ $\mathrm{Zn}$ and a pristine Zn anode. d Cyclic stripping/plating process of symmetrical cells using $100 \mathrm{TiO}_{2} @ \mathrm{Zn}$ and pristine $\mathrm{Zn}$ at $1 \mathrm{~mA} \mathrm{~cm}{ }^{-2}$. Copyright 2019 Wiley-VCH [47]. e Schematic illustration of the $\mathrm{Zn}$ plating process with different coating layers. $\mathbf{f}$ Calculation models of $\mathrm{Zn}$ absorbed on a $\mathrm{TiO}_{2}\left(\begin{array}{lll}0 & 0 & 1\end{array}\right)$ facet, $\mathrm{TiO}_{2}\left(\begin{array}{lll}1 & 0 & 0\end{array}\right)$ facet, and $\mathrm{Zn}\left(\begin{array}{ll}0 \\ 0\end{array}\right.$ 0 1) facet. $\mathbf{g}$ Calculated binding energies of $\mathrm{Zn}$ atom with different facets. $\mathbf{h}$ Schematic illustration of the interaction between $\mathrm{Zn}$ and anatase $\mathrm{TiO}_{2}$ with different exposed facets. i Cycling performance of $\mathrm{ZnllZn}$ symmetrical cells at $2 \mathrm{~mA} \mathrm{~cm} \mathrm{cor}^{-2}$ fo $\mathrm{mAh}^{-2}$. Copyright $2020 \mathrm{Springer}$ Nature [95]

effectively prevented dendrite generation and short-circuit problems (Fig. 9d). After the Zn stripping/plating cycle, the $\mathrm{ZF}$ covered by nano- $\mathrm{CaCO}_{3}$ formed a compact and uniform micro-sheet layer, enabling a longer life for the $\mathrm{Zn}$ metal anode. Zhu et al. [100] hydrothermally synthesized a fast ion conductor, $\mathrm{NaTi}_{2}\left(\mathrm{PO}_{4}\right)_{3}(\mathrm{NTP})$, on the surface of a $\mathrm{Zn}$ anode as a solid electrolyte protective layer. DFT calculations and cyclic voltammetry tests showed that NTP has a higher ionic conductivity than other insoluble phosphates (Fig. 9e). The internal transport/mobility of $\mathrm{Zn}^{2+}$ was used in the NTP layer as an "ion can pass through the fence." The NTP layer with a thickness of 20-25 $\mu \mathrm{m}$ not only prevented side reactions and $\mathrm{Zn}$ dendrites (Fig. 9f, g), but also improved the reversibility and electrochemical performance of the $\mathrm{Zn}$ anode. Mao et al. [101] introduced $\mathrm{Zn}\left(\mathrm{H}_{2} \mathrm{PO}_{4}\right)_{2}$ salt into an aqueous electrolyte to form a solid and highly $\mathrm{Zn}^{2+}$-conductive SEI layer (hopeite) in situ by taking advantage of the local $\mathrm{pH}$ increase caused by water decomposition. Compared with bare $\mathrm{Zn}$, the corrosion potential of SEI-Zn increased, the tendency of the corrosion reaction was smaller, and the reaction rate decreased, which had a protective effect on the $\mathrm{Zn}$ electrode (Fig. 9h). In addition, by measuring the activation energy of the desolvation of symmetrical cells during $\mathrm{Zn}$ plating at different temperatures, it was found that the activation energy of SEI-Zn was lower than that of bare $\mathrm{Zn}$, which indicates that the SEI layer 

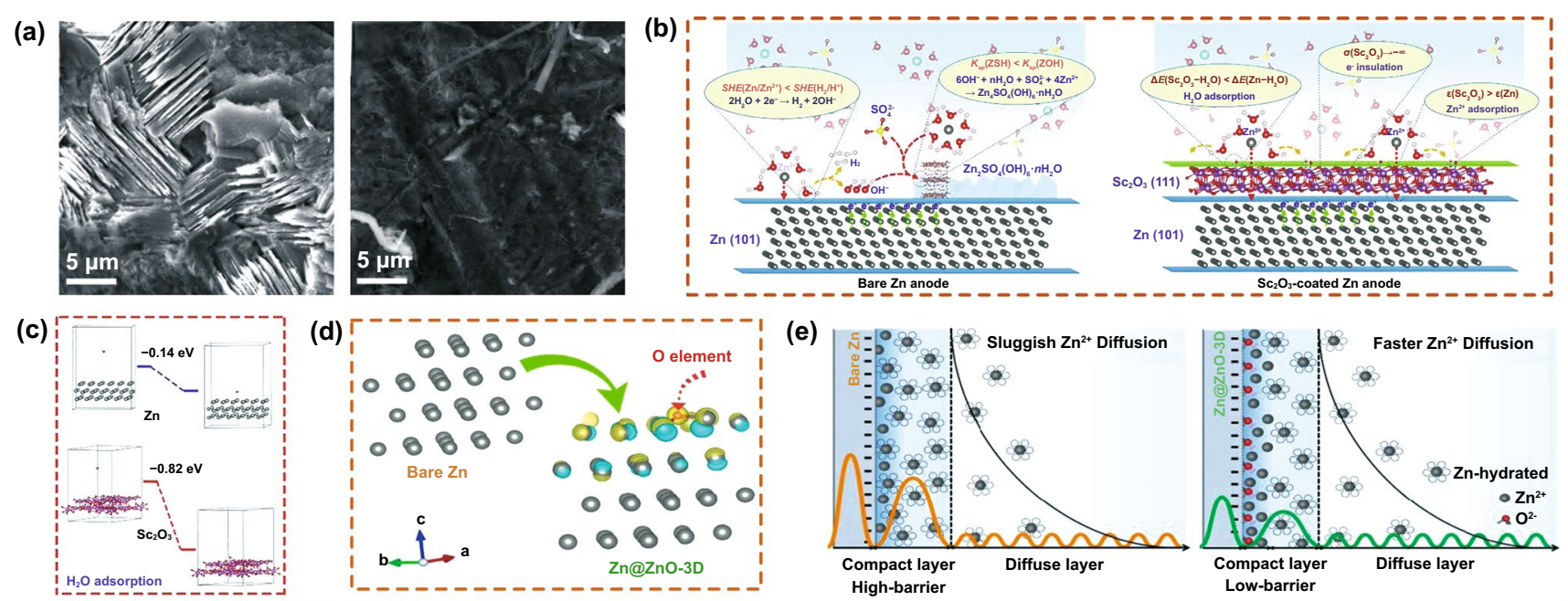

(d)

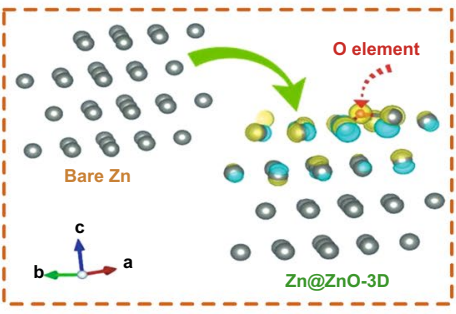

(e)

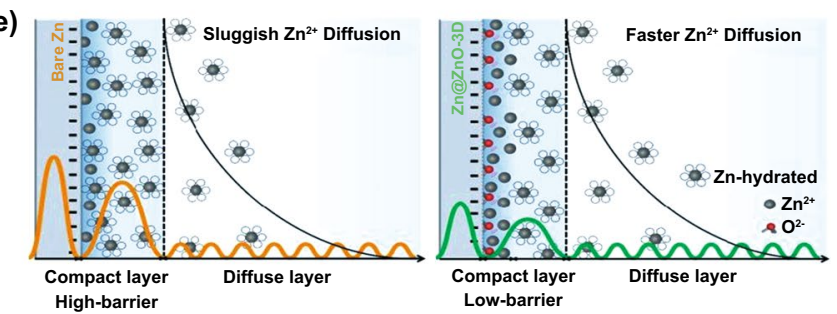

(f)!

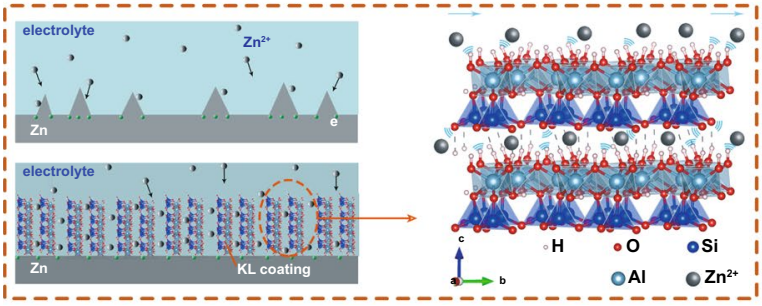

(g)

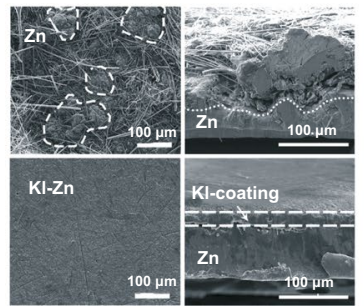

(h)

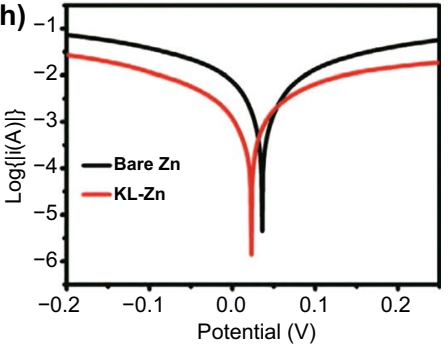

Fig. 8 a SEM images of bare Zn after cycling. Copyright 2020 Royal Society of Chemistry [96]. b Long-term cycling stability of bare Zn and $100 \mathrm{Al}_{2} \mathrm{O}_{3} @ \mathrm{Zn}$ with a 200- $\mu$ lectrolyte. c Schematic diagram of the reaction process on the surface of a bare $\mathrm{Zn}$ anode and $\mathrm{Sc}_{2} \mathrm{O}_{3}$-coated $\mathrm{Zn}$ anode. Copyright 2020 Elsevier [97]. d Differential charge density distribution of Zn@ZnO-3D calculated by first-principle calculations. e Electric double-layer structure in the vicinity of the anode and the corresponding energy barrier. Copyright 2016 Royal Society of Chemistry [68]. f Schematic diagram of $\mathrm{Zn}^{2+}$ deposition on the surface of naked $\mathrm{Zn}$ and KL-Zn and detailed schematic diagram of the limited $\mathrm{Zn}^{2+}$ transport in kaolin. g SEM images of the surface and cross-sectional morphology of the KL-Zn anode after 600 cycles with a $\mathrm{MnO}_{2}$ cathode under $0.5 \mathrm{~A}$ $\mathrm{g}^{-1}$. h Linear polarization curves for the corrosion of bare Zn and KL-Zn. Copyright 2020 Wiley-VCH [98]

provides a rapid transport channel for $\mathrm{Zn}^{2+}$ and accelerates the reaction kinetics (Fig. 9i, j).

Briefly, non-metallic inorganic material coatings are non-conductive protective layers, and there are no problems caused by uneven strength in the electric field. This type of inorganic coating uses a porous channel structure to modify the deposition behavior and migration path of $\mathrm{Zn}^{2+}$ and induces the orderly deposition of $\mathrm{Zn}^{2+}$ along the channels. In addition, the uniform flux of the electrolyte was controlled to induce a smaller $\mathrm{Zn}$ nucleation size by the restriction effect. Table 2 presents a summary of recently reported coating modification strategies for non-metallic inorganic materials. However, from the perspective of ion and electron transport, the dense interface layer hinders the migration of ions on the electrode surface. The use of these electrochemically inert protective materials reduces the rate performance of the anode to a certain extent.

\subsection{Polymers}

Polymer coatings, such as PA, 502 glue, polyvinyl butyral (PVB), and polyacrylonitrile (PAN), are generally used as artificial SEIs. These polymers normally exhibit good ionic conductivity and abundant polar groups, which interact with solvated metal ions. Additionally, the coatings not only effectively protect $\mathrm{Zn}$ from the influence of $\mathrm{H}_{2} \mathrm{O}$ but also manipulate the uniform nucleation sites of $\mathrm{Zn}$ plating/ stripping.

Cui et al. [80] proposed that the PA coating possesses a strong coordination ability for metal ions and a unique $\mathrm{H}$ bonding network. The coating reduces the number of harmful water molecules involved in the side reactions. Consequently, the water molecules that are bound by the $\mathrm{H}$ bonding network cannot destroy the solvation sheath of $\mathrm{Zn}^{2+}$, resulting in a higher number of $\mathrm{Zn}^{2+}$ migrations (Fig. 10a). 

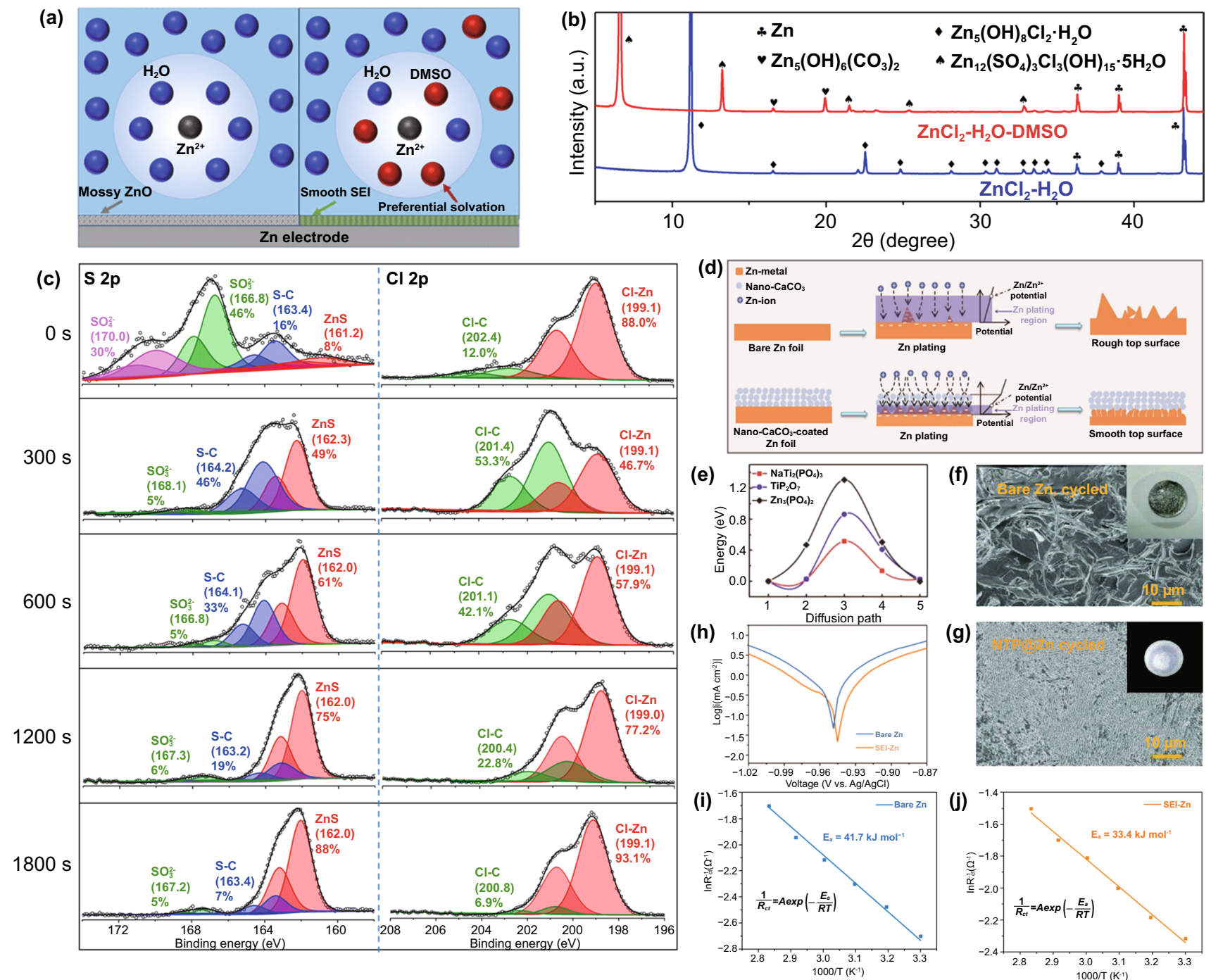

Fig. 9 a Scheme of the $\mathrm{Zn}^{2+}$ solvation structure and $\mathrm{Zn}$ surface passivation in $\mathrm{H}_{2} \mathrm{O}$ and $\mathrm{H}_{2} \mathrm{O}$-DMSO solvents. b XRD patterns of $\mathrm{Zn}$ anodes after plating/stripping cycles in $\mathrm{ZnCl}_{2}-\mathrm{H}_{2} \mathrm{O}$-DMSO and $\mathrm{ZnCl}_{2}-\mathrm{H}_{2} \mathrm{O}$ electrolytes. c XPS characterization of the SEI formed on $\mathrm{Zn}$ cycled in $\mathrm{ZnCl}_{2}-\mathrm{H}_{2} \mathrm{O}$-DMSO electrolyte. Copyright 2020 American Chemical Society [83]. d Schematic diagram of the morphological evolution of bare and nano- $\mathrm{CaCO}_{3}$-coated $\mathrm{ZFs}$ during $\mathrm{Zn}$ stripping/plating cycling. Copyright $2018 \mathrm{Wiley-VCH}$ [99]. e Proposed migration energy barriers of $\mathrm{Zn}$ ions in bulk NTP, TiP $\mathrm{O}_{7}$, and $\mathrm{Zn}_{3}\left(\mathrm{PO}_{4}\right)_{2}$. The SEM images of $\mathbf{f}$ bare $\mathrm{Zn}$ and $\mathbf{g}$ NTP@ $\mathrm{Zn}$ foil after 100 stripping/plating cycles. Copyright 2020 Wiley-VCH [100]. h Linear polarization curves showing the corrosion on bare $\mathrm{Zn}$ and SEI-Zn electrodes. Corresponding Arrhenius curves of $\mathrm{Zn}$ symmetric cells at different temperatures: i bare Zn and j SEI-Zn. Copyright 2021 Wiley-VCH [101]

In addition, the PA coating coordinates the uniform migration of $\mathrm{Zn}^{2+}$ by densifying the crystal nucleus (Fig. 10b) and acts as a water $/ \mathrm{O}_{2}$-resistant buffer layer to isolate $\mathrm{Zn}$ from the electrolyte, thus inhibiting corrosion and passivation of the $\mathrm{Zn}$ anode (Fig. 10c). A symmetrical $\mathrm{Zn}$ battery with a polymer-modified $\mathrm{Zn}$ anode could work in reverse for $8000 \mathrm{~h}$ without $\mathrm{Zn}$ dendrites (60 times that of bare $\mathrm{Zn}$ ) through this synergistic effect (Fig. 10d). The capacity retention rate and
CE of the $\mathrm{Zn} / \mathrm{MnO}_{2}$ cell with coated $\mathrm{Zn}$ were $88 \%$ and $99 \%$, respectively, after 1000 cycles (Fig. 10e).

Cao et al. [102] applied 502 glue (solvent-free cyanoacrylate adhesive) uniformly on the $\mathrm{Zn}$ surface using the spincoating method (Fig. 11a). This coating has the important function of acting as an artificial SEI film to effectively inhibit the corrosion of $\mathrm{O}_{2}$ and $\mathrm{H}_{2} \mathrm{O}$ molecules on the $\mathrm{Zn}$ anode, the formation of $\mathrm{Zn}$ dendrites, and the occurrence of 
Table 2 Summary of recently reported coatings modification strategies for non-metallic inorganic materials

\begin{tabular}{|c|c|c|c|}
\hline Anode materials & Voltage hysteresis & Lifespan & References \\
\hline Nano- $\mathrm{ZrO}_{2}$-coated $\mathrm{Zn}$ anode & $32 \mathrm{mV}\left(5 \mathrm{~mA} \mathrm{~cm}{ }^{-2}\right)$ & $2100 \mathrm{~h}\left(5 \mathrm{~mA} \mathrm{~cm}-2,1 \mathrm{mAh} \mathrm{cm}^{-2}\right)$ & {$[55]$} \\
\hline Ultrathin $\mathrm{TiO}_{2}$-coated $\mathrm{Zn}$ anode & $57 \mathrm{mV}\left(1 \mathrm{~mA} \mathrm{~cm}^{-2}\right)$ & $150 \mathrm{~h}\left(1 \mathrm{~mA} \mathrm{~cm}{ }^{-2}, 1 \mathrm{mAh} \mathrm{cm}^{-2}\right)$ & [47] \\
\hline $\mathrm{TiO}_{2}$ of low $\mathrm{Zn}$ affinity-coated $\mathrm{Zn}$ anode & $\approx 40 \mathrm{mV}\left(1 \mathrm{~mA} \mathrm{~cm}{ }^{-2}\right)$ & $460 \mathrm{~h}\left(1 \mathrm{~mA} \mathrm{~cm}{ }^{-2}, 1 \mathrm{mAh} \mathrm{cm}^{-2}\right)$ & {$[95]$} \\
\hline $\mathrm{Al}_{2} \mathrm{O}_{3}$-coated $\mathrm{Zn}$ anode & $36.5 \mathrm{mV}\left(1 \mathrm{~mA} \mathrm{~cm}^{-2}\right)$ & $500 \mathrm{~h}\left(1 \mathrm{~mA} \mathrm{~cm}^{-2}, 1 \mathrm{mAh} \mathrm{cm}^{-2}\right)$ & [96] \\
\hline $\mathrm{Sc}_{2} \mathrm{O}_{3}$-coated $\mathrm{Zn}$ anode & $71 \mathrm{mV}\left(1 \mathrm{~mA} \mathrm{~cm}^{-2}\right)$ & $200 \mathrm{~h}\left(1 \mathrm{~mA} \mathrm{~cm}{ }^{-2}, 1 \mathrm{mAh} \mathrm{cm}^{-2}\right)$ & [97] \\
\hline Zn@ZnO-3D anode & $43 \mathrm{mV}\left(5 \mathrm{~mA} \mathrm{~cm}{ }^{-2}\right)$ & $500 \mathrm{~h}\left(5 \mathrm{~mA} \mathrm{~cm}{ }^{-2}, 1.25 \mathrm{mAh} \mathrm{cm}^{-2}\right)$ & [68] \\
\hline Kaolin-coated $\mathrm{Zn}$ foil & $\approx 70 \mathrm{mV}\left(4.4 \mathrm{~mA} \mathrm{~cm}^{-2}\right)$ & $800 \mathrm{~h}\left(4.4 \mathrm{~mA} \mathrm{~cm}{ }^{-2}, 1.1 \mathrm{mAh} \mathrm{cm}^{-2}\right)$ & [98] \\
\hline $\mathrm{Zn}$ anode with $\mathrm{ZnS}$ SEI & $\approx 41 \mathrm{mV}\left(0.5 \mathrm{~mA} \mathrm{~cm}^{-2}\right)$ & $1000 \mathrm{~h}\left(0.5 \mathrm{~mA} \mathrm{~cm}^{-2}, 0.5 \mathrm{mAh} \mathrm{cm}{ }^{-2}\right)$ & [83] \\
\hline Nanoporous $\mathrm{CaCO}_{3}$-coated $\mathrm{Zn}$ anode & $80 \mathrm{mV}\left(0.25 \mathrm{~mA} \mathrm{~cm}^{-2}\right)$ & $836 \mathrm{~h}\left(0.25 \mathrm{~mA} \mathrm{~cm}^{-2}, 0.05 \mathrm{mAh} \mathrm{cm}^{-2}\right)$ & [99] \\
\hline NTP@Zn & $50 \mathrm{mV}\left(1 \mathrm{~mA} \mathrm{~cm}^{-2}\right)$ & $260 \mathrm{~h}\left(1 \mathrm{~mA} \mathrm{~cm}{ }^{-2}, 1 \mathrm{mAh} \mathrm{cm}^{-2}\right)$ & {$[100]$} \\
\hline Zn with hopeite SEI & $\approx 80 \mathrm{mV}\left(1 \mathrm{~mA} \mathrm{~cm} \mathrm{c}^{-2}\right)$ & $1200 \mathrm{~h}\left(1 \mathrm{~mA} \mathrm{~cm}^{-2}, 1 \mathrm{mAh} \mathrm{cm}^{-2}\right)$ & [101] \\
\hline
\end{tabular}

other side reactions (Fig. 11b). Additionally, owing to the adsorption effect between $\mathrm{Zn}^{2+}$ and the polar cyano groups in the backbones of 502 glue, the $\mathrm{Zn}$ nucleation sites are more evenly and orderly distributed (Fig. 11c). Furthermore, the 502 glue-coated $\mathrm{Zn}$ cell showed excellent cycling stability and a high CE (99.74\%) (Fig. 11d). Hao et al. [103] fabricated a PVB coating with rich polar functional groups. The PVB coating effectively removed the solvated water during $\mathrm{Zn}$ plating/stripping and significantly inhibited the occurrence of side reactions (Fig. 11e). The electrolyte on the Zn surface was also evenly distributed by the PVB coating, which guided the dissolution and deposition process of $\mathrm{Zn}$ ions. Therefore, employing PVB coatings inhibits the side reactions and growth of $\mathrm{Zn}$ dendrites (Fig. 11f, g). Recently, Hu et al. [104] used a simple drop-coating method to prepare a PAN coating on a $\mathrm{Zn}$ anode to solve the dendrite problem. Because of the microchannels in the polymer network and the interaction effect between $\mathrm{Zn}^{2+}$ and the cyano groups $(-\mathrm{CN})$, the PAN coating combined with $\mathrm{Zn}$ salt not only promoted the uniform transport of dissolved $\mathrm{Zn}^{2+}$ in the film, but also drove the uniform electrodeposition of $\mathrm{Zn}$ metal.

A polymer coating was used as a stable artificial SEI between the electrode and the electrolyte. Polymers have a large number of polar groups and cooperate with $\mathrm{Zn}^{2+}$, which provides abundant active sites for nucleation and deposition. In addition, some polymer coatings can reduce the number of harmful water molecules involved in side reactions and effectively inhibit the side reactions, such as hydrogen evolution, corrosion, and passivation. Similar to non-metal inorganic materials, polymers are non-conductive protective layers. The recently reported coating modification strategies for polymers are listed in Table 3. However, these strategies provide an additional quality of inert materials and increase the length of the migration path of $\mathrm{Zn}^{2+}$, thereby affecting the rate performance of the anode.

\subsection{Composite Materials}

There are various types of $\mathrm{Zn}$ anode surface coatings. Moreover, each material has its own advantages and limitations. For example, metals as effective heterogeneous seeds guide the uniform deposition of metallic $\mathrm{Zn}$ [94], but are expensive. Most inorganic substances have a porous structure [99], but they are brittle and break easily after long-term cycling or rapid $\mathrm{Zn}$ plating/stripping. The organic polymer layer is flexible, but on the one hand, the hydrophobic polymer layer significantly increases the polarization potential of Zn plating/stripping owing to the increase in the nucleation barrier and the limitation of the 2D diffusion of $\mathrm{Zn}^{2+}$ [80]. On the other hand, hydrophilic polymers easily dissolve in aqueous electrolytes, thus losing the protection of the $\mathrm{Zn}$ anode. Consequently, the preparation of composite coatings is a new strategy for protecting $\mathrm{Zn}$ anodes. Current research results show that the metal-organic framework (MOF) has a porous structure and that the organic-inorganic composite coating has a unique organic-inorganic structure. In addition, these composite coatings have good wettability to the electrolyte to suppress water-induced side reactions by the desolvation effect.

Pan et al. [105] proposed an artificial composite protective layer composed of a nano-MOF to reconstruct the $\mathrm{Zn}$ / electrolyte interface. The MOF particles immersed in the 
(a)

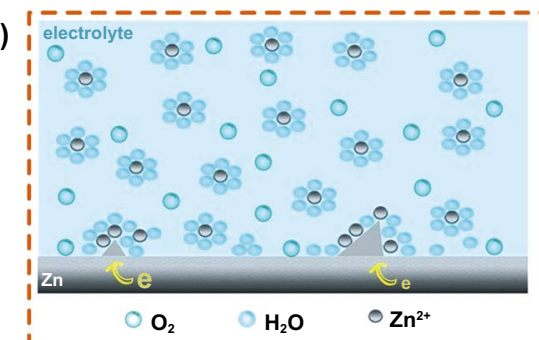

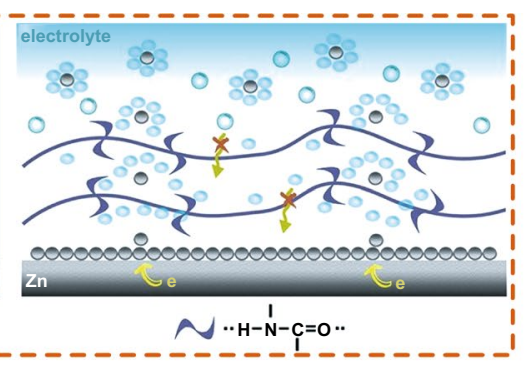

(b)

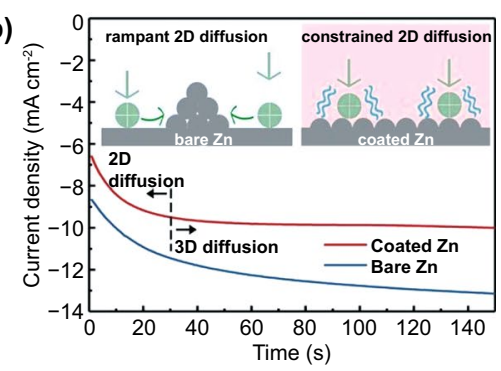

(c)
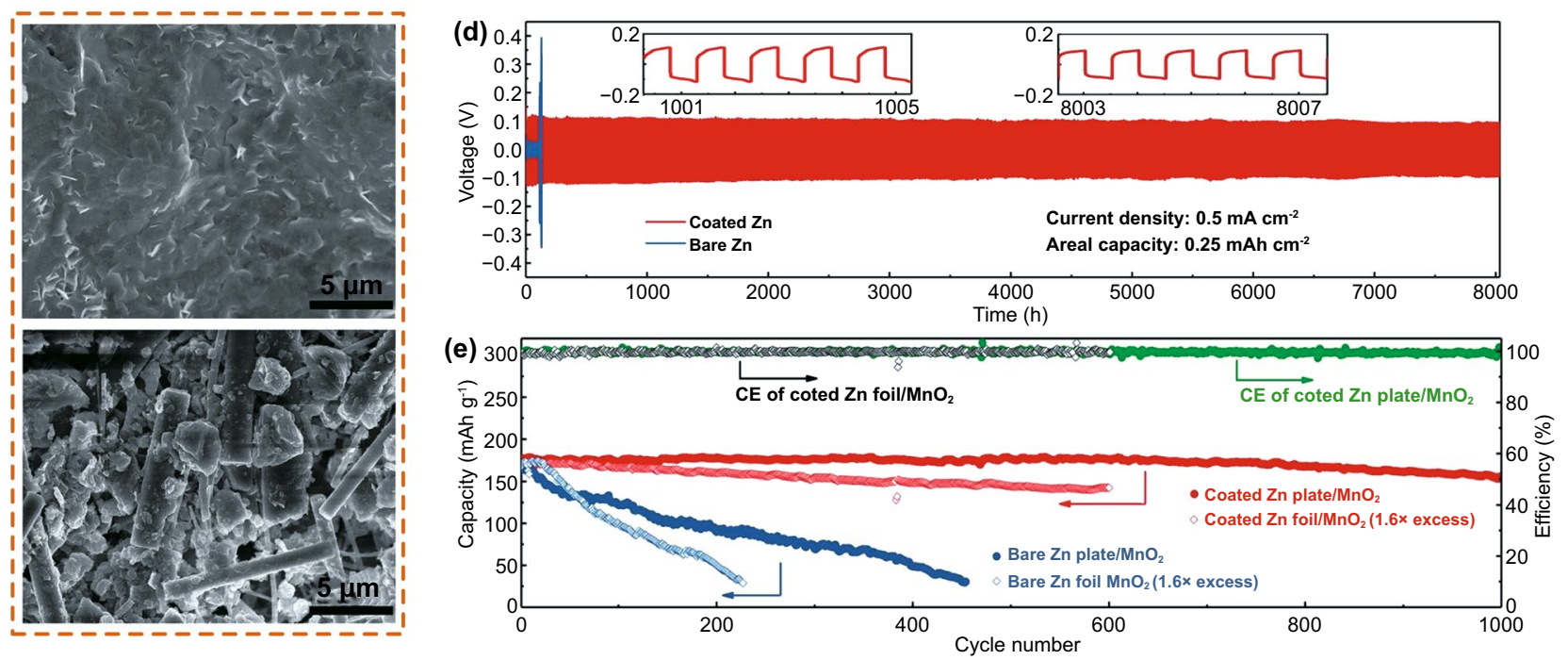

Fig. 10 a Schematic diagrams for $\mathrm{Zn}$ deposition on bare $\mathrm{Zn}$ and coated $\mathrm{Zn}$. b Chronoamperograms of bare $\mathrm{Zn}$ and coated $\mathrm{Zn}$ at a $-150 \mathrm{mV}$ overpotential. Insets: schematics of the $\mathrm{Zn}^{2+}$ diffusion and reduction processes on bare and coated $\mathrm{Zn}$ electrodes. $\mathbf{c}$ SEM images of the surface of a coated Zn plate anode after 1000 cycles and a bare Zn plate after 450 cycles. d Long-term galvanostatic cycling of symmetrical Zn cells with coated and bare $\mathrm{Zn}$ plates at $0.5 \mathrm{~mA} \mathrm{~cm}{ }^{-2}$. e Cycling performance at a current density of 2 C. Copyright 2019 Royal Society of Chemistry [80]

electrolyte formed a good interface contact (Fig. 12a). The microporous structure of the MOF improved the wettability of the $\mathrm{Zn}$ anode and created a zincophilic interface, which significantly reduced the interface charge transfer resistance (Fig. 12b). The MOF coating decreased the overpotential of the battery (Fig. 12c), reduced the nucleation energy, and enhanced the zincophilicity of the interface. Qian et al. [78] also studied MOF materials. They used MOF as the front surface layer and MOF channels to maintain a supersaturated electrolyte layer on the $\mathrm{Zn}$ anode. Bare $\mathrm{Zn}$ suffers from water decomposition and passivation during the desolvation process of $\mathrm{Zn}$-aqueous ionic association $\left[\mathrm{Zn}\left(\mathrm{H}_{2} \mathrm{O}\right)_{6}{ }^{2+} \mathrm{SO}_{4}{ }^{2-}\right]$. However, through the mechanism of water inhibition, the MOF layer repelled a large amount of water in advance and obtained the positive side of the super-saturated electrolyte (Fig. 12d, e). Moreover, it is beneficial to guide the uniform deposition of $\mathrm{Zn}$ to obtain a dendrite- and corrosion-free $\mathrm{Zn}$ anode.
Yang et al. [26] designed and synthesized a type of organic-inorganic composite protective layer (Nafion-Zn$\mathrm{X})$. They incorporated hydrophilic $\mathrm{Zn}-\mathrm{X}$ zeolite into the hydrophilic region of the Nafion membrane. In the composite layer, $\mathrm{Zn}^{2+}$ connected the interface between $\mathrm{Zn}-\mathrm{X}$ and Nafion, forming a well-bridged and dense organic-inorganic interface, so that ion migration changed from the Nafion channel migration to the organic-inorganic interface transition mechanism (Fig. 13a). The Nafion-based films exhibited a lower desolvation energy (Fig. 13b), which was beneficial for improving the $\mathrm{Zn}$ plating/stripping kinetics and for the growth of dendrites. The Nafion- $\mathrm{Zn}-\mathrm{X}$ composite coating effectively shielded $\mathrm{SO}_{4}{ }^{2-}$ anions, freed $\mathrm{H}_{2} \mathrm{O}$ to inhibit side reactions (Fig. 13c), and protected the $\mathrm{Zn}$ anode. In addition, Liu et al. [106] synthesized alucone (an inorganic-organic hybrid coating) using a molecular deposition technique. The coating improved the wettability of the $\mathrm{Zn}$ anode and led to the uniform deposition of $\mathrm{Zn}$ (Fig. 13d). Compared with the 
(a)
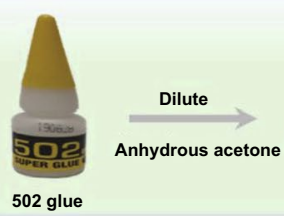

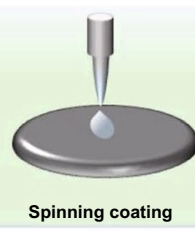

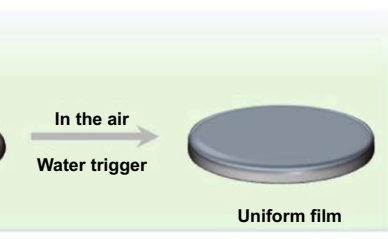

(d) (b)

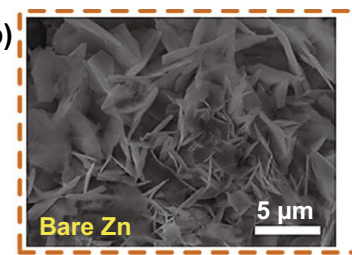

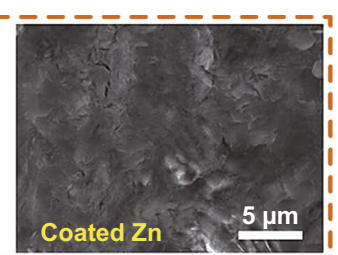

Coated Zn (c)

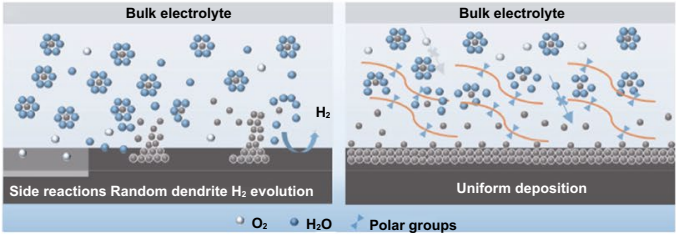

(d) $0.2-$

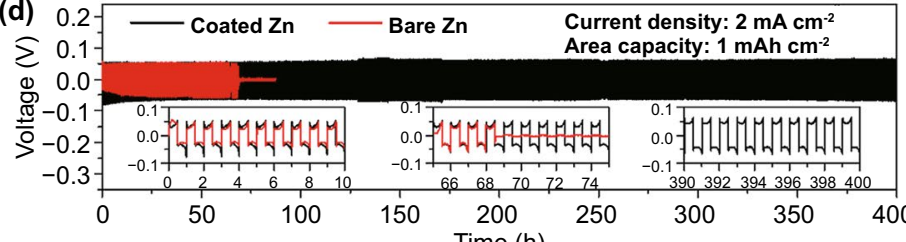

(e)

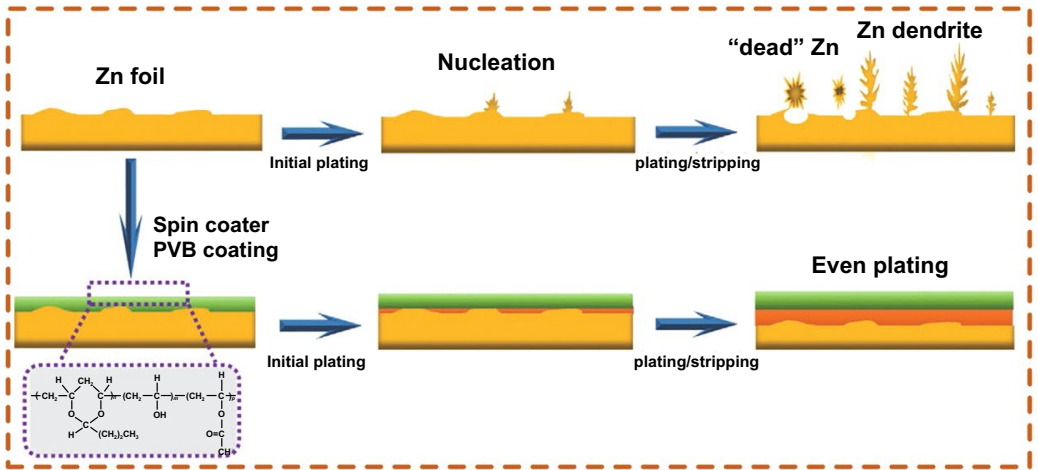
Time (h)

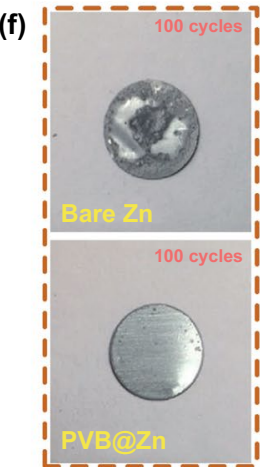

(g)

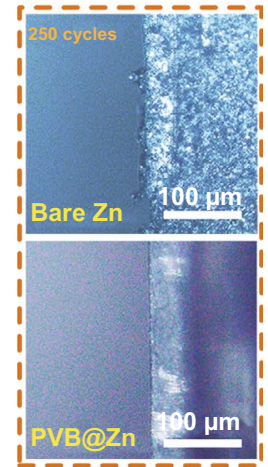

Fig. 11 a Schematic diagram of the preparation of a 502 glue protective layer. b Morphology of bare ZF and 502-decorated ZF obtained from symmetrical $\mathrm{Zn}$ cells after $\mathrm{Zn}$ stripping/plating for 100 cycles at $0.5 \mathrm{~mA} \mathrm{~cm}{ }^{-2}$ for $0.25 \mathrm{mAh} \mathrm{cm}{ }^{-2}$. c Schematic diagram of the mechanism of 502 glue for suppressing $\mathrm{Zn}$ dendrite. d Long-term cycling stability for symmetrical cells with various current densities and capacities. Copyright 2020 Elsevier [102]. e Schematic illustration of the morphological evolution for both a bare Zn and PVB@Zn symmetrical cell during repeated stripping/plating cycles. f Digital images of Zn and PVB @Zn electrodes that were stripped out of the cells after 100 cycles. $\mathbf{g}$ Zn electrodes and PVB@Zn electrodes in symmetrical transparent cells, along with the specified numbers of plating/stripping cycles. Copyright 2020 Royal Society of Chemistry [103]

Table 3 Summary of recently reported coatings modification strategies for polymer

\begin{tabular}{|c|c|c|c|}
\hline Anode materials & Voltage hysteresis & Lifespan & References \\
\hline PA layer/Zn foil & $100 \mathrm{mV}\left(0.5 \mathrm{~mA} \mathrm{~cm}^{-2}\right)$ & $8000 \mathrm{~h}\left(0.5 \mathrm{~mA} \mathrm{~cm}{ }^{-2}, 0.25 \mathrm{mAh} \mathrm{cm}^{-2}\right)$ & [80] \\
\hline 502 glue-coated $\mathrm{Zn}$ & $\approx 50 \mathrm{mV}\left(2 \mathrm{~mA} \mathrm{~cm}{ }^{-2}\right)$ & $400 \mathrm{~h}\left(2 \mathrm{~mA} \mathrm{~cm}^{-2}, 1 \mathrm{mAh} \mathrm{cm}^{-2}\right)$ & {$[102]$} \\
\hline PVB-coated Zn & $\approx 80 \mathrm{mV}\left(0.5 \mathrm{~mA} \mathrm{~cm}^{-2}\right)$ & $2200 \mathrm{~h}\left(0.5 \mathrm{~mA} \mathrm{~cm}^{-2}, 0.5 \mathrm{mAh} \mathrm{cm}^{-2}\right)$ & [103] \\
\hline PAN-coated Zn & $75 \mathrm{mV}\left(1 \mathrm{~mA} \mathrm{~cm}^{-2}\right)$ & $1145 \mathrm{~h}\left(1 \mathrm{~mA} \mathrm{~cm}{ }^{-2}, 1 \mathrm{mAh} \mathrm{cm}^{-2}\right)$ & [104] \\
\hline
\end{tabular}

bare $\mathrm{Zn}$ anode, the coated $\mathrm{Zn}$ anode exhibited a long cycle life and low voltage hysteresis (Fig. 13e) and inhibited dendrite growth on the surface of the $\mathrm{Zn}$ anode (Fig. 13f). Mao et al. [84] used the flame-retardant triethyl phosphate (TEP) as a co-solvent by adjusting the solvation structure of the non-aqueous electrolyte. TEP preferentially forms a TEPoccupied inner solvation sheath around $\mathrm{Zn}^{2+}$ and strong $\mathrm{H}$ bonding with $\mathrm{H}_{2} \mathrm{O}$ (Fig. 13g), leading to a robust polymericinorganic interphase (poly- $\mathrm{ZnP}_{2} \mathrm{O}_{6}$ and $\mathrm{ZnF}_{2}$ ) (Fig. 13h, i) on the $\mathrm{Zn}$ anode, effectively preventing dendrite growth and the side reactions of $\mathrm{H}_{2} \mathrm{O}$.

Table 4 presents a summary of recently reported coating modification strategies for composite materials. Composite coatings are prepared by combining different materials to overcome the limitations of a single material. Composite material coatings are difficult to prepare and are not easily mass produced. In contrast, carbon-based materials are easily available and have a significant effect 


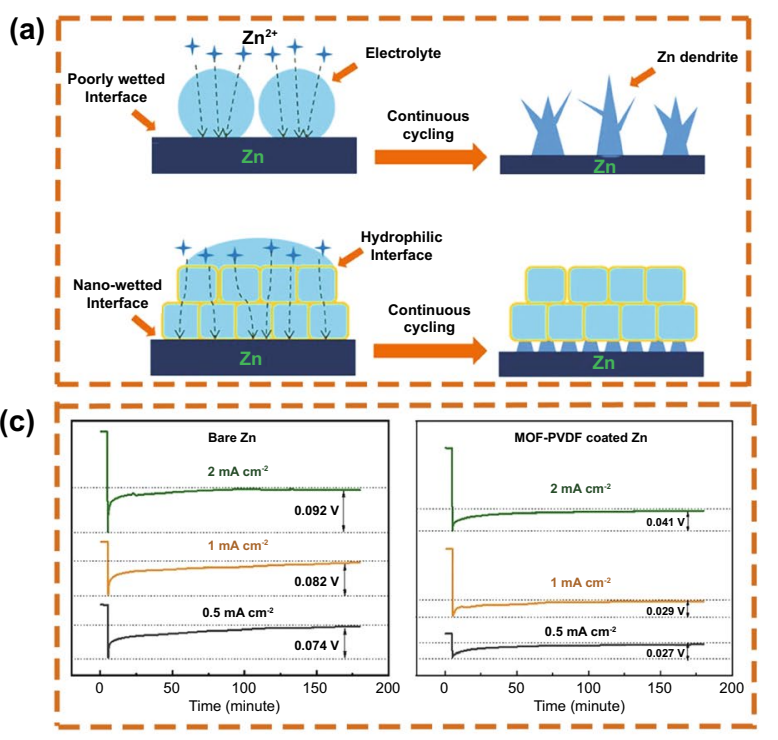

(d)

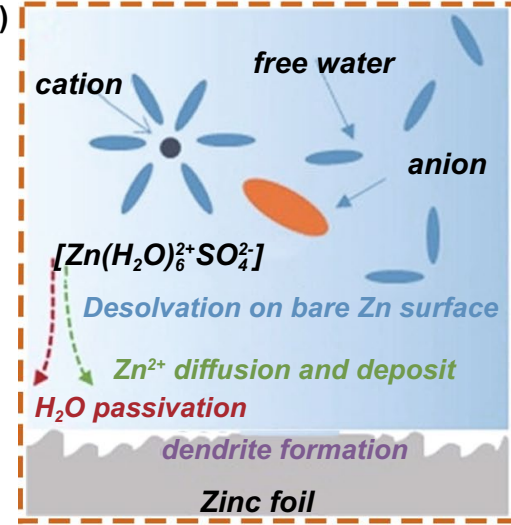

(b)

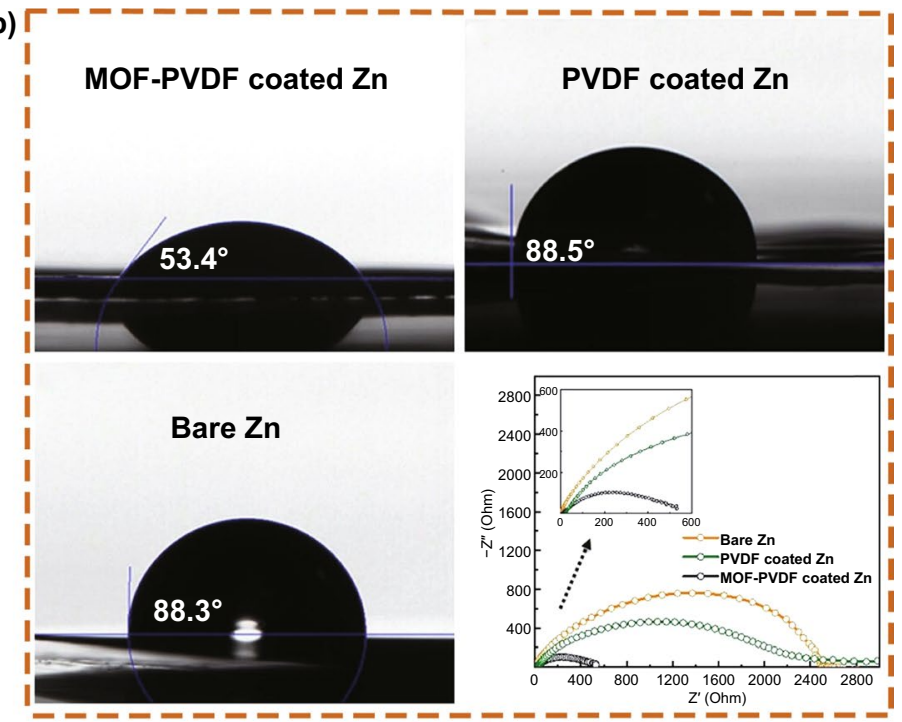

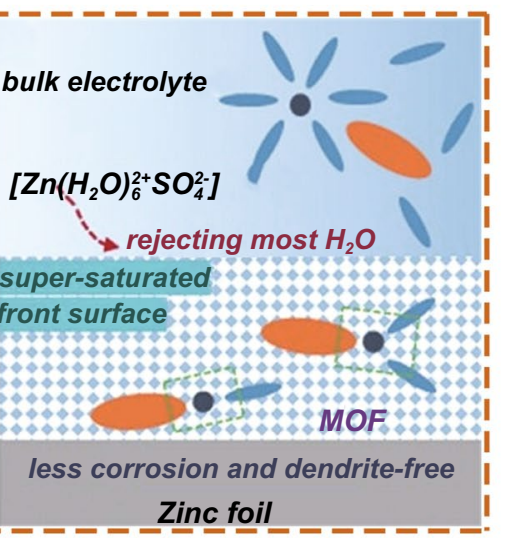

(e)

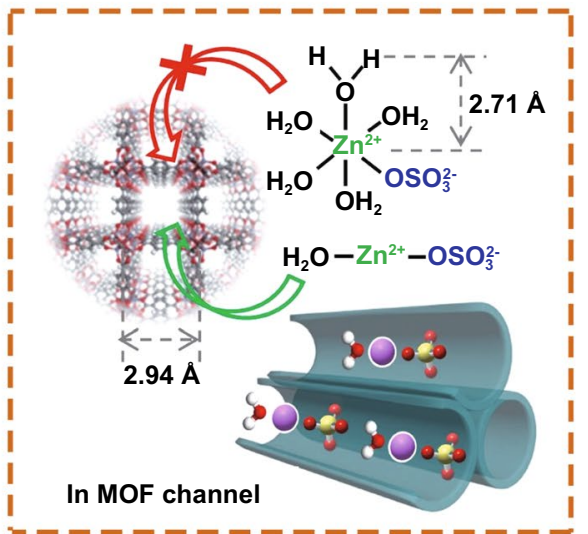

Fig. 12 a Proposed Zn plating mechanisms on bare Zn and MOF-PVDF-coated Zn. b Images of contact angles between the electrolyte and different anodes, and electrochemical impedance spectra of $\mathrm{Zn}$ symmetrical cells with different anodes. $\mathbf{c}$ Voltage curves of $\mathrm{Zn}$ plating on bare $\mathrm{Zn}$ and coated $\mathrm{Zn}$ at various current densities. Copyright 2019 American Chemical Society [105]. d Schematic illustration of the Zn surface evolution. e Schematic illustration of the highly-coordinated ion complexes of $\mathrm{H}_{2} \mathrm{O}-\mathrm{Zn}^{2+} \cdot \mathrm{OSO}_{3}{ }^{2-}$ migrating through MOF channels. Copyright 2020 Wiley-VCH [78]

on dendrite suppression. Metal-based materials with high conductivity are optional coating materials, but precious metals are expensive, which hinders their wide application. Non-metal inorganic materials and polymers are easy to prepare and inexpensive. However, the use of these electrochemically inert protective materials reduces the rate performance of the anode to a certain extent. Therefore, it is necessary to continuously explore easily prepared, low-cost, and excellent performance coating materials as the anode protective layer in the future.

\section{Interface Modification of Electrolyte/Zn Anode by Electrolyte Additives}

In addition to surface coatings, electrolyte additives are an important strategy in interface engineering. Electrolyte additives are used to adjust the surface morphology of the $\mathrm{Zn}$ anode and inhibit side reactions, such as $\mathrm{Zn}$ dendrite growth, hydrogen evolution reaction, and $\mathrm{Zn}$ surface corrosion and passivation. Various electrolyte additives have been applied to RAZIBs to protect the $\mathrm{Zn}$ 
(a)

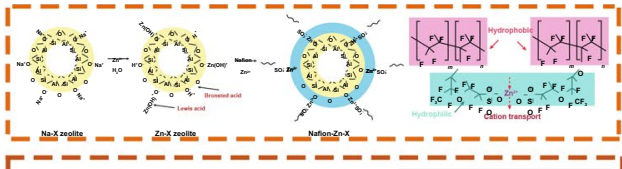

(b)

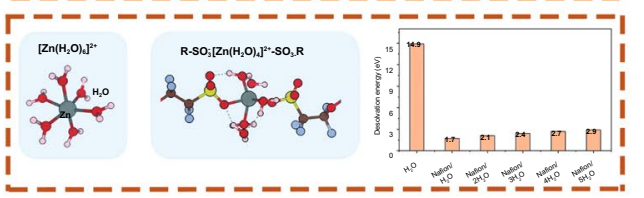

(c)

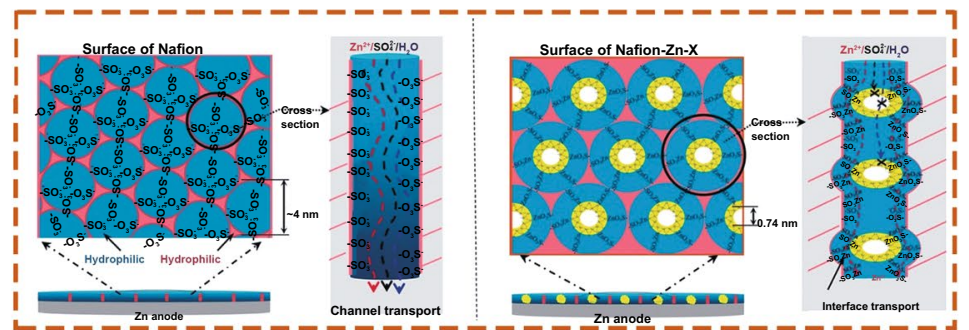

(d)

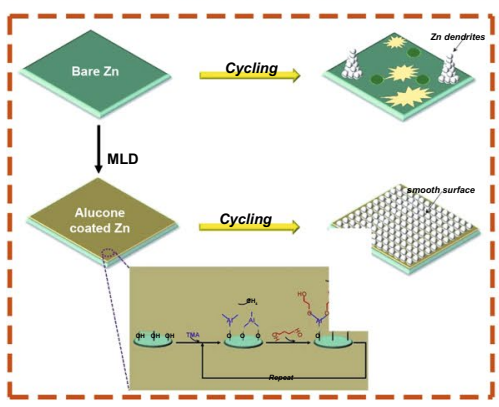

(e)

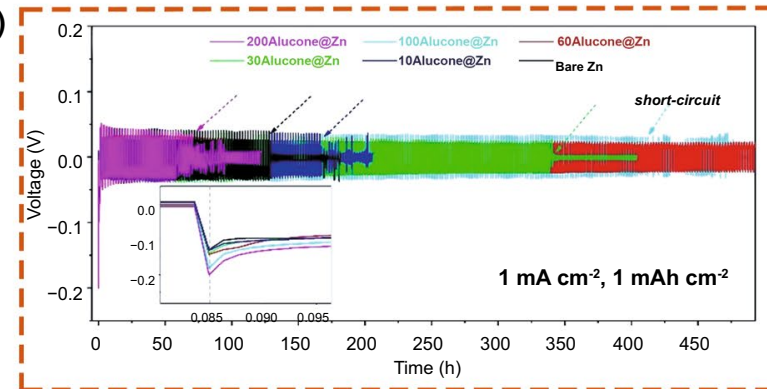

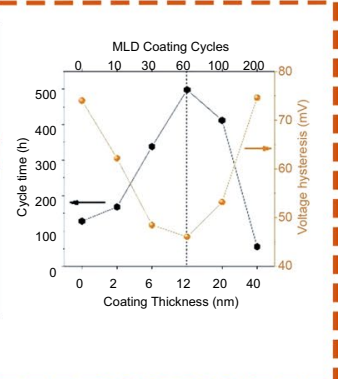

(f)

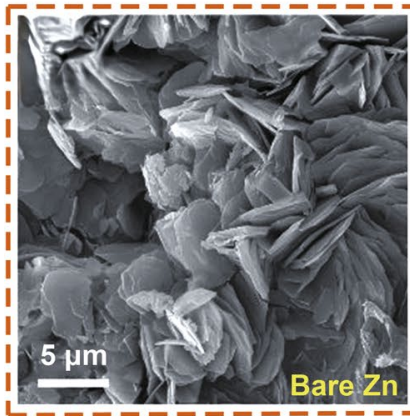

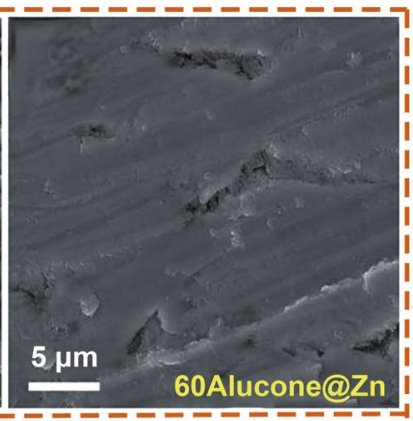

(g)

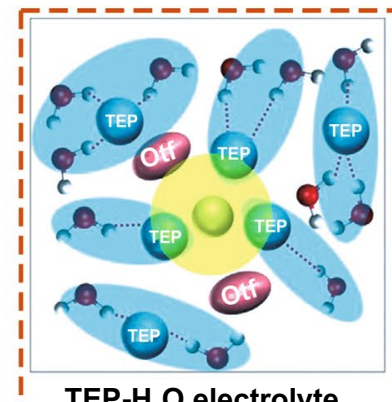

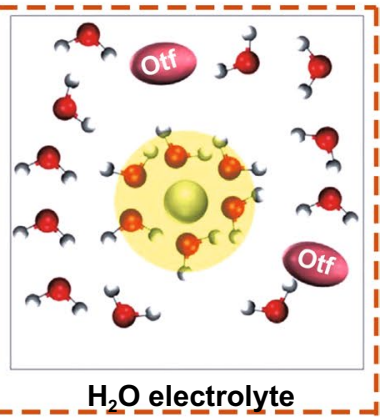

(h)

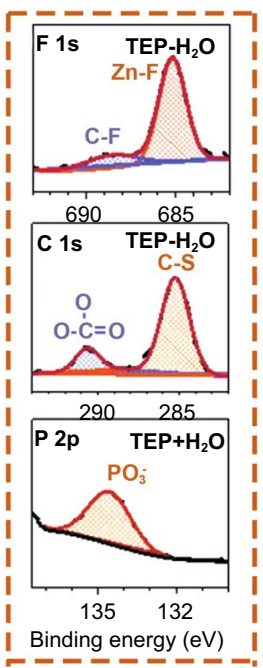

(i)

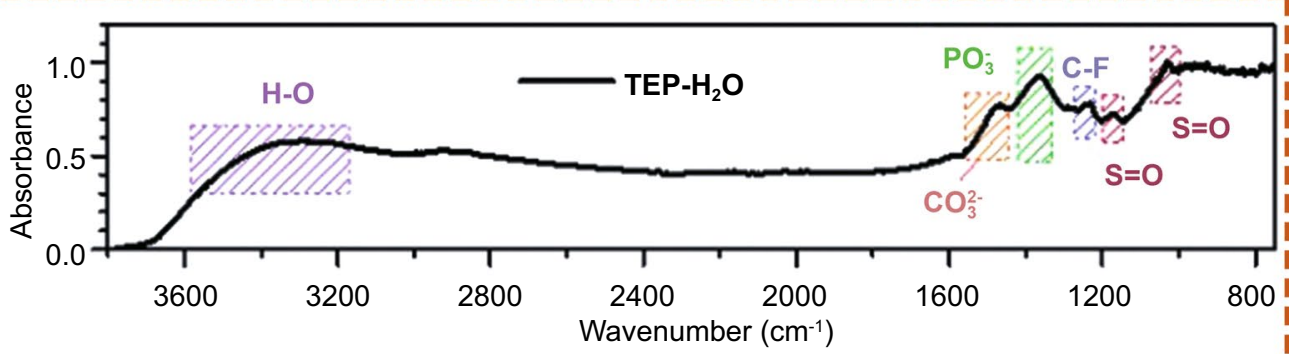

Wavenumber $\left(\mathrm{cm}^{-1}\right)$

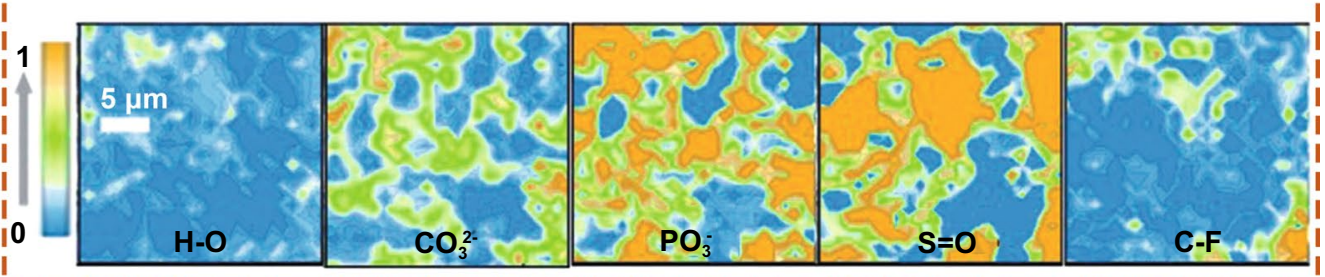

Fig. 13 a Schematic diagram of the formation process for the $\sim \mathrm{SO}_{3}{ }^{-}-\mathrm{Zn}^{2+} \sim$ bridge bond at the interface between organic Nafion and inorganic $\mathrm{Zn}-\mathrm{X}$ zeolite and the organic structure of Nafion with $\mathrm{Zn}^{2+}$. b Coordination environment of $\mathrm{Zn}^{2+}$ in water and $\mathrm{Nafion}$ with $4 \mathrm{H}_{2} \mathrm{O}$ and desolvation energy values of $\mathrm{Zn}^{2+}$ in water or in Nafion with various $\mathrm{H}_{2} \mathrm{O}$. c Ion transport mechanisms in Nafion and Nafion-Zn-X protective layers. Copyright 2020 Wiley-VCH [26]. d Schematic illustration showing the effect of an inorganic-organic molecular layer deposition (MLD) alucone coating on $\mathrm{Zn}$ metal anodes when cycling. e Galvanostatic charge-discharge profiles of symmetrical $\mathrm{Zn}$ cells with different electrodes at $1 \mathrm{~mA} \mathrm{~cm}^{-2}$ and an areal capacity of $1 \mathrm{mAh} \mathrm{cm}{ }^{-2}$, and statistical graphs of cycling time and voltage hysteresis against the coating thickness/MLD cycles. $\mathrm{f}$ Top-view morphologies of cycled bare Zn and 60Alcuone@Zn. Copyright 2020 Royal Society of Chemistry [106]. g Electrolyte solvation structure and its influence on the $\mathrm{V}_{2} \mathrm{O}_{5}$ dissolution of $\mathrm{Zn}(\mathrm{OTf})_{2}-\mathrm{TEP}-\mathrm{H}_{2} \mathrm{O}$ electrolyte and pure aqueous electrolyte. Characterization of the interphase on the cycled Zn surface: $\mathbf{h}$ XPS fitted curves of the F 1s, C 1s, and P 2p elements and $\mathbf{i}$ the interference reflection microscopy spectrum of the cycled Zn electrode and the acquired distribution of surface functional groups. Copyright $2021 \mathrm{Wiley-VCH}$ [84] 
anode by electrostatic shielding, crystallographic orientation induction, and modulation of the coordination status mechanism. According to previous research results, electrolyte additives can be divided into ionic and non-ionic additives.

\subsection{Ionic Additives}

Ionic additives regulate the deposition position of $\mathrm{Zn}^{2+}$ and inhibit dendrite growth through electrostatic shielding, crystallographic orientation induction, or modulation of the coordination status mechanism to obtain a uniform $\mathrm{Zn}$ deposition layer.

Using positive ions with a lower reduction potential than $\mathrm{Zn}^{2+}$ (such as $\mathrm{Na}^{+}$) inhibits the growth of $\mathrm{Zn}$ dendrites by the electrostatic shielding mechanism. Niu et al. [70] proposed an effective strategy by adding $\mathrm{Na}_{2} \mathrm{SO}_{4}$ to a $\mathrm{ZnSO}_{4}$ electrolyte to alleviate the growth of $\mathrm{Zn}$ dendrites (Fig. 14a, b). The addition of $\mathrm{Na}^{+}$to the electrolyte could change the dissolution equilibrium of $\mathrm{Na}^{+}$in a $\mathrm{NaV}_{3} \mathrm{O}_{8} \cdot 1.5 \mathrm{H}_{2} \mathrm{O}$ (NVO) cathode, hindering the dissolution of the $\mathrm{NVO}$ cathode. The discharge capacity of a cell with $\mathrm{Na}_{2} \mathrm{SO}_{4}$ electrolyte was maintained at $221 \mathrm{mAh} \mathrm{g}^{-1}$ with a retention rate of $90 \%$ after 100 cycles at $1 \mathrm{~A} \mathrm{~g}^{-1}$. The cell showed a capacity retention rate of $82 \%$ after 1000 cycles at a high current density of 4 $\mathrm{A} \mathrm{g}^{-1}$. Furthermore, using cationic surfactant-type electrolyte additives can have similar effects on the $\mathrm{Zn}$ anode. $\mathrm{Zhu}$ et al. [107] added tetrabutylammonium sulfate $\left(\mathrm{TBA}_{2} \mathrm{SO}_{4}\right)$ to the electrolyte to form a $\mathrm{TBA}^{+}$protective layer (Fig. 14c) around the $\mathrm{Zn}$ dendrites by electrostatic adsorption, which uniformly deposited $\mathrm{Zn}^{2+}$ and inhibited the growth of $\mathrm{Zn}$ dendrites. Ma et al. [108] studied the influence of adding 1-ethyl-3-methylimidazolium ethyl sulfate to an electrolyte to inhibit the growth of $\mathrm{Zn}$ dendrites. The added imidazole ions could be adsorbed on the electrode surface to prevent the growth of $\mathrm{Zn}$ dendrites and cooperated with metal ions to form reducing substances to optimize the electrode/ electrolyte interface behavior. Furthermore, Hu et al. [109] reported imidazolium ionic additives with different anions $\left(\mathrm{Cl}^{-}, \mathrm{PF}^{-}, \mathrm{TFSA}^{-}\right.$, and $\left.\mathrm{DCA}^{-}\right)$to inhibit the formation of $\mathrm{Zn}$ dendrites by increasing the degree of the nucleation overpotential and polarization (Fig. 14d).

Recently, Yang et al. [110] proposed the introduction of a series of low-cost "green" molecules with a cation coordination ability into aqueous $\left(\mathrm{ZnCl}_{2}\right.$ and $\left.\mathrm{ZnSO}_{4}\right)$ electrolytes. Triethylamine hydrochloride (TEHC) delivered the lowest binding energy of $-6.56 \mathrm{eV}$ according to DFT simulations, indicating that the binding between TEHC and $\mathrm{Zn}^{2+}$ was the most stable. Meanwhile, TEHC exhibited the most robust electron-donating capability (Fig. 14e). Small Lewis base molecules, featuring amine or phosphorous groups, compete with excess $\mathrm{H}_{2} \mathrm{O}$ molecules to bind with $\mathrm{Zn}$ cations (Fig. 14f). By introducing ligand molecules, the solvation structure of $\mathrm{Zn}^{2+}$ can be well adjusted, and the formation of by-products in the water electrolyte can be effectively inhibited, realizing a highly reversible $\mathrm{Zn}$ anode.

In addition, manipulating the crystalline direction of $\mathrm{Zn}$ deposition can effectively solve the problem of $\mathrm{Zn}$ dendrites. Yuan et al. [73] constructed a Zn (002) structure by sulfonate-based electrolyte electrodeposition, which reshaped the $\mathrm{Zn}$ coordination in the salt-in-water regime and further at the deposition interface. According to the co-collimation of the $\mathrm{Zn}(002)$ plane normal and substrate normal, a hexagonal columnar structure formed by $\mathrm{Zn}(\mathrm{OTf})_{2}$ deposited on the substrate was established (Fig. 14g, h). Highly reversible Zn stripping/plating was achieved, and a $\mathrm{Zn}(002)$ texture-based aqueous $\mathrm{Zn}$ battery with excellent cycling stability was constructed.

In summary, the use of ionic additives results in a more stable electrolyte/Zn anode interface. In future studies, ionic additives that inhibit cathodic dissolution and form a shielding or protective layer on the $\mathrm{Zn}$ anode surface are preferred.

Table 4 Summary of recently reported coatings modification strategies for composite materials

\begin{tabular}{|c|c|c|c|}
\hline Anode materials & Voltage hysteresis & Lifespan & References \\
\hline MOF-PVDF coated Zn & $\approx 150 \mathrm{mV}\left(3 \mathrm{~mA} \mathrm{~cm}{ }^{-2}\right)$ & $500 \mathrm{~h}\left(3 \mathrm{~mA} \mathrm{~cm}{ }^{-2}, 0.5 \mathrm{mAh} \mathrm{cm}^{-2}\right)$ & [105] \\
\hline MOF-coated $\mathrm{Zn}$ foils & $\approx 85 \mathrm{mV}\left(0.5 \mathrm{~mA} \mathrm{~cm}^{-2}\right)$ & $3000 \mathrm{~h}\left(0.5 \mathrm{~mA} \mathrm{~cm}^{-2}, 0.5 \mathrm{mAh} \mathrm{cm}^{-2}\right)$ & [78] \\
\hline Zn@Nafion-Zn-X composite anode & $\approx 50 \mathrm{mV}\left(2 \mathrm{~mA} \mathrm{~cm}^{-2}\right)$ & $1000 \mathrm{~h}\left(2 \mathrm{~mA} \mathrm{~cm}{ }^{-2}, 0.5 \mathrm{mAh} \mathrm{cm}{ }^{-2}\right)$ & [26] \\
\hline Alucone-coated Zn & $\approx 103 \mathrm{mV}\left(3 \mathrm{~mA} \mathrm{~cm}{ }^{-2}\right)$ & $780 \mathrm{~h}\left(3 \mathrm{~mA} \mathrm{~cm}{ }^{-2}, 1 \mathrm{mAh} \mathrm{cm} \mathrm{cm}^{-2}\right)$ & [106] \\
\hline $\mathrm{Zn}$ with poly- $\mathrm{ZnP}_{2} \mathrm{O}_{6}$ and $\mathrm{ZnF}_{2}$ interphase & $150 \mathrm{mV}\left(1 \mathrm{~mA} \mathrm{~cm}^{-2}\right)$ & $1500 \mathrm{~h}\left(1 \mathrm{~mA} \mathrm{~cm}{ }^{-2}, 1 \mathrm{mAh} \mathrm{cm}^{-2}\right)$ & {$[84]$} \\
\hline
\end{tabular}


(a)

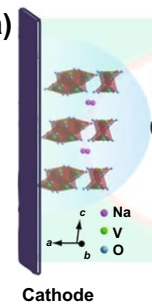

(d)

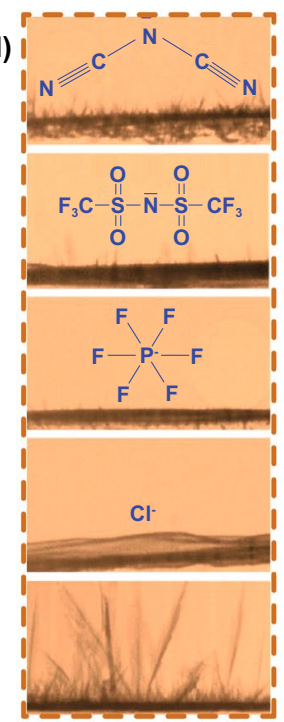

(b)

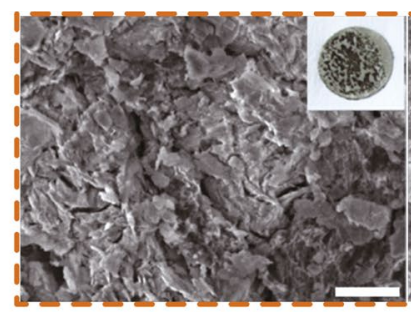

Zn anode

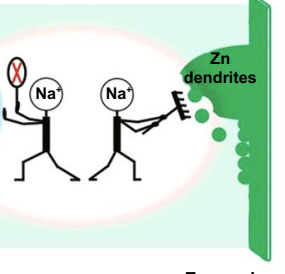

(e)

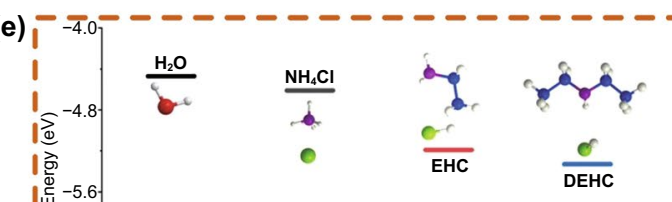

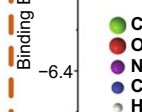

\begin{tabular}{l|l|l|l|l|l|}
$\mathrm{Cl}$ & $\mathrm{H}_{2} \mathrm{O}$ & $\mathrm{NH}_{4} \mathrm{Cl}$ & $\mathrm{EHC}$ & $\mathrm{DEHC}$ & TEHC \\
\hdashline $\mathrm{O}$ & Electron- & $\mathrm{O}$ & &
\end{tabular}

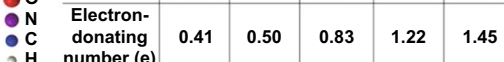

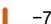

(f)

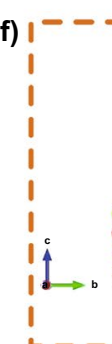

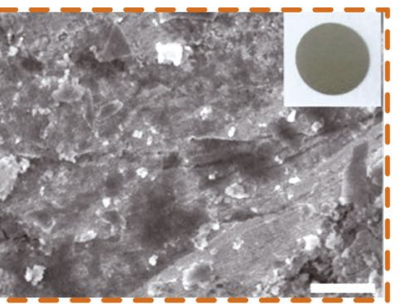

(c)

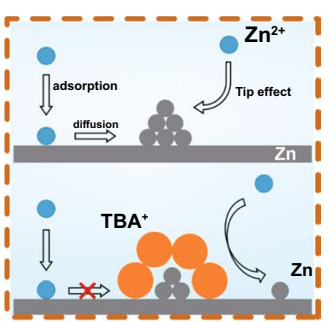

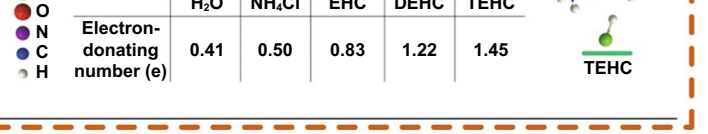

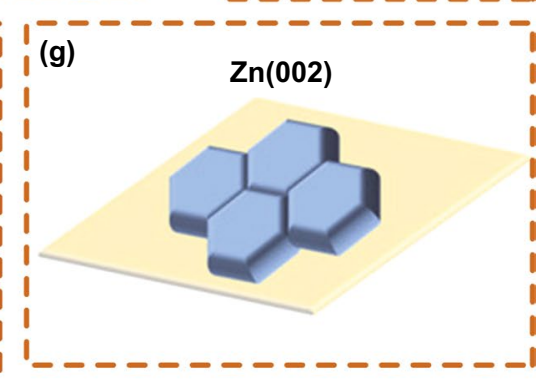

(h)

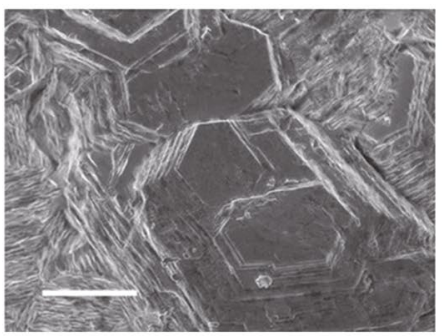

Fig. 14 a Schematic diagram of a $\mathrm{Na}_{2} \mathrm{SO}_{4}$ additive suppressing the dissolution of NVO nanobelts and the formation of Zn dendrites. $\mathbf{b}$ SEM images of $\mathrm{Zn}$ negative electrodes $\left(1 \mathrm{~A} \mathrm{~g}^{-1}\right.$, 100th cycle) from $\mathrm{Zn} / \mathrm{NVO}$ cells. Copyright 2020 Springer Nature [70]. $\mathbf{c}$ Schematics of the $\mathrm{Zn}^{2+}$ ion diffusion and reduction processes on electrodes in $\mathrm{ZnSO}_{4}$ and a $\mathrm{ZnSO}_{4}$ electrolyte with $0.05 \mathrm{mM} \mathrm{TBA} \mathrm{SO}_{4}$. Copyright 2020 American Chemical Society [107]. d Real-time X-ray images of Zn deposits at $-1.45 \mathrm{~V}$ in the presence of additive-free, EMI-Cl, EMI-PF6, EMI-TFSA, and EMI-DCA. Copyright 2016 American Chemical Society [109]. e The binding energy between $\mathrm{Zn}^{2+}$ and the ligand molecule calculated by DFT. f 3D snapshot of the molecular dynamics simulation and solvation structure of $\mathrm{Zn}^{2+}$ at 3-1 $0.5 \mathrm{M}$ TEHC. Copyright $2021 \mathrm{Wiley-VCH}$ [110]. g Scheme depicting the proposed columnar structure formation of the deposited $\mathrm{Zn}$ on the substrate by $\mathrm{Zn}(\mathrm{OTf})_{2}$. $\mathbf{h}$ SEM image showing the hexagonal-like plate planar morphology of the $\mathrm{Zn}$ film grown by $\mathrm{Zn}(\mathrm{OTf})_{2}$. Copyright Wiley-VCH [73]

\subsection{Non-ionic Additives}

Non-ionic additives, such as organics, regulate $\mathrm{Zn}^{2+}$ deposition and hinder $\mathrm{Zn}$ dendrite growth by forming an electrostatic shielding layer on the $\mathrm{Zn}$ anode surface. In addition, some organic molecules can adjust the solvation structure of $\mathrm{Zn}^{2+}$, inhibit side reactions due to the decomposition of active $\mathrm{H}_{2} \mathrm{O}$, and prevent dendrite growth.

$\mathrm{Xu}$ et al. [71] added a small amount of diethyl ether $\left(\mathrm{Et}_{2} \mathrm{O}\right)$ to the electrolyte, which greatly improved the electrochemical performance of the $\mathrm{Zn}-\mathrm{MnO}_{2}$ cells. As shown in Fig. 15a, during the deposition process, the first deposited $\mathrm{Zn}^{2+}$ formed a tip with a higher electric field strength, thereby inducing fast ion deposition. $\mathrm{The}^{\mathrm{E}} \mathrm{t}_{2} \mathrm{O}$ molecules with high polarization properties preferentially adsorbed on the tips of the high-potential $\mathrm{Zn}$ dendrites to act as an electrostatic shield. The adsorption of an appropriate amount of $\mathrm{Et}_{2} \mathrm{O}$ molecules repelled the deposition of $\mathrm{Zn}^{2+}$ at the tip of the dendrite and promoted deposition in other flat areas to reduce the growth rate of $\mathrm{Zn}$ dendrites. In Fig. 15b, c, the reversible capacity of the $\mathrm{Zn}-\mathrm{MnO}_{2}$ cell and capacity retention were $113 \mathrm{mAh} \mathrm{g}^{-1}$ and $97.7 \%$ after 400 cycles at $5 \mathrm{~A}$ $\mathrm{g}^{-1}$, respectively. However, the cell without $\mathrm{Et}_{2} \mathrm{O}$ only had a capacity of $71.8 \mathrm{mAh} \mathrm{g}^{-1}$ and failed after 1950 cycles. In addition, Hou et al. [111] found that adding sodium dodecyl sulfate to the electrolyte inhibited the corrosion of the $\mathrm{Zn}$ anode and growth of $\mathrm{Zn}$ dendrites. Recently, Chao et al. [112] added glucose to a $\mathrm{ZnSO}_{4}$ aqueous solution to simultaneously modulate the solvation structure of the $\mathrm{Zn}^{2+}$ and $\mathrm{Zn}$ anode-electrolyte interface. Experiments and theoretical simulations confirmed that glucose can enter the main solvation layer of $\mathrm{Zn}^{2+}$, reducing the number of active $\mathrm{H}_{2} \mathrm{O}$ 
molecules, thereby inhibiting the formation of by-products. Concurrently, glucose molecules tend to be adsorbed on the surface of the $\mathrm{Zn}$ anode, inhibiting the random growth of $\mathrm{Zn}$ dendrites. Interestingly, Guo et al. [113] reported a practical and low-cost antisolvent strategy. By adding methanol to the $\mathrm{ZnSO}_{4}$ electrolyte, the free water and coordination water in the $\mathrm{Zn}^{2+}$ solvation sheath gradually interacted with the antisolvent, thereby minimizing water activity and weakening $\mathrm{Zn}^{2+}$ solvation.

Mitha et al. [114] added polyethylene glycol to an electrolyte to inhibit the growth of $\mathrm{Zn}$ dendrites. The addition of $0.1 \mathrm{vol} \% 200 \mathrm{~g} \mathrm{~mol}^{-1}$ polyethylene glycol (PEG200) electrolyte significantly enhanced the battery performance, and the corresponding mechanism diagram is shown in Fig. 15d. In cells without additives in the electrolyte, $\mathrm{Zn}^{2+}$ diffuses in $2 \mathrm{D}$ and undergoes aggregation deposition. To minimize the surface energy, $\mathrm{Zn}^{2+}$ adsorbs and reduces on the first deposited $\mathrm{Zn}^{2+}$ surface, forming large dendrites. When PEG200 is added to the electrolyte, PEG200 adsorbs on the surface of the $\mathrm{Zn}$ anode faster than $\mathrm{Zn}^{2+}$ and occupies active adsorption sites. PEG200 can act as a physical barrier that limits the deposition of $\mathrm{Zn}^{2+}$ at the initial adsorption site. This is conducive to increasing nucleation sites and the formation of significantly denser small dendrites, thereby preventing the uncontrolled growth of large dendrites, which cause short circuits in the cell. The scanning electron microscopy (SEM) image (Fig. 15e) shows the inhibition effect of PEG200 on dendrite formation. As depicted in Fig. 15eI, II, the dendrites of the control sample are larger than those of the PEG200 sample and exhibit a flaky shape. With the cycling, the dendrites of the control sample exhibited a dendritic shape (Fig. 15eIII), "moss-like" shape (Fig. 15eV), cobble-like shape (Fig. 15eVII), boulder-like shape (Fig. 15eIX), and finally returned to a flaky shape (Fig. 15eXI). In the PEG200 sample, densely packed flake dendrites were transformed into evenly and densely packed boulder-shaped dendritic micro-dendrites because of uniform nucleation (Fig. 15eIV, VI, VIII, X, and XII). The (a)

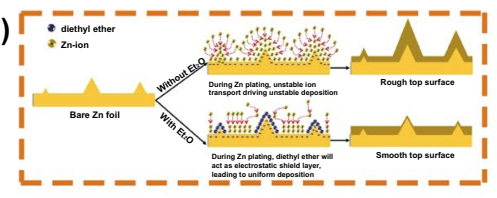

(b)

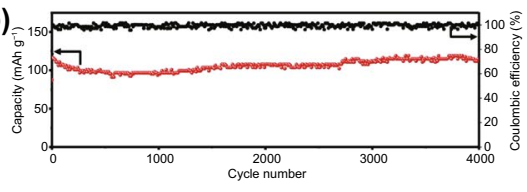

(d)

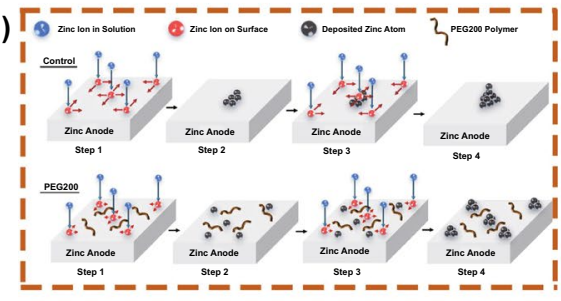

(g)

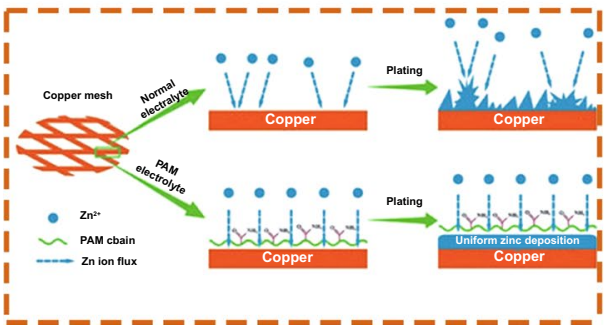

(e)
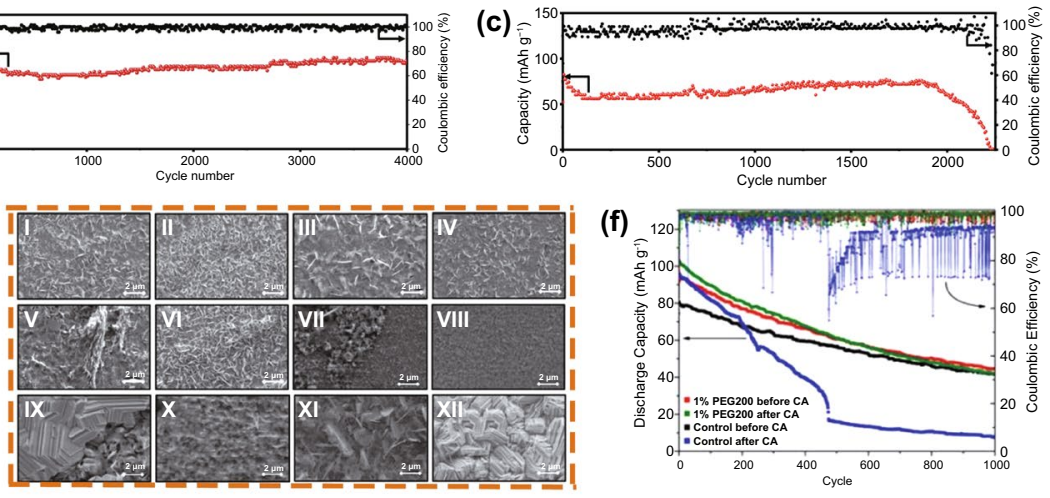

(h)

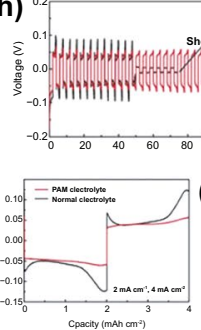

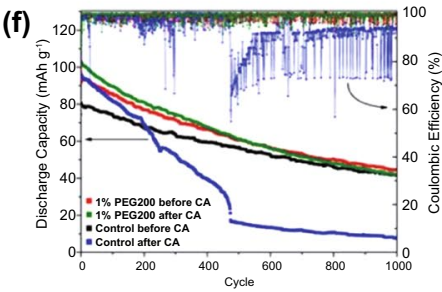

$(\mathbf{k})$

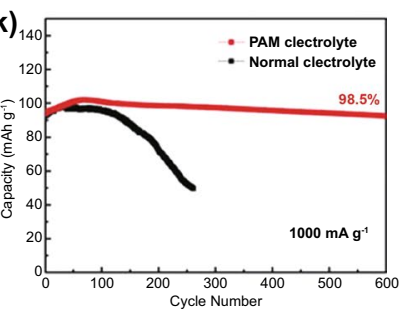

Fig. 15 a Schematic diagram of the morphological evolution for $\mathrm{Zn}$ anodes in a mild aqueous electrolyte with and without $\mathrm{Et}_{2} \mathrm{O}$ additive during $\mathrm{Zn}$ stripping/plating cycling. Long-term cycling performance of $\mathrm{Zn}-\mathrm{MnO}_{2}$ cell at $5 \mathrm{~A} \mathrm{~g}^{-1} \mathbf{b}$ with $\mathrm{Et}_{2} \mathrm{O}$ additive and $\mathbf{c}$ without $\mathrm{Et}_{2} \mathrm{O}$ additive. Copyright 2019 Elsevier [71]. d Schematic diagram of the step-by-step Zn reduction and deposition process in control and PEG200 electrolytes under negative potential bias on the $\mathrm{Zn}$ electrode. e SEM image of $\mathrm{Zn}$ electrodes after exposure to $1 \mathrm{~h}$ CA at $-135 \mathrm{mV}$ overpotential vs. opencircuit voltage $(\mathrm{OCV})$ under different conditions. $\mathrm{f}$ Cycling performance of a small rechargeable hybrid aqueous battery under $4 \mathrm{C}$ before and after exposure to CA for $3 \mathrm{~h}$ at $-135 \mathrm{mV}$ overpotential vs. OCV. Copyright 2018 Wiley-VCH [114]. g Schematic illustration of Zn deposition on a $\mathrm{Cu}$ mesh in normal and PAM-added electrolytes. $\mathbf{h}$ Cycling performance in symmetrical cells and $\mathbf{i}$ the corresponding voltage profiles in the 10th cycle at $2 \mathrm{~mA} \mathrm{~cm}^{-2}$ for $4 \mathrm{mAh} \mathrm{cm}^{-2}$. j SEM images of a 3D Zn anode using (I) PAM electrolyte and (II) normal electrolyte after 10 cycles. $\mathbf{k}$ Cycling performance comparison of the $\mathrm{Zn}-\mathrm{MnO}_{2}$ full cells using a 3D dendrite-free $\mathrm{Zn}$ anode and different electrolytes at $1000 \mathrm{~mA} \mathrm{~g}^{-1}$. Copyright 2019 Wiley-VCH [115] 
addition of PEG200 also contributed to improving the cycle performance of the cell. As shown in Fig. 15f, the cell capacity with the control electrolyte dropped rapidly after the $\mathrm{Zn}$ anode was tested by chronoamperometry (CA). In contrast, regardless of whether the $\mathrm{Zn}$ anode was subjected to $\mathrm{CA}$, the discharge capacity of the PEG200 sample remained constant after 1000 cycles, which indicates that the PEG200 additive can inhibit dendrites.

Zhang et al. [115] constructed a dendrite-free $\mathrm{Zn}$ anode by adding polyacrylamide (PAM) to the electrolyte (Fig. 15g). After adding PAM to the electrolyte, PAM preferentially adsorbed on the surface of a $\mathrm{Cu}$ mesh. $\mathrm{Zn}^{2+}$ was adsorbed on the acyl groups of PAM and transferred along the polymer chain evenly distributed on the electrode surface. Therefore, the PAM additive increased the number of nucleation sites and guided the uniform deposition of $\mathrm{Zn}$, which is beneficial for forming a flat electroplating surface. The addition of PAM also improved the electrochemical performance of the RAZIBs. The symmetrical cell cycled in a PAM electrolyte for $280 \mathrm{~h}$ without short circuit and exhibited a low voltage hysteresis of $93.1 \mathrm{mV}$ (Fig. 15h, i). The cell using the normal electrolyte quickly failed after $52 \mathrm{~h}$ of cycling (Fig. 15h, i). In the normal electrolyte, the anode after cycling exhibited many dendrites deposited by thin sheets, and the $\mathrm{Zn}$ anode using the PAM electrolyte exhibited no dendrites (Fig. 15j). The PAM electrolyte showed a long life and high capacity retention of $98.5 \%$ in the $\mathrm{Zn}-\mathrm{MnO}_{2}$ full cell (Fig. 15k).

Recently, Zhang et al. [116] selected GO powder as an electrolyte additive for $\mathrm{Zn}$ anodes and dispersed it in small amounts in the $\mathrm{ZnSO}_{4}$ electrolyte to obtain a highly stable and dendrite-free $\mathrm{Zn}$ anode. GO electrolyte additives can promote the uniform distribution of the electric field at the interface of the $\mathrm{Zn}$ anode, thus improving the binding energy of GO and $\mathrm{Zn}^{2+}$, such that $\mathrm{Zn}^{2+}$ exhibits an excellent plating/stripping behavior and $\mathrm{Zn}$ is uniformly deposited. In addition, the GO electrolyte additive reduced the nucleation overpotential and charge transfer resistance of $\mathrm{Zn}^{2+}$, thus providing more nucleation sites and promoting the reaction kinetics. Therefore, compared with the pure $\mathrm{ZnSO}_{4}$ electrolyte, the $\mathrm{ZnllZn}$ cell, which used $\mathrm{GO}$ as the $\mathrm{Zn}$ electrolyte additive, exhibited a service life which exceeded $650 \mathrm{~h}$ at $1 \mathrm{~mA} \mathrm{~cm}{ }^{-2}$. Even at $10 \mathrm{~mA} \mathrm{~cm}^{-2}$, its cycle life achieved $140 \mathrm{~h}$. A ZnIITi cell exhibited an average $\mathrm{CE}$ of $99.16 \%$ after 100 cycles. A full cell composed of $\mathrm{MnO}_{2}$ and $\mathrm{GO}$ as the cathode and electrolyte additive, respectively, achieved 250 cycles at $5 \mathrm{~A} \mathrm{~g} \mathrm{~g}^{-1}$, and the capacity retention rate was $93 \%$. The performance improved after the addition of the electrolyte additive.

In summary, the addition of organic matter to the electrolyte can significantly inhibit dendritic growth. Polar molecules preferentially reach initial protrusions to prevent $\mathrm{Zn}^{2+}$ deposition by the electrostatic shielding effect. In addition to $\mathrm{Et}_{2} \mathrm{O}$, other polar molecules, such as ethanol and acetone, can be used as additives. The addition of some organic molecules to the electrolyte can adjust the solvation structure of $\mathrm{Zn}^{2+}$, which further demonstrates that adding additives to the electrolyte is an effective way to eliminate dendrites.

\section{Conclusion and Perspectives}

RAZIBs exhibit great application prospects in green energy storage systems owing to their advantages, including low cost, high safety, good durability, and relatively high energy density. Research on cathode materials for RAZIBs has reached a relatively mature stage. However, the poor reversibility of the $\mathrm{Zn}$ anode arising from $\mathrm{Zn}$ dendrites and side reactions restricts the development of RAZIBs. Interfacial engineering strategies, including surface modification and the addition of electrolyte additives, have received much attention because of their easy operation, diversity of chosen materials, and high efficiency. Based on the working principle of the anode and the expected high performance, the ideal interfacial layer should meet the following requirements: (a) good adhesive force with ZF, maintaining continuous protection of the surface coating; (b) high ionic conductivity and low electrical conductivity, assuring that $\mathrm{Zn}^{2+}$ will be deposited on the surface of the $\mathrm{Zn}$ anode rather than on the interfacial layer; (c) insolubility and chemical inactivity, inhibiting direct contact between the $\mathrm{Zn}$ anode and electrolyte; (d) excellent mechanical properties, accommodating the volume change of the $\mathrm{Zn}$ anode during cycling; and (e) moderate thickness, providing an appropriate physical barrier. Research on electrolyte additives is still in its infancy. The influence of additives on the electrolyte structure and many reaction mechanisms are still ambiguous; thus, it is necessary to study the action mechanism of the electrolyte additive to further improve battery performance. Although much progress has been achieved in improving the performance of $\mathrm{Zn}$ anodes by interfacial engineering strategies, there is still much space for enhancing the $\mathrm{Zn}$ anode performance of RAZIBs. 
1. Development of novel coating materials and methods Novel coating materials, specifically polymer materials, need to be developed because of the characteristics of uniform active sites, poor conductivity, and good hydrophilicity. Additionally, after considering the interaction of various coatings and chemical bonds, multi-component coating materials deserve further exploration owing to the synergistic effect between their components. For example, a double-layer coating consisting of an electronic conductor layer and an ionic conductor effectively suppresses $\mathrm{Zn}$ dendrites and side reactions. The electronic conductor layer on the $\mathrm{Zn}$ anode surface provides a more uniform electric field, whereas the ionic conductor realizes the confinement effect of $\mathrm{Zn}$ ions. In addition, the binding force, uniformity, and thickness of the coating layers should be comprehensively considered.

2. Balancing the trade-offs of various aspects For example, the balance between reaction thermodynamics and ion migration kinetic energy, that is, the inhibition of interface side reactions and ion conduction performance, must be weighed. Moreover, the balance between the energy density and coating thickness should be considered. Based on ensuring the integrity and uniformity of the coating, a thicker coating will cause a greater transmission distance and transmission resistance of $\mathrm{Zn}$ ions, which will damage the battery performance. Therefore, it is necessary to appropriately reduce the thickness of the interface layer to improve the quality and volume energy density of the battery system.

3. Exploring new electrolyte additives Because the electrolyte contacts both the cathode and the anode, new electrolyte additives can be explored to not only regulate the deposition behavior of $\mathrm{Zn}$ ions on the $\mathrm{Zn}$ anode surface, but also act on the cathode interface to improve the cycling stability of the cathode material. Furthermore, it is a good strategy to develop super-hydrophilic electrolyte additives, which can effectively fix the free active water molecules in the electrolyte and significantly suppress the side reactions caused by water.

4. Combining the multiple effects of electrolyte additives Electrolyte additives can effectively regulate the electrochemical behavior of $\mathrm{Zn}$ ions at the $\mathrm{Zn}$ anode-electrolyte interface. In addition, the dendrites and side reactions generated on the surface of the metal $\mathrm{Zn}$ anode affect each other. However, the function of a single electrolyte additive is relatively limited. Therefore, under the premise of ensuring that there will be no interaction between multiple additives, it is possible to consider adding multiple additives to obtain the best performance.

5. Nanothickness interface alloying Nanothickness interface alloying is another effective strategy for achieving high-performance $\mathrm{Zn}$ anodes. The current relatively mature metal anticorrosion strategies and electrolyte control methods can be used to alloy $\mathrm{Zn}$ anodes. In addition, in view of the interfacial characteristics of the metal itself, synergy regulation with the electrolyte is expected to develop into a novel $\mathrm{Zn}$ metal interface engineering strategy.

Acknowledgements This work was financially supported by the National Natural Science Foundation of China (Nos. 51872090, 51772097, 51972346), the Hebei Natural Science Fund for Distinguished Young Scholar (No. E2019209433), the Natural Science Foundation of Hebei Province (No. E2020209151), the Hunan Natural Science Fund for Distinguished Young Scholar (2021JJ10064), the Program of Youth Talent Support for Hunan Province (2020RC3011), the Innovation-Driven Project of Central South University (No. 2020CX024).

Funding Open access funding provided by Shanghai Jiao Tong University.

Open Access This article is licensed under a Creative Commons Attribution 4.0 International License, which permits use, sharing, adaptation, distribution and reproduction in any medium or format, as long as you give appropriate credit to the original author(s) and the source, provide a link to the Creative Commons licence, and indicate if changes were made. The images or other third party material in this article are included in the article's Creative Commons licence, unless indicated otherwise in a credit line to the material. If material is not included in the article's Creative Commons licence and your intended use is not permitted by statutory regulation or exceeds the permitted use, you will need to obtain permission directly from the copyright holder. To view a copy of this licence, visit http://creativecommons.org/licenses/by/4.0/.

\section{References}

1. T. Jin, H.X. Li, K.J. Zhu, P.F. Wang, P. Liu et al., Polyaniontype cathode materials for sodium-ion batteries. Chem. Soc. Rev. 49(8), 2342-2377 (2020). https://doi.org/10.1039/c9cs0 0846b

2. J.W. Li, Z. Kong, X.X. Liu, B.C. Zheng, Q.H. Fan et al., Strategies to anode protection in lithium metal battery: a review. InfoMat (2021). https://doi.org/10.1002/inf2.12189

3. X. Shi, Y. Zhang, G. Xu, S. Guo, A. Pan et al., Enlarged interlayer spacing and enhanced capacitive behavior of a carbon anode for superior potassium storage. Sci. Bull. 65(23), 2014-2021 (2020). https://doi.org/10.1016/j.scib.2020.07. 001

4. X. Shi, Z. Xu, C. Han, R. Shi, X. Wu et al., Highly dispersed cobalt nanoparticles embedded in nitrogen-doped graphitized carbon for fast and durable potassium storage. 
Nano-Micro Lett. 13, 21 (2021). https://doi.org/10.1007/ s40820-020-00534-x

5. G.A. Elia, K. Marquardt, K. Hoeppner, S. Fantini, R.Y. Lin et al., An overview and future perspectives of aluminum batteries. Adv. Mater. 28(35), 7564-7579 (2016). https://doi.org/ 10.1002/adma.201601357

6. J.T. Huang, J. Zhou, S.Q. Liang, Guest pre-intercalation strategy to boost the electrochemical performance of aqueous zinc-ion battery cathodes. Acta Phys. Chim. Sin. 37(3), 2005020 (2021). https://doi.org/10.3866/pku.whxb202005 020

7. H.F. Li, L.T. Ma, C.P. Han, Z.F. Wang, Z.X. Liu et al., Advanced rechargeable zinc-based batteries: recent progress and future perspectives. Nano Energy 62, 550-587 (2019). https://doi.org/10.1016/j.nanoen.2019.05.059

8. X. Han, N. Li, P. Xiong, M.G. Jung, Y. Kang et al., Electronically coupled layered double hydroxide/MXene quantum dot metallic hybrids for high-performance flexible zinc-air batteries. InfoMat 3(10), 1134-1144 (2021). https://doi.org/10. 1002/inf2.12226

9. P. Gu, M.B. Zheng, Q.X. Zhao, X. Xiao, H.G. Xue et al., Rechargeable zinc-air batteries: a promising way to green energy. J. Mater. Chem. A 5(17), 7651-7666 (2017). https:// doi.org/10.1039/c7ta01693j

10. X.M. Xu, F.Y. Xiong, J.S. Meng, X.P. Wang, C.J. Niu et al., Vanadium-based nanomaterials: a promising family for emerging metal-ion batteries. Adv. Funct. Mater. 30(10), 1904398 (2020). https://doi.org/10.1002/adfm.201904398

11. Z.D. Zhao, M.Q. Sun, T.Q. Wu, J.J. Zhang, P. Wang et al., A bifunctional-modulated conformal Li/Mn-rich layered cathode for fast-charging, high volumetric density and durable Li-ion full cells. Nano-Micro Lett. 13, 118 (2021). https:// doi.org/10.1007/s40820-021-00643-1

12. C. Ma, W.F. Cui, X.Z. Liu, Y. Ding, Y.G. Wang, In situ preparation of gel polymer electrolyte for lithium batteries: progress and perspectives. InfoMat (2021). https://doi.org/ 10.1002/inf 2.12232

13. D.L. Chao, W.H. Zhou, F.X. Xie, C. Ye, H. Li et al., Roadmap for advanced aqueous batteries: from design of materials to applications. Sci. Adv. 6(21), 4098 (2020). https:// doi.org/10.1126/sciadv.aba4098

14. S.S. Zhang, Identifying rate limitation and a guide to design of fast-charging Li-ion battery. InfoMat 2(5), 942-949 (2019). https://doi.org/10.1002/inf2.12058

15. X. Guo, J. Zhou, C. Bai, X. Li, G. Fang et al., Zn/MnO battery chemistry with dissolution-deposition mechanism. Mater. Today Energy 16, 100396 (2020). https://doi.org/10. 1016/j.mtener.2020.100396

16. D. Chao, C.R. Zhu, M. Song, P. Liang, X. Zhang et al., A high-rate and stable quasi-solid-state zinc-ion battery with novel 2D layered zinc orthovanadate array. Adv. Mater. 30(32), e1803181 (2018). https://doi.org/10.1002/adma. 201803181

17. L. Gou, K.L. Mou, X.Y. Fan, M.J. Zhao, Y. Wang et al., $\mathrm{Mn}_{2} \mathrm{O}_{3} / \mathrm{Al}_{2} \mathrm{O}_{3}$ cathode material derived from a metalorganic framework with enhanced cycling performance for aqueous zinc-ion batteries. Dalton Trans. 49(3), 711-718 (2020). https://doi.org/10.1039/c9dt03995c

18. W. Zhou, M. Chen, A. Wang, A. Huang, J. Chen et al., Optimizing the electrolyte salt of aqueous zinc-ion batteries based on a high-performance calcium vanadate hydrate cathode material. J. Energy Chem. 52, 377-384 (2021). https://doi.org/10.1016/j.jechem.2020.05.005

19. P. Zhao, B.J. Yang, J.T. Chen, J.W. Lang, T.Y. Zhang et al., A safe, high-performance, and long-cycle life zincion hybrid capacitor based on three-dimensional porous activated carbon. Acta Phys. Chim. Sin. 36(2), 1904050 (2020). https://doi.org/10.3866/pku.whxb201904050

20. Q. Zong, W. Du, C.F. Liu, H. Yang, Q.L. Zhang et al., Enhanced reversible zinc ion intercalation in deficient ammonium vanadate for high-performance aqueous zincion battery. Nano-Micro Lett. 13, 116 (2021). https://doi. org/10.1007/s40820-021-00641-3

21. J.W. Gao, X.S. Xie, S.Q. Liang, B.A. Lu, J. Zhou, Inorganic colloidal electrolyte for highly robust zinc-ion batteries. Nano-Micro Lett. 13, 69 (2021). https://doi.org/10.1007/ s40820-021-00595-6

22. X. Xu, Y. Chen, D. Zheng, P. Ruan, Y. Cai et al., Ultra-fast and scalable saline immersion strategy enabling uniform $\mathrm{Zn}$ nucleation and deposition for high-performance $\mathrm{Zn}$-ion batteries. Small 17(33), 2101901 (2021). https://doi.org/10. 1002/smll.202101901

23. C. Li, X. Xie, H. Liu, P. Wang, C. Deng et al., Integrated "all-in-one" strategy to stabilize zinc anodes for high-performance zinc-ion batteries. Natl. Sci. Rev. (2021). https:// doi.org/10.1093/nsr/nwab177

24. F. Wang, O. Borodin, T. Gao, X.L. Fan, W. Sun et al., Highly reversible zinc metal anode for aqueous batteries. Nat. Mater. 17(6), 543-549 (2018). https://doi.org/10.1038/ s41563-018-0063-z

25. T. Shoji, M. Hishinuma, T. Yamamoto, Zinc-manganese dioxide galvanic cell using zinc sulphate as electrolyterechargeability of the cell. J. Appl. Electrochem. 18(4), 521-526 (1988). https://doi.org/10.1007/bf01022245

26. Y. Cui, Q. Zhao, X. Wu, X. Chen, J. Yang et al., An interface-bridged organic-inorganic layer that suppresses dendrite formation and side reactions for ultra-long-life aqueous zinc metal anodes. Angew. Chem. Int. Ed. 59(38), 16594-16601 (2020). https://doi.org/10.1002/anie.20200 5472

27. B.T. Liu, S.J. Wang, Z.L. Wang, H. Lei, Z.T. Chen et al., Novel 3D nanoporous $\mathrm{Zn}-\mathrm{Cu}$ alloy as long-life anode toward high-voltage double electrolyte aqueous zinc-ion batteries. Small 16(22), 2001323 (2020). https://doi.org/10.1002/smll. 202001323

28. X.C. Pu, B.Z. Jiang, X.L. Wang, W.B. Liu, L.B. Dong et al., High-performance aqueous zinc-ion batteries realized by MOF materials. Nano-Micro Lett. 12, 152 (2020). https:// doi.org/10.1007/s40820-020-00487-1

29. S.B. Wang, Q. Ran, R.Q. Yao, H. Shi, Z. Wen et al., Lamellananostructured eutectic zinc-aluminum alloys as reversible and dendrite-free anodes for aqueous rechargeable batteries. 
Nat. Commun. 11(1), 1634 (2020). https://doi.org/10.1038/ s41467-020-15478-4

30. N. Liu, B. Li, Z. He, L. Dai, H. Wang et al., Recent advances and perspectives on vanadium- and manganese-based cathode materials for aqueous zinc ion batteries. J. Energy Chem. 59, 134-159 (2021). https://doi.org/10.1016/j.jechem.2020.10. 044

31. X.Y. Liu, J. Yi, K. Wu, Y. Jiang, Y.Y. Liu et al., Rechargeable $\mathrm{Zn}-\mathrm{MnO}_{2}$ batteries: advances, challenges and perspectives. Nanotechnology 31(12), 122001 (2020). https://doi.org/10. 1088/1361-6528/ab5b38

32. W.J. Zhou, J.Z. Chen, M.F. Chen, X.W. Xu, Q.H. Tian et al., Rod-like anhydrous $\mathrm{V}_{2} \mathrm{O}_{5}$ assembled by tiny nanosheets as a high-performance cathode material for aqueous zinc-ion batteries. RSC Adv. 9(52), 30556-30564 (2019). https://doi. org/10.1039/c9ra06143f

33. Y.Q. Yang, Y. Tang, S.Q. Liang, Z.X. Wu, G.Z. Fang et al., Transition metal ion-preintercalated $\mathrm{V}_{2} \mathrm{O}_{5}$ as high-performance aqueous zinc-ion battery cathode with broad temperature adaptability. Nano Energy 61, 617-625 (2019). https:// doi.org/10.1016/j.nanoen.2019.05.005

34. F. Wu, Y. Wang, P. Ruan, X. Niu, D. Zheng et al., Fe-doping enabled a stable vanadium oxide cathode with rapid $\mathrm{Zn}$ diffusion channel for aqueous zinc-ion batteries. Mater. Today Energy 21, 100842 (2021). https://doi.org/10.1016/j.mtener. 2021.100842

35. Y. Zhao, Y. Zhu, X. Zhang, Challenges and perspectives for manganese-based oxides for advanced aqueous zinc-ion batteries. InfoMat 2(2), 237-260 (2019). https://doi.org/10.1002/ inf2.12042

36. W. Li, K.L. Wang, S.J. Cheng, K. Jiang, An ultrastable presodiated titanium disulfide anode for aqueous "rocking-chair" zinc ion battery. Adv. Energy Mater. 9(27), 1900993 (2019). https://doi.org/10.1002/aenm.201900993

37. Y.W. Cheng, L.L. Luo, L. Zhong, J.Z. Chen, B. Li et al., Highly reversible zinc-ion intercalation into chevrel phase $\mathrm{Mo}_{6} \mathrm{~S}_{8}$ nanocubes and applications for advanced zinc-ion batteries. ACS Appl. Mater. Interfaces 8(22), 13673-13677 (2016). https://doi.org/10.1021/acsami.6b03197

38. M.S. Chae, J.W. Heo, S.C. Lim, S.T. Hong, Electrochemical zinc-ion intercalation properties and crystal structures of $\mathrm{ZnMo}_{6} \mathrm{~S}_{8}$ and $\mathrm{Zn}_{2} \mathrm{Mo}_{6} \mathrm{~S}_{8}$ chevrel phases in aqueous electrolytes. Inorg. Chem. 55(7), 3294-3301 (2016). https://doi.org/ 10.1021/acs.inorgchem.5b02362

39. T. Wang, C. Li, X. Xie, B. Lu, Z. He et al., Anode materials for aqueous zinc ion batteries: mechanisms, properties, and perspectives. ACS Nano 14(12), 16321-16347 (2020). https://doi.org/10.1021/acsnano.0c07041

40. N.Y. Ma, P.J. Wu, Y.X. Wu, D.H. Jiang, G.T. Lei, Progress and perspective of aqueous zinc-ion battery. Funct. Mater. Lett. 12(5), 1930003 (2019). https://doi.org/10.1142/s1793 604719300032

41. X. Zeng, J. Hao, Z. Wang, J. Mao, Z. Guo, Recent progress and perspectives on aqueous $\mathrm{Zn}$-based rechargeable batteries with mild aqueous electrolytes. Energy Storage Mater. 20, 410-437 (2019). https://doi.org/10.1016/j.ensm.2019.04.022
42. L.N. Chen, Q.Y. An, L.Q. Mai, Recent advances and prospects of cathode materials for rechargeable aqueous zinc-ion batteries. Adv. Mater. Interfaces 6(17), 1900387 (2019). https://doi.org/10.1002/admi.201900387

43. Y. Zhang, A. Chen, J. Sun, Promise and challenge of vanadium-based cathodes for aqueous zinc-ion batteries. J. Energy Chem. 54, 655-667 (2021). https://doi.org/10.1016/j.jechem. 2020.06.013

44. X.Z. Zhai, J. Qu, S.M. Hao, Y.Q. Jing, W. Chang et al., Layered birnessite cathode with a displacement/intercalation mechanism for high-performance aqueous zinc-ion batteries. Nano-Micro Lett. 12, 56 (2020). https://doi.org/10.1007/ s40820-020-0397-3

45. Q. Zhang, J.Y. Luan, Y.G. Tang, X.B. Ji, H.Y. Wang, Interfacial design of dendrite-free zinc anodes for aqueous zincion batteries. Angew. Chem. Int. Ed. 59(32), 13180-13191 (2020). https://doi.org/10.1002/anie.202000162

46. Z.W. Tie, Z.Q. Niu, Design strategies for high-performance aqueous $\mathrm{Zn/organic}$ batteries. Angew. Chem. Int. Ed. 59(48), 21293-21303 (2020). https://doi.org/10.1002/anie.20200 8960

47. K.N. Zhao, C.X. Wang, Y.H. Yu, M.Y. Yan, Q.L. Wei et al., Ultrathin surface coating enables stabilized zinc metal anode. Adv. Mater. Interfaces 5(16), 1800848 (2018). https://doi.org/ 10.1002/admi. 201800848

48. L.T. Ma, S.M. Chen, N. Li, Z.X. Liu, Z.J. Tang et al., Hydrogen-free and dendrite-free all-solid-state $\mathrm{Zn}$-ion batteries. Adv. Mater. 32(14), 1908121 (2020). https://doi.org/10.1002/ adma.201908121

49. G.Z. Fang, J. Zhou, A.Q. Pan, S.Q. Liang, Recent advances in aqueous zinc-ion batteries. ACS Energy Lett. 3, 2480-2501 (2018). https://doi.org/10.1021/acsenergylett.8b01426

50. B. Sun, P. Xiong, U. Maitra, D. Langsdorf, K. Yan et al., Design strategies to enable the efficient use of sodium metal anodes in high-energy batteries. Adv. Mater. 32(18), 1903891 (2020). https://doi.org/10.1002/adma.201903891

51. Y. Tian, Y.L. An, C.L. Wei, B.J. Xi, S.L.L. Xiong et al., Flexible and free-standing $\mathrm{Ti}_{3} \mathrm{C}_{2} \mathrm{~T}_{\mathrm{x}}$ MXene@Zn paper for dendrite-free aqueous zinc metal batteries and nonaqueous lithium metal batteries. ACS Nano 13(10), 11676-11685 (2019). https://doi.org/10.1021/acsnano.9b05599

52. J. Hao, X. Li, X. Zeng, D. Li, J. Mao et al., Deeply understanding the $\mathrm{Zn}$ anode behaviour and corresponding improvement strategies in different aqueous $\mathrm{Zn}$-based batteries. Energy Environ. Sci. 13(11), 3917-3949 (2020). https://doi. org/10.1039/d0ee02162h

53. H. Pan, Y. Shao, P. Yan, Y. Cheng, K.S. Han et al., Reversible aqueous zinc/manganese oxide energy storage from conversion reactions. Nat. Energy 1(5), 16039 (2016). https://doi. org/10.1038/nenergy.2016.39

54. H. Jia, Z.Q. Wang, B. Tawiah, Y.D. Wang, C.Y. Chan et al., Recent advances in zinc anodes for high-performance aqueous Zn-ion batteries. Nano Energy 70, 104523 (2020). https:// doi.org/10.1016/j.nanoen.2020.104523

55. P.C. Liang, J. Yi, X.Y. Liu, K. Wu, Z. Wang et al., Highly reversible $\mathrm{Zn}$ anode enabled by controllable formation of 
nucleation sites for Zn-based batteries. Adv. Funct. Mater. 30(13), 1908528 (2020). https://doi.org/10.1002/adfm.20190 8528

56. Y.X. Zeng, X.Y. Zhang, R.F. Qin, X.Q. Liu, P.P. Fang et al., Dendrite-free Zinc deposition induced by multifunctional CNT frameworks for stable flexible Zn-ion batteries. Adv. Mater. 31(36), 1903675 (2019). https://doi.org/10.1002/ adma.201903675

57. C. Sun, C.P. Wu, X.X. Gu, C. Wang, Q.H. Wang, Interface engineering via $\mathrm{Ti}_{3} \mathrm{C}_{2} \mathrm{~T}_{\mathrm{x}}$ MXene electrolyte additive toward dendrite-free Zinc deposition. Nano-Micro Lett. 13, 89 (2021). https://doi.org/10.1007/s40820-021-00612-8

58. P. Gao, Q. Ru, H. Yan, S. Cheng, Y. Liu et al., A durable $\mathrm{Na}_{0.56} \mathrm{~V}_{2} \mathrm{O}_{5}$ nanobelt cathode material assisted by hybrid cationic electrolyte for high-performance aqueous zinc-ion batteries. ChemElectroChem 7(1), 283-288 (2020). https:// doi.org/10.1002/celc.201901851

59. W. Li, K.L. Wang, S.J. Cheng, K. Jiang, A long-life aqueous $\mathrm{Zn}$-ion battery based on $\mathrm{Na}_{3} \mathrm{~V}_{2}\left(\mathrm{PO}_{4}\right)_{2} \mathrm{~F}_{3}$ cathode. Energy Storage Mater. 15, 14-21 (2018). https://doi.org/10.1016/j. ensm.2018.03.003

60. W.J. Lu, C.X. Xie, H.M. Zhang, X.F. Li, Inhibition of zinc dendrite growth in zinc-based batteries. Chemsuschem 11(23), 3996-4006 (2018). https://doi.org/10.1002/cssc. 201801657

61. C.A. Laska, M. Auinger, P.U. Biedermann, D. Iqbal, N. Laska et al., Effect of hydrogen carbonate and chloride on zinc corrosion investigated by a scanning flow cell system. Electrochim. Acta 159, 198-209 (2015). https://doi.org/10.1016/j. electacta.2015.01.217

62. B.Y. Tang, L.T. Shan, S.Q. Liang, J. Zhou, Issues and opportunities facing aqueous zinc-ion batteries. Energy Environ. Sci. 12(11), 3288-3304 (2019). https://doi.org/10.1039/c9ee0 $2526 \mathrm{j}$

63. S. Guo, L.P. Qin, T.S. Zhang, M. Zhou, J. Zhou et al., Fundamentals and perspectives of electrolyte additives for aqueous zinc-ion batteries. Energy Storage Mater. 34, 545-562 (2021). https://doi.org/10.1016/j.ensm.2020.10.019

64. Z.Y. Cao, P.Y. Zhuang, X. Zhang, M.X. Ye, J.F. Shen et al., Strategies for dendrite-free anode in aqueous rechargeable zinc ion batteries. Adv. Energy Mater. 10(30), 2001599 (2020). https://doi.org/10.1002/aenm.202001599

65. G. Jiang, N. Jiang, N. Zheng, X. Chen, J. Mao et al., MOFderived porous $\mathrm{Co}_{3} \mathrm{O}_{4}-\mathrm{NC}$ nanoflake arrays on carbon fiber cloth as stable hosts for dendrite-free Li metal anodes. Energy Storage Mater. 23, 181-189 (2019). https://doi.org/10.1016/j. ensm.2019.05.014

66. A. Pei, G.Y. Zheng, F.F. Shi, Y.Z. Li, Y. Cui, Nanoscale nucleation and growth of electrodeposited lithium metal. Nano Lett. 17(2), 1132-1139 (2017). https://doi.org/10.1021/ acs.nanolett.6b04755

67. F. Xie, H. Li, X. Wang, X. Zhi, D. Chao et al., Mechanism for zincophilic sites on zinc-metal anode hosts in aqueous batteries. Adv. Energy Mater. 11(9), 2003419 (2021). https:// doi.org/10.1002/aenm.202003419
68. X.S. Xie, S.Q. Liang, J.W. Gao, S. Guo, J.B. Guo et al., Manipulating the ion-transfer kinetics and interface stability for high-performance zinc metal anodes. Energy Environ. Sci. 13(2), 503-510 (2020). https://doi.org/10.1039/c9ee0 $3545 \mathrm{a}$

69. A.L. Xia, X.M. Pu, Y.Y. Tao, H.M. Liu, Y.G. Wang, Graphene oxide spontaneous reduction and self-assembly on the zinc metal surface enabling a dendrite-free anode for long-life zinc rechargeable aqueous batteries. Appl. Surf. Sci. 481, 852-859 (2019). https://doi.org/10.1016/j.apsusc.2019.03. 197

70. F. Wan, L. Zhang, X. Dai, X. Wang, Z. Niu et al., Aqueous rechargeable zinc/sodium vanadate batteries with enhanced performance from simultaneous insertion of dual carriers. Nat. Commun. 9, 1656 (2018). https://doi.org/10.1038/ s41467-018-04060-8

71. W. Xu, K. Zhao, W. Huo, Y. Wang, G. Yao et al., Diethyl ether as self-healing electrolyte additive enabled long-life rechargeable aqueous zinc ion batteries. Nano Energy 62, 275-281 (2019). https://doi.org/10.1016/j.nanoen.2019.05. 042

72. K.E.K. Sun, T.K.A. Hoang, T.N.L. Doan, Y. Yu, P. Chen, Highly sustainable zinc anodes for a rechargeable hybrid aqueous battery. Chem. Eur. J. 24(7), 1667-1673 (2018). https://doi.org/10.1002/chem.201704440

73. D. Yuan, J. Zhao, H. Ren, Y.Q. Chen, R. Chua et al., Anion texturing towards dendrite-free $\mathrm{Zn}$ anode for aqueous rechargeable batteries. Angew. Chem. Int. Ed. 60(13), 7213-7219 (2021). https://doi.org/10.1002/anie.202015488

74. J. Zhou, M. Xie, F. Wu, Y. Mei, Y. Hao et al., Ultrathin surface coating of nitrogen-doped graphene enables stable zinc anodes for aqueous zinc-ion batteries. Adv. Mater. 33(33), 2101649 (2021). https://doi.org/10.1002/adma.202101649

75. W.W. Xu, Y. Wang, Recent progress on zinc-ion rechargeable batteries. Nano-Micro Lett. 11, 90 (2019). https://doi.org/10. 1007/s40820-019-0322-9

76. F. Wan, L.L. Zhang, X.Y. Wang, S.S. Bi, Z.Q. Niu et al., An aqueous rechargeable zinc-organic battery with hybrid mechanism. Adv. Funct. Mater. 28(45), 1804975 (2018). https://doi.org/10.1002/adfm.201804975

77. F. Wang, E.Y. Hu, W. Sun, T. Gao, X. Ji et al., A rechargeable aqueous $\mathrm{Zn}^{2+}$-battery with high power density and a long cycle-life. Energy Environ. Sci. 11(11), 3168-3175 (2018). https://doi.org/10.1039/c8ee01883a

78. H.J. Yang, Z. Chang, Y. Qiao, H. Deng, X.W. Mu et al., Constructing a super-saturated electrolyte front surface for stable rechargeable aqueous zinc batteries. Angew. Chem. Int. Ed. 59(24), 9377-9381 (2020). https://doi.org/10.1002/anie. 202001844

79. D. Kundu, S.H. Vajargah, L.W. Wan, B. Adams, D. Prendergast et al., nonaqueous $\mathrm{Zn}$-ion batteries: consequences of the desolvation penalty at the interface. Energy Environ. Sci. 11(4), 881-892 (2018). https://doi.org/10.1039/c8ee00378e

80. Z.M. Zhao, J.W. Zhao, Z.L. Hu, J.D. Li, J.J. Li et al., Longlife and deeply rechargeable aqueous $\mathrm{Zn}$ anodes enabled by a multifunctional brightener-inspired interphase. Energy 
Environ. Sci. 12(6), 1938-1949 (2019). https://doi.org/10. 1039/c9ee00596j

81. L.E. Blanc, D. Kundu, L.F. Nazar, Scientific challenges for the implementation of Zn-ion batteries. Joule 4(4), 771-799 (2020). https://doi.org/10.1016/j.joule.2020.03.002

82. Y. Jin, L. Zou, L. Liu, M.H. Engelhard, R.L. Patel et al., Joint charge storage for high-rate aqueous zinc-manganese dioxide batteries. Adv. Mater. 31(29), 1900567 (2019). https://doi. org/10.1002/adma.201900567

83. L. Cao, D. Li, E. Hu, J. Xu, T. Deng et al., Solvation structure design for aqueous $\mathrm{Zn}$ metal batteries. J. Am. Chem. Soc. 142(51), 21404-21409 (2020). https://doi.org/10.1021/jacs. 0c09794

84. S. Liu, J. Mao, W.K. Pang, J. Vongsvivut, X. Zeng et al., Tuning the electrolyte solvation structure to suppress cathode dissolution, water reactivity, and $\mathrm{Zn}$ dendrite growth in zincion batteries. Adv. Funct. Mater. 31(38), 2104281 (2021). https://doi.org/10.1002/adfm.202104281

85. A. Bhatnagar, W. Hogland, M. Marques, M. Sillanpää, An overview of the modification methods of activated carbon for its water treatment applications. Chem. Eng. J. 219, 499-511 (2013). https://doi.org/10.1016/j.cej.2012.12.038

86. G. Pognon, T. Brousse, L. Demarconnay, D. Bélanger, Performance and stability of electrochemical capacitor based on anthraquinone modified activated carbon. J. Power Sources 196(8), 4117-4122 (2010). https://doi.org/10.1016/j.jpows our.2010.09.097

87. C. Shen, X. Li, N. Li, K.Y. Xie, J.G. Wang et al., Grapheneboosted, high-performance aqueous $\mathrm{Zn}$-ion battery. ACS Appl. Mater. Interfaces 10(30), 25446-25453 (2018). https:// doi.org/10.1021/acsami.8b07781

88. J.X. Zheng, Q. Zhao, T. Tang, J.F. Yin, C.D. Quilty et al., Reversible epitaxial electrodeposition of metals in battery anodes. Science 366(6465), 645-648 (2019). https://doi.org/ $10.1126 /$ science.aax6873

89. L. Hongfei, X. Chengjun, H. Cuiping, C. Yanyi, W. Chunguang et al., Enhancement on cycle performance of $\mathrm{Zn}$ anodes by activated carbon modification for neutral rechargeable zinc ion batteries. J. Electrochem. Soc. 162(8), A1439A1444 (2015). https://doi.org/10.1149/2.0141508jes

90. L. Wei, W. Kangli, Z. Min, Z. Houchao, C. Shijie et al., Advanced low-cost, high-voltage, long-life aqueous hybrid sodium/zinc batteries enabled by a dendrite-free zinc anode and concentrated electrolyte. ACS Appl. Mater. Interfaces 10, 22059-22066 (2018). https://doi.org/10.1021/acsami.8b040 85

91. L. Dong, W. Yang, W. Yang, H. Tian, Y. Huang et al., Flexible and conductive scaffold-stabilized zinc metal anodes for ultralong-life zinc-ion batteries and zinc-ion hybrid capacitors. Chem. Eng. J. 384, 123355 (2020). https://doi.org/10. 1016/j.cej.2019.123355

92. W. Anran, Z. Weijun, H. Aixiang, C. Minfeng, C. Jizhang et al., Modifying the $\mathrm{Zn}$ anode with carbon black coating and nanofibrillated cellulose binder: a strategy to realize dendritefree $\mathrm{Zn}-\mathrm{MnO}_{2}$ batteries. J. Colloid Interf. Sci. 577, 256-264 (2020). https://doi.org/10.1016/j.jcis.2020.05.102
93. D.L. Han, S.C. Wu, S.W. Zhang, Y.Q. Deng, C.J. Cui et al., A corrosion-resistant and dendrite-free zinc metal anode in aqueous systems. Small 16(29), 2001736 (2020). https://doi. org/10.1002/smll.202001736

94. M.W. Cui, Y. Xiao, L.T. Kang, W. Du, Y.F. Gao et al., Quasiisolated $\mathrm{Au}$ particles as heterogeneous seeds to guide uniform $\mathrm{Zn}$ deposition for aqueous zinc-ion batteries. ACS Appl. Energy Mater. 2(9), 6490-6496 (2019). https://doi.org/10. 1021/acsaem.9b01063

95. Q. Zhang, J. Luan, X. Huang, Q. Wang, D. Sun et al., Revealing the role of crystal orientation of protective layers for stable zinc anode. Nat. Commun. 11(1), 3961 (2020). https:// doi.org/10.1038/s41467-020-17752-X

96. H. He, H. Tong, X. Song, X. Song, J. Liu, Highly stable Zn metal anodes enabled by atomic layer deposited $\mathrm{Al}_{2} \mathrm{O}_{3}$ coating for aqueous zinc-ion batteries. J. Mater. Chem. A 8(16), 7836-7846 (2020). https://doi.org/10.1039/d0ta00748j

97. M. Zhou, S. Guo, G. Fang, H. Sun, X. Cao et al., Suppressing by-product via stratified adsorption effect to assist highly reversible zinc anode in aqueous electrolyte. J. Energy Chem. 55, 549-556 (2021). https://doi.org/10.1016/j.jechem.2020. 07.021

98. C. Deng, X. Xie, J. Han, Y. Tang, J. Gao et al., A sievefunctional and uniform-porous kaolin layer toward stable zinc metal anode. Adv. Funct. Mater. 30(21), 2000599 (2020). https://doi.org/10.1002/adfm.202000599

99. L. Kang, M. Cui, F. Jiang, Y. Gao, H. Luo et al., Nanoporous $\mathrm{CaCO}_{3}$ coatings enabled uniform $\mathrm{Zn}$ stripping/plating for long-life zinc rechargeable aqueous batteries. Adv. Energy Mater. 8(25), 1801090 (2018). https://doi.org/10.1002/aenm. 201801090

100. M. Liu, J. Cai, H. Ao, Z. Hou, Y. Zhu et al., $\mathrm{NaTi}_{2}\left(\mathrm{PO}_{4}\right)_{3}$ solid-state electrolyte protection layer on $\mathrm{Zn}$ metal anode for superior long-life aqueous zinc-ion batteries. Adv. Funct. Mater. 30(50), 2004885 (2020). https://doi.org/10.1002/adfm. 202004885

101. X. Zeng, J. Mao, J. Hao, J. Liu, S. Liu et al., Electrolyte design for in situ construction of highly $\mathrm{Zn}^{2+}$-conductive solid electrolyte interphase to enable high-performance aqueous $\mathrm{Zn}$-ion batteries under practical conditions. Adv. Mater. 33(11), 2007416 (2021). https://doi.org/10.1002/adma.20200 7416

102. Z. Cao, X. Zhu, D. Xu, P. Dong, M.O.L. Chee et al., Eliminating $\mathrm{Zn}$ dendrites by commercial cyanoacrylate adhesive for zinc ion battery. Energy Storage Mater. 36, 132-138 (2021). https://doi.org/10.1016/j.ensm.2020.12.022

103. J. Hao, X. Li, S. Zhang, F. Yang, X. Zeng et al., Designing dendrite-free zinc anodes for advanced aqueous zinc batteries. Adv. Funct. Mater. 30(30), 2001263 (2020). https://doi. org/10.1002/adfm.202001263

104. P. Chen, X. Yuan, Y. Xia, Y. Zhang, L. Fu et al., An artificial polyacrylonitrile coating layer confining zinc dendrite growth for highly reversible aqueous zinc-based batteries. Adv. Sci. 8(11), 2100309 (2021). https://doi.org/10.1002/advs.20210 0309 
105. M. Liu, L. Yang, H. Liu, A. Amine, Q. Zhao et al., Artificial solid-electrolyte interface facilitating dendrite-free zinc metal anodes via nanowetting effect. ACS Appl. Mater. Interfaces 11(35), 32046-32051 (2019). https://doi.org/10.1021/acsami. $9 \mathrm{~b} 11243$

106. H. He, J. Liu, Suppressing Zn dendrite growth by molecular layer deposition to enable long-life and deeply rechargeable aqueous $\mathrm{Zn}$ anodes. J. Mater. Chem. A 8(42), 22100-22110 (2020). https://doi.org/10.1039/d0ta07232j

107. A. Bayaguud, X. Luo, Y. Fu, C. Zhu, Cationic surfactant-type electrolyte additive enables three-dimensional dendrite-free zinc anode for stable zinc-ion batteries. ACS Energy Lett. 5(9), 3012-3020 (2020). https://doi.org/10.1021/acsenergyl ett.0c01792

108. Z. Ma, J. Kan, Study of cylindrical Zn/PANI secondary batteries with the electrolyte containing alkylimidazolium ionic liquid. Synthetic Met. 174, 58-62 (2013). https://doi.org/10. 1016/j.synthmet.2013.04.005

109. Y. Song, J. Hu, J. Tang, W. Gu, L. He et al., Real-time X-ray imaging reveals interfacial growth, suppression, and dissolution of zinc dendrites dependent on anions of ionic liquid additives for rechargeable battery applications. ACS Appl. Mater. Interfaces 8(46), 32031-32040 (2016). https://doi.org/ 10.1021/acsami.6b11098

110. L. Qian, W. Yao, R. Yao, Y. Sui, H. Zhu et al., Cations coordination-regulated reversibility enhancement for aqueous Zn-ion battery. Adv. Funct. Mater. 31(40), 2105736 (2021). https://doi.org/10.1002/adfm.202105736

111. Z. Hou, X. Zhang, X. Li, Y. Zhu, J. Liang et al., Surfactant widens the electrochemical window of an aqueous electrolyte for better rechargeable aqueous sodium/zinc battery. J. Mater. Chem. A 5(2), 730-738 (2017). https://doi.org/10.1039/c6ta0 $8736 \mathrm{a}$

112. P. Sun, L. Ma, W.H. Zhou, M.J. Qiu, Z.L. Wang et al., Simultaneous regulation on solvation shell and electrode interface for dendrite-free $\mathrm{Zn}$ ion batteries achieved by a low-cost glucose additive. Angew. Chem. Int. Ed. 60(33), 18247-18255 (2021). https://doi.org/10.1002/anie.202105756

113. J.N. Hao, L.B. Yuan, C. Ye, D.L. Chao, K. Davey et al., Boosting zinc electrode reversibility in aqueous electrolytes by using low-cost antisolvents. Angew. Chem. Int. Ed. 60(13), 7366-7375 (2021). https://doi.org/10.1002/anie.202016531

114. A. Mitha, A.Z. Yazdi, M. Ahmed, P. Chen, Surface adsorption of polyethylene glycol to suppress dendrite formation on zinc anodes in rechargeable aqueous batteries. ChemElectroChem 5(17), 2409-2418 (2018). https://doi.org/10.1002/celc. 201800572

115. Q. Zhang, J.Y. Luan, L. Fu, S.G. Wu, Y.G. Tang et al., The three-dimensional dendrite-free zinc anode on a copper mesh with a zinc-oriented polyacrylamide electrolyte additive. Angew. Chem. Int. Ed. 58(44), 15841-15847 (2019). https:// doi.org/10.1002/anie.201907830

116. J. Abdulla, J. Cao, D. Zhang, X. Zhang, C. Sriprachuabwong et al., Elimination of zinc dendrites by graphene oxide electrolyte additive for zinc-ion batteries. ACS Appl. Energy Mater. 4(5), 4602-4609 (2021). https://doi.org/10.1021/ acsaem. $1 \mathrm{c} 00224$ 